\title{
Unveiling the structure and reactivity of fatty-acid based (nano)materials thanks to efficient and scalable ${ }^{17} \mathrm{O}$ and ${ }^{18} \mathrm{O}$-isotopic labeling schemes
}

\author{
Jessica Špačková, Charlyn Fabra, Sébastien Mittelette, Emeline Gaillard, Chia-Hsin Chen, \\ Guillaume Cazals, Aurélien Lebrun, Saad Sene, Dorothée Berthomieu, Kuizhi Chen, Zhehong Gan, \\ Christel Gervais, Thomas-Xavier Métro,* Danielle Laurencin*
}

\section{Table of contents}

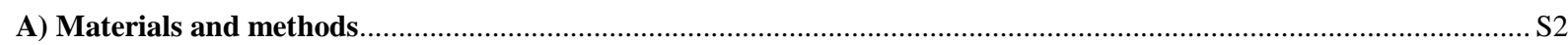

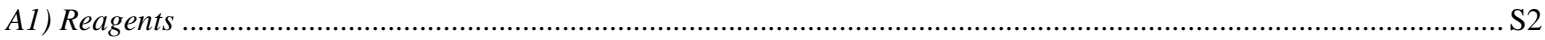

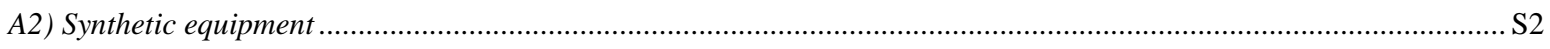

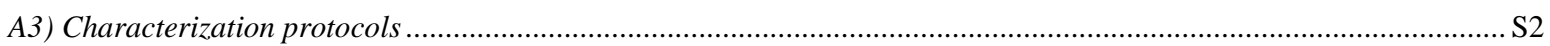

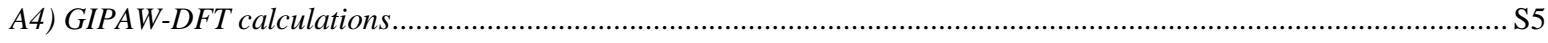

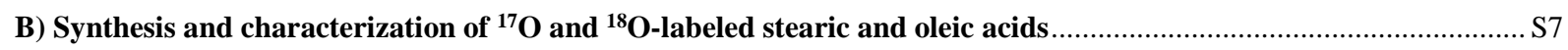

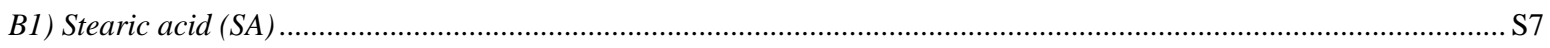

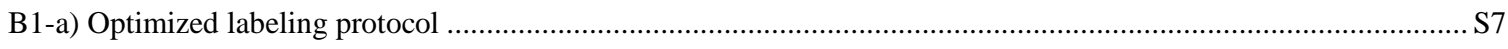

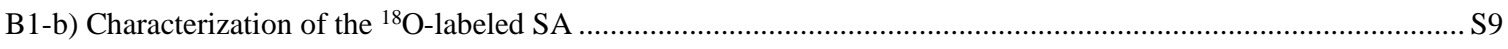

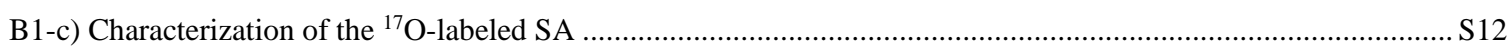

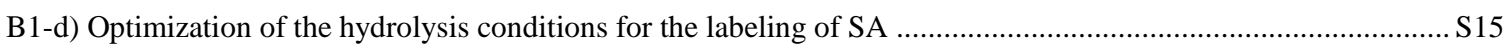

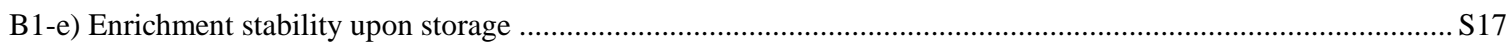

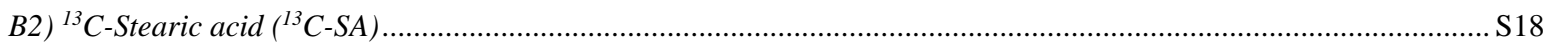

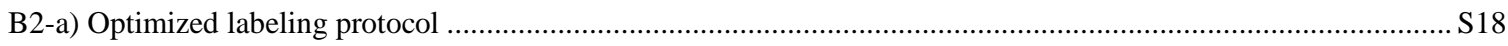

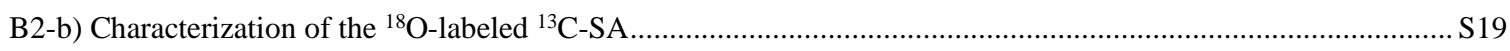

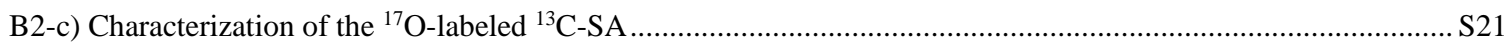

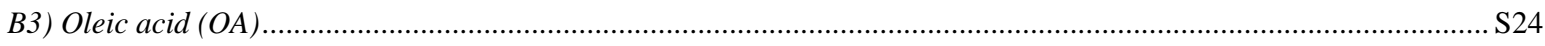

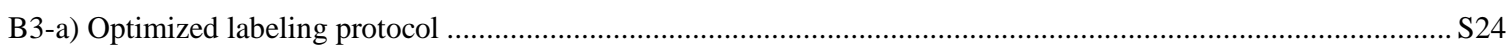

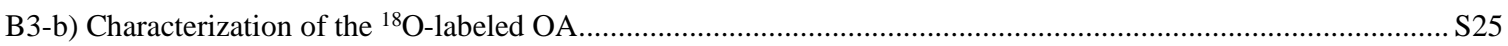

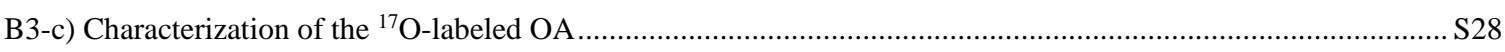

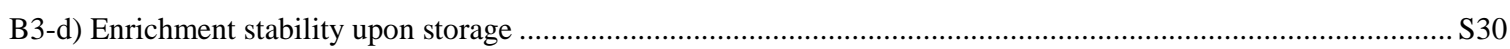

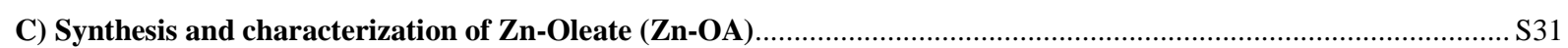

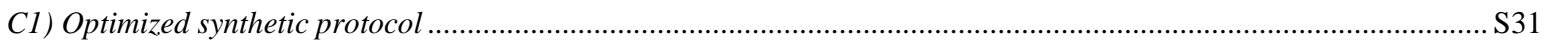

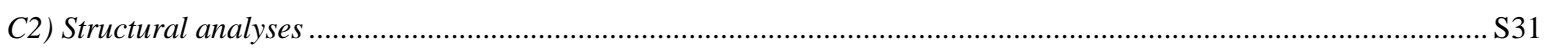

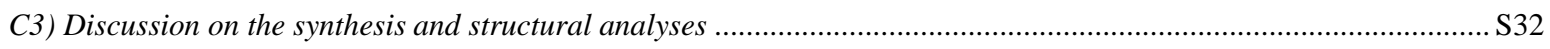

C3-a) New synthetic protocol for Zn-oleate using mechanochemistry …............................................................ S32

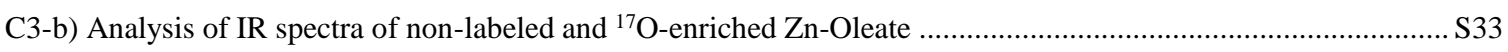

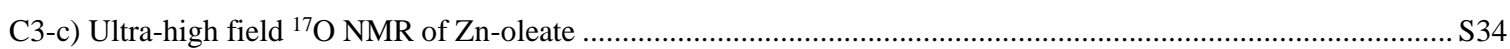

C3-d) GIPAW-DFT calculations of NMR parameters in Zn-carboxylates ........................................................... S35

D) Synthesis, characterization and reactivity studies of oleic-acid grafted $\mathrm{ZnO}$ nanorods ........................................... 37

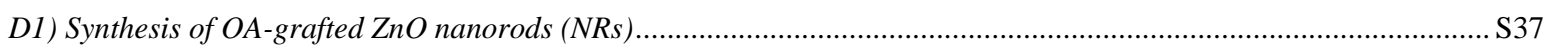

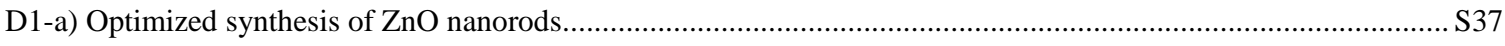

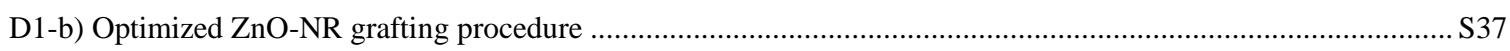

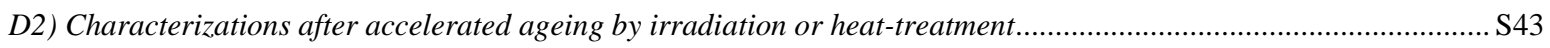

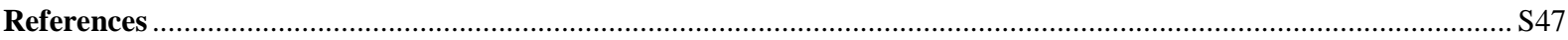




\section{A) Materials and methods}

\section{A1) Reagents}

The following reagents were used as received: stearic acid $\left(\mathrm{C}_{17} \mathrm{H}_{35} \mathrm{COOH}\right.$, Sigma-Aldrich, $95 \%$, noted here SA), ${ }^{13} \mathrm{C}$-stearic acid $\left(\mathrm{C}_{17} \mathrm{H}_{35}{ }^{13} \mathrm{COOH}\right.$, Sigma-Aldrich, 99 atom\% ${ }^{13} \mathrm{C}$, noted here ${ }^{13} \mathrm{C}$-SA), oleic acid $\left(\mathrm{C}_{17} \mathrm{H}_{33} \mathrm{COOH}\right.$, Sigma-Aldrich, $\geq 99 \%$, noted here OA $), 1,1$ '-carbonyldiimidazole $\left(\mathrm{C}_{7} \mathrm{H}_{6} \mathrm{~N}_{4} \mathrm{O}\right.$, TCI, > 97\%, noted here CDI), anhydrous potassium carbonate $\left(\mathrm{K}_{2} \mathrm{CO}_{3}\right.$, Alfa Aesar, $\left.99 \%\right)$, zinc chloride ( $\mathrm{ZnCl}_{2}$, Aldrich, $99.99 \%$ ), and sodium hydroxide ( $\mathrm{NaOH}$, Acros Organics). For $\mathrm{ZnO}$ nanorod syntheses (ZnO-NRs), zinc acetate dihydrate $\left(\mathrm{C}_{4} \mathrm{H}_{10} \mathrm{O}_{6} \mathrm{Zn}\right.$, Sigma-Aldrich), potassium hydroxide (KOH, SigmaAldrich, $\geq 85 \%$ ), as well as methanol (HPLC - isocratic grade, VWR) and tetrahydrofurane (THF, $\geq 99.8 \%$, Fisher Chemical) were used as received. Reagent grade solvents were used in all other purification protocols.

${ }^{17} \mathrm{O}$-labeled water was purchased from CortecNet (its isotopic composition, as indicated in the certificate of analysis, is $8.6 \%{ }^{18} \mathrm{O}, 90.4 \%{ }^{17} \mathrm{O}, 1.0 \%{ }^{16} \mathrm{O}$ for the $\sim 90 \%{ }^{17} \mathrm{O} \mathrm{H}_{2}{ }^{17} \mathrm{O}$, and $44.6 \%{ }^{18} \mathrm{O}$, $39.3 \%{ }^{17} \mathrm{O}, 16.1 \%{ }^{16} \mathrm{O}$ for the $\sim 40 \%{ }^{17} \mathrm{O} \mathrm{H}_{2}{ }^{17} \mathrm{O}$.

${ }^{18} \mathrm{O}$-labeled water was purchased from Eurisotop (its isotopic composition, as indicated in the certificate of analysis, is $97.1 \%{ }^{18} \mathrm{O}, 1.1 \%{ }^{17} \mathrm{O}, 1.8 \%{ }^{16} \mathrm{O}$ ) or CortecNet (its isotopic composition, as indicated in the certificate of analysis, is $97.1 \%{ }^{18} \mathrm{O}, 1.4 \%{ }^{17} \mathrm{O}, 1.5 \%{ }^{16} \mathrm{O}$ or $99.3 \%{ }^{18} \mathrm{O}, 0.2 \%{ }^{17} \mathrm{O}$, $0.5 \%$, the later having been used for scale-up procedure of stearic acid.

\section{A2) Synthetic equipment}

Most milling treatments were carried out in a Retsch Mixer Mill 400 apparatus (MM400), using $10 \mathrm{~mL}$ or $50 \mathrm{~mL}$ inner-volume screw-type grinding jars, containing $10 \mathrm{~mm}$ diameter beads. Some milling experiments for the scale-up of stearic-acid labeling were performed on a Fristch planetary mill apparatus (P7), using $20 \mathrm{~mL}$ inner-volume jars, containing $5 \mathrm{~mm}$ diameter beads. All milling material (jar and beads) were made of stainless steel. All protocols were first tested using non-labeled water and then optimized using ${ }^{18} \mathrm{O}$-labeled water, before performing experiments with ${ }^{17} \mathrm{O}$-labeled water.

Accelerated ageing tests upon irradiation of $\mathrm{ZnO}$ nanorods and $\mathrm{Zn}$-oleate were performed in an ATLAS/SUNTEST CPS+ apparatus. The spectrum of this apparatus between 300 and $800 \mathrm{~nm}$ mimics that of solar light, but with more powerful radiation $\left(\sim 60 \mathrm{~mW} / \mathrm{cm}^{2}\right)$. Powdered samples were deposited such that they cover the inside surface of a closed quartz cuvettes, and then irradiated for $6 \mathrm{~h}$. Samples were then characterized by IR, XRD, TEM and solid state NMR.

Accelerated ageing tests upon heat-treatment of $\mathrm{ZnO}$ nanorods and $\mathrm{Zn}$-oleate were performed in an oven at $60^{\circ} \mathrm{C}$, in absence of light. Powdered samples were placed in glassy vials and heated for $6 \mathrm{~h}$, after which they were characterized by IR, XRD, TEM and solid-state NMR.

\section{A3) Characterization protocols}

Infrared (IR) spectra were recorded on a Perkin Elmer Spectrum 2 FT-IR instrument. The attenuated total reflectance (ATR) measurement mode was used (diamond crystal), and measurements were performed in the $400-4000 \mathrm{~cm}^{-1}$ range.

Powder XRD analyses were carried out on an X'Pert MPD diffractometer using $\mathrm{Cu} \mathrm{K}_{\alpha 1}$ radiation $(\lambda=1.5406 \AA)$ with the operation voltage and current maintained at $40 \mathrm{kV}$ and $25 \mathrm{~mA}$, respectively. Diffractograms were recorded between $5^{\circ}$ and $70^{\circ}$ in $2 \theta$, with a step size of $0.017^{\circ}$, and a time per step of 20 to $40 \mathrm{~s}$.

Transition electron microscopy (TEM) analyses were performed on a LaB6 JEOL 1400 Plus electron microscope operating at $100 \mathrm{kV}$. Samples for TEM were prepared by depositing a dispersed suspension of nanorods in THF onto carbon-supported copper grids, and left to dry overnight at air, prior to analyses. 
Thermal gravimetric analyses (TGA) were carried out under air on a TA instrument Q500, at a heating rate of $10{ }^{\circ} \mathrm{C} / \mathrm{min}$ up to $600{ }^{\circ} \mathrm{C}$, with a flow rate of $60 \mathrm{~mL} / \mathrm{min}$.

The Brunauer-Emmett-Teller (BET) specific surface area of $\mathrm{ZnO}$ NRs was measured using a Tristar surface area and porosity analyzer. The measurement was performed by $\mathrm{N}_{2}$ adsorption at liquid nitrogen temperature after degassing for $16 \mathrm{~h}$ at $80^{\circ} \mathrm{C}$.

Mass spectrometry (MS) analyses were performed on a Waters Synapt G2-S apparatus, using electrospray ionization in negative mode in a range of 50-1500 Da. Capillary and cone voltages were set to $2000 \mathrm{~V}$ and $30 \mathrm{~V}$, respectively. The source temperature was $100{ }^{\circ} \mathrm{C}$ and desolvation temperature was set to $50^{\circ} \mathrm{C}$. Data were processed by MassLynxV4.1 software. For each product three solutions were prepared (in acetonitrile or methanol, depending on the solubility), which were analyzed five-times by ESI-MS. For each synthesis, five MS analyses were performed.

The ${ }^{17} \mathrm{O} /{ }^{18} \mathrm{O}$-enrichement level was estimated based on the calculation of an apparent average atomic weight for oxygen in the isolated phase, from which the average enrichment level per carboxylic oxygen was subsequently derived using the ${ }^{18} \mathrm{O} /{ }^{17} \mathrm{O}$ isotopic ratio of the labeled water. Reported error bars correspond either to the analytical standard deviation arising from 5 independent measurements (for $\mathrm{n}=1$ ), or to the standard deviation coming from the analysis of different synthetic batches (for $\mathrm{n}>$ $1)$.

Enrichment yields correspond to the ratio between the average enrichment level per carboxylic oxygen determined by MS and the maximum average enrichment level per carboxylic oxygen which could have been obtained, considering the composition of the enriched water used for the hydrolysis, and assuming that each carboxylic group is only enriched on one of the 2 oxygen atoms (based on the hydrolysis of the acyl-imidazole intermediate).

LC-MS (liquid chromatography-mass spectrometry) analyses were done using an Acquity HClass (Waters) system equipped with a Kinetex EVO C18 column $(1.7 \mu \mathrm{m}$ particle size, $50 \mathrm{x} 2.1 \mathrm{~mm}$, Phenomenex). Mobile phase A consisted of water while mobile phase B was acetonitrile, both containing $0.1 \%$ formic acid. The gradient started at $50 \%$ mobile phase B and increased to $100 \%$ mobile phase B over $5 \mathrm{~min}$. After holding for $2 \mathrm{~min}$ the gradient returned to $50 \% \mathrm{~B}$ before re-equilibration for $3 \mathrm{~min}$, to give a total run time of $10 \mathrm{~min}$. The flow rate was $0.2 \mathrm{~mL} / \mathrm{min}$ and the eluent was directed to the atmospheric pressure ionization source of an Synapt G2-S (Waters) operating under the conditions described above.

${ }^{1} \mathrm{H}$ and ${ }^{13} \mathrm{C}$ solution NMR spectra were recorded on an Avance III Bruker $600 \mathrm{MHz}$ NMR spectrometer equipped with a TCI Prodigy cryoprobe, using DMSO- $d_{6}$ as a solvent. Chemical shifts were referenced to the residual solvent peaks at $2.50 \mathrm{ppm}\left({ }^{1} \mathrm{H}\right.$ NMR spectra) and $39.52 \mathrm{ppm}\left({ }^{13} \mathrm{C} \mathrm{NMR}\right.$ spectra).

The majority of ${ }^{13} \mathrm{C}$ solid state NMR experiments were performed on a VNMRS $300 \mathrm{MHz}$ (7.05 T) NMR spectrometer, using a Varian $3.2 \mathrm{~mm}$ HX probe tuned to ${ }^{1} \mathrm{H}(299.99 \mathrm{MHz})$ and ${ }^{13} \mathrm{C}$ (75.43 MHz). Oleic acid was analyzed on a VNMRS $400 \mathrm{MHz}(9.4 \mathrm{~T})$ NMR spectrometer, using a Varian $3.2 \mathrm{~mm} \mathrm{HXY}$ probe tuned to ${ }^{1} \mathrm{H}(399.92 \mathrm{MHz})$ and ${ }^{13} \mathrm{C}(100.56 \mathrm{MHz})$, and setting the temperature unit to $-20{ }^{\circ} \mathrm{C}$ to freeze the sample. A high resolution ${ }^{13} \mathrm{C}$ NMR spectrum of enriched $\mathrm{Zn}$ oleate was also recorded on a Varian VNMRS $600 \mathrm{MHz}$ (14.1T) NMR spectrometer, using a Varian 3.2 mm HX probe tuned to ${ }^{1} \mathrm{H}(599.82 \mathrm{MHz})$ and ${ }^{13} \mathrm{C}(150.81 \mathrm{MHz})$. All $1 \mathrm{D}^{13} \mathrm{C}$ NMR spectra were recorded under MAS (Magic Angle Spinning) conditions, with a spinning frequency $12 \mathrm{kHz}$. A ${ }^{1} \mathrm{H} \rightarrow{ }^{13} \mathrm{C} \mathrm{CPMAS}$ NMR sequence was used with a $4 \mu \mathrm{s}^{1} \mathrm{H}$ excitation pulse, followed by a ramped $\mathrm{CP}$ pulse of $8 \mathrm{~ms}$ contact time, and applying spinal-64 ${ }^{1} \mathrm{H}$-decoupling during acquisition ( $\left.63 \mathrm{kHz} \mathrm{RF}\right)$. This long contact time was used to suppress the background signals from the probe, caps and inserts (as verified by control experiments performed in the same conditions on the empty rotors). All acquisition parameters for 1D CPMAS experiments are summarized in Table A3S1. ${ }^{1} \mathrm{H}$ and ${ }^{13} \mathrm{C}$ chemical shifts were referenced to adamantane at $1.8 \mathrm{ppm}$ and $38.5 \mathrm{ppm}$ (high frequency peak), respectively. 
Table A3S1. ${ }^{13} \mathrm{C}$ solid state NMR acquisition parameters.

\begin{tabular}{|c|c|c|c|c|c|c|c|c|c|}
\hline Sample & Figure & $\begin{array}{c}\text { Magnetic } \\
\text { field } \mathbf{B}_{0} \\
{[\mathrm{~T}]} \\
\end{array}$ & $\begin{array}{c}\text { MAS } \\
\text { frequency } \\
{[\mathrm{kHz}]}\end{array}$ & $\begin{array}{c}\text { Temp. } \\
\text { set } \\
{\left[{ }^{\circ} \mathrm{C}\right]}\end{array}$ & $\begin{array}{c}\text { Recycle } \\
\text { delay } \\
\text { (D1) }[\mathrm{s}]\end{array}$ & $\begin{array}{c}\text { Contact } \\
\text { time } \\
{[\mathrm{ms}]} \\
\end{array}$ & $\begin{array}{l}\text { Acq. } \\
\text { time } \\
{[\mathrm{ms}]}\end{array}$ & $\begin{array}{c}\text { Number } \\
\text { of scans } \\
(\mathrm{NS}) \\
\end{array}$ & $\begin{array}{l}\text { Exp. } \\
\text { time }\end{array}$ \\
\hline \multicolumn{10}{|c|}{ Oleic acid } \\
\hline $\mathrm{OA}$ & & 9.4 & 12 & -20 & 3 & 8 & 40 & 2000 & $\sim 1 \mathrm{~h} 45$ \\
\hline \multicolumn{10}{|c|}{ Zn-OA } \\
\hline \multirow[b]{2}{*}{ as-prepared } & $\mathrm{D} 2 \mathrm{~S} 3 \mathrm{c} /$ & 7.1 & 12 & No reg. & 2 & 8 & 40 & 4700 & $\sim 2 \mathrm{~h} 45$ \\
\hline & $\begin{array}{c}2 \mathrm{a} \text { and } \\
\mathrm{C} 2 \mathrm{~S} 2 \mathrm{a} /\end{array}$ & 14.1 & 12 & No reg. & 4 & 8 & 40 & 620 & $\sim 0 \mathrm{~h} 45$ \\
\hline irradiated & $\mathrm{D} 2 \mathrm{~S} 3 \mathrm{c} /$ & 7.1 & 12 & No reg. & 2 & 8 & 40 & 4700 & $\sim 2 \mathrm{~h} 45$ \\
\hline heated & $\mathrm{D} 2 \mathrm{~S} 3 \mathrm{c} /$ & 7.1 & 12 & No reg. & 2 & 8 & 40 & 4700 & $\sim 2 \mathrm{~h} 45$ \\
\hline \multicolumn{10}{|c|}{${ }^{17} \mathrm{O}-\mathrm{OA}$ grafted NRs } \\
\hline as-prepared & $3 \mathrm{~d}$ and $4 \mathrm{~d}$ & 7.1 & 12 & No reg. & 2 & 8 & 40 & 4700 & $\sim 2 \mathrm{~h} 45$ \\
\hline irradiated & $4 \mathrm{~d}$ & 7.1 & 12 & No reg. & 2 & 8 & 40 & 8000 & $\sim 4 \mathrm{~h} 30$ \\
\hline heated & $4 d$ & 7.1 & 12 & No reg. & 2 & 8 & 40 & 6500 & $\sim 3 \mathrm{~h} 45$ \\
\hline \multicolumn{10}{|c|}{ Non-labeled OA-grafted NRs } \\
\hline as-prepared & $\begin{array}{l}3 \mathrm{~d} \text { and } \\
\mathrm{D} 2 \mathrm{~S} 1 \mathrm{~d} /\end{array}$ & 7.1 & 12 & No reg. & 2 & 8 & 40 & 6500 & $\sim 3 \mathrm{~h} 45$ \\
\hline irradiated & $\mathrm{D} 2 \mathrm{~S} 1 \mathrm{~d} /$ & 7.1 & 12 & No reg. & 2 & 8 & 40 & 6500 & $\sim 3 \mathrm{~h} 45$ \\
\hline heated & D2S1 d/ & 7.1 & 12 & No reg. & 2 & 8 & 40 & 6500 & $\sim 3 \mathrm{~h} 45$ \\
\hline \multicolumn{10}{|c|}{ Bare NRs } \\
\hline as-prepared & $\begin{array}{l}3 \mathrm{~d} \text { and } \\
\mathrm{D} 2 \mathrm{~S} 2 \mathrm{~d} /\end{array}$ & 7.1 & 12 & No reg. & 2 & 8 & 40 & 8400 & $\sim 4 \mathrm{~h} 45$ \\
\hline irradiated & $\mathrm{D} 2 \mathrm{~S} 2 \mathrm{~d} /$ & 7.1 & 12 & No reg. & 2 & 8 & 40 & 8200 & $\sim 4 \mathrm{~h} 45$ \\
\hline heated & $\mathrm{D} 2 \mathrm{~S} 2 \mathrm{~d} /$ & 7.1 & 12 & No reg. & 2 & 8 & 40 & 8400 & $\sim 4 \mathrm{~h} 45$ \\
\hline
\end{tabular}

${ }^{17} \mathrm{O}$ solid state NMR experiments were performed on a VNMRS $600 \mathrm{MHz}(14.1 \mathrm{~T}) \mathrm{NMR}$ spectrometer, using a $3.2 \mathrm{~mm}$ probe tuned to ${ }^{1} \mathrm{H}(599.82 \mathrm{MHz})$ and ${ }^{17} \mathrm{O}(81.31 \mathrm{MHz})$. Three types of probes were used, depending on the availability of the equipment: a $3.2 \mathrm{~mm}$ Varian HX probe, a $3.2 \mathrm{~mm}$ Varian HXY probe, or a Phoenix NMR HXY probe equipped with a $3.2 \mathrm{~mm}$ probe head. Spectra were recorded under MAS conditions, using a spinning frequency $16 \mathrm{kHz}$. A double frequency sweep (DFS $)^{1}$ excitation scheme was used for ${ }^{17} \mathrm{O}$-signal enhancement, followed by an excitation pulse of 1 to $2 \mu$ s (1 $\mu$ s pulse for all spectra recorded on the $\mathrm{ZnO} N R s$, corresponding to a $\pi / 12$ excitation for $\left.\mathrm{H}_{2} \mathrm{O}_{(\mathrm{l})}\right)$. No ${ }^{1} \mathrm{H}-$ decoupling was applied during acquisition (as no significant impact of ${ }^{1} \mathrm{H}$ decoupling on the ${ }^{17} \mathrm{O}$ lineshapes was observed). More details on the acquisition conditions are reported in Table A3S2. For the variable-temperature ${ }^{17} \mathrm{O}$ NMR study of the grafted $\mathrm{ZnO}$-NRs (between $-100^{\circ} \mathrm{C}$ and $+60^{\circ} \mathrm{C}$ ), similar acquisition conditions were used as for the as-prepared NRs. For the study on grafted ZnO-NRs under ageing conditions, ${ }^{17} \mathrm{O}$ MAS NMR spectra were recorded with the temperature regulation unit set to $-20^{\circ} \mathrm{C} .{ }^{17} \mathrm{O}$ chemical shifts were referenced to $\mathrm{D}_{2} \mathrm{O}$ at $-2.7 \mathrm{ppm}$ (which corresponds to tap-water at 0 ppm).

Additional ${ }^{17} \mathrm{O}$ solid state NMR experiments were performed at ultra-high magnetic field on the $1.5 \mathrm{GHz}(35.2 \mathrm{~T}) \mathrm{SCH}-i n s t r u m e n t$ in Tallahassee. ${ }^{2}$ For the Zn-oleate coordination polymer, a $3.2 \mathrm{~mm}$ single-channel MAS probe was used, which was tuned to ${ }^{17} \mathrm{O}\left(v_{0}=203.4 \mathrm{MHz}\right)$, and spun at $18 \mathrm{kHz}$. A Hahn-echo spectrum was acquired using 4 and $8 \mu$ s pulses, an echo delay of 1 rotor period, and a recycle delay of $0.5 \mathrm{~s}$, and collecting 508 transients. A 3QMAS NMR spectrum was acquired using a shiftedecho pulse sequence with the SPAM conversion scheme. ${ }^{3}$ The $3 \mathrm{Q}$ excitation and conversion pulses are 3.75 and $1.25 \mu$ s with about $100 \mathrm{kHz}$ rf field, respectively, and the soft echo pulses are 4 and $8 \mu \mathrm{s} .192$ scans were acquired for each of the rotor synchronized $\mathrm{t}_{1}$ increments. For the ${ }^{17} \mathrm{O}-\mathrm{OA}$ grafted nanorods, experiments were performed on a $2.0 \mathrm{~mm} \mathrm{HX}$ MAS probe, spinning at $32 \mathrm{kHz}$ (and without temperature regulation). A WURST-enhancement was used, ${ }^{1}$ followed by a Hahn echo, which was acquired using 3 and $6 \mu$ s pulses, and an echo delay of 1 rotor period. The recycle delay was set to $0.5 \mathrm{~s}$, and 10240 transients were collected. All ${ }^{17} \mathrm{O}$ chemical shifts were referenced to $\mathrm{D}_{2} \mathrm{O}$ at $-2.7 \mathrm{ppm}$. 
Table A3S2. ${ }^{17} \mathrm{O}$ solid state NMR acquisition parameters used at 14.1T.

\begin{tabular}{|c|c|c|c|c|c|c|c|}
\hline Sample & Figure & $\begin{array}{c}\text { MAS } \\
\text { frequency } \\
{[\mathrm{kHz}]}\end{array}$ & $\begin{array}{c}\text { Temp. } \\
\text { reg. } \\
{\left[{ }^{\circ} \mathrm{C}\right]}\end{array}$ & $\begin{array}{c}\text { Recycle } \\
\text { delay } \\
\text { (D1) [s] }\end{array}$ & $\begin{array}{c}\text { Acq. time } \\
{[\mathrm{ms}]}\end{array}$ & $\begin{array}{c}\text { Number } \\
\text { of scans } \\
\text { (NS) }\end{array}$ & Exp. time \\
\hline \multicolumn{8}{|c|}{ Stearic acid } \\
\hline SA & $1 \mathrm{~b}$ & 16 & 5 & 0.8 & 6 & 16000 & $\sim 3 \mathrm{~h} 30$ \\
\hline${ }^{13} \mathrm{C}-\mathrm{SA}$ & B2S10 & 16 & 5 & 0.8 & 6 & 10000 & $\sim 2 \mathrm{~h} 15$ \\
\hline \multicolumn{8}{|c|}{ Oleic acid } \\
\hline $\mathrm{OA}$ & $\begin{array}{c}1 b \text { and } \\
3 \mathrm{e}\end{array}$ & 16 & -40 & 0.8 & 6 & 1170 & $\sim 0 \mathrm{~h} 15$ \\
\hline \multicolumn{8}{|c|}{ Zn-OA } \\
\hline as-prepared & $\begin{array}{c}3 \mathrm{e} \\
\mathrm{C} 2 \mathrm{~S} 2 \mathrm{~b} / \\
\mathrm{D} 2 \mathrm{~S} 3 \mathrm{~d} /\end{array}$ & 16 & No reg. & 2 & 5 & 2400 & $\sim 1 \mathrm{~h} 15$ \\
\hline irradiated & $\mathrm{D} 2 \mathrm{~S} 3 \mathrm{~d} /$ & 16 & -20 & 2 & 20 & 2800 & $\sim 1 \mathrm{~h} 30$ \\
\hline heated & $\mathrm{D} 2 \mathrm{~S} 3 \mathrm{~d} /$ & 16 & -20 & 2 & 20 & 4000 & $\sim 2 \mathrm{~h} 15$ \\
\hline \multicolumn{8}{|c|}{${ }^{17} \mathrm{O}-\mathrm{OA}$ grafted NRs } \\
\hline as-prepared & $3 e, 4 \mathrm{e}$ & 16 & -20 & 1 & 20 & 65500 & $\sim 18 \mathrm{~h} 30$ \\
\hline irradiated & $4 \mathrm{e}$ & 16 & -20 & 1 & 20 & 80000 & $\sim 22 \mathrm{~h} 45$ \\
\hline heated & $4 \mathrm{e}$ & 16 & -20 & 1 & 20 & 36000 & $\sim 10 \mathrm{~h} 15$ \\
\hline \multicolumn{8}{|c|}{ Non-labeled OA-grafted NRs } \\
\hline as-prepared & $\begin{array}{c}3 \mathrm{e} \text { and } \\
\mathrm{D} 2 \mathrm{~S} 1 \mathrm{e} /\end{array}$ & 16 & -20 & 1 & 20 & 44400 & $\sim 12 \mathrm{~h} 30$ \\
\hline irradiated & $\mathrm{D} 2 \mathrm{~S} 1 \mathrm{e} /$ & 16 & -20 & 1 & 20 & 36000 & $\sim 10 \mathrm{~h} 15$ \\
\hline heated & $\mathrm{D} 2 \mathrm{~S} 1 \mathrm{e} /$ & 16 & -20 & 1 & 20 & 36000 & $\sim 10 \mathrm{~h} 15$ \\
\hline \multicolumn{8}{|c|}{ Bare NRs } \\
\hline as-prepared & $\begin{array}{c}3 \mathrm{e} \text { and } \\
\mathrm{D} 2 \mathrm{~S} 2 \mathrm{e} /\end{array}$ & 16 & -20 & 1 & 20 & 5840 & $\sim 1 \mathrm{~h} 30$ \\
\hline irradiated & $\mathrm{D} 2 \mathrm{~S} 2 \mathrm{e} /$ & 16 & -20 & 1 & 20 & 5840 & $\sim 1 \mathrm{~h} 30$ \\
\hline heated & $\mathrm{D} 2 \mathrm{~S} 2 \mathrm{e} /$ & 16 & -20 & 1 & 20 & 5840 & $\sim 1 \mathrm{~h} 30$ \\
\hline
\end{tabular}

The ${ }^{23} \mathrm{Na}$ solid state NMR spectrum of Zn-oleate was recorded on a VNMRS $600 \mathrm{MHz}(14.1 \mathrm{~T})$ NMR spectrometer, using a $3.2 \mathrm{~mm}$ Varian HXY probe tuned to ${ }^{23} \mathrm{Na}(158.66 \mathrm{MHz})$ and ${ }^{1} \mathrm{H}(599.82$ $\mathrm{MHz}$ ), and spinning at $20 \mathrm{kHz}$. A single-pulse experiment was performed using a $0.5 \mu$ s excitation pulse (corresponding to a $\pi / 12$ excitation for $\mathrm{NaCl}$ in solution), and spinal-64 ${ }^{1} \mathrm{H}$ decoupling during acquisition. Spectra were referenced to a 1 mol. $\mathrm{L}^{-1}$ solution of $\mathrm{NaCl}$ at $0 \mathrm{ppm}$.

Variable temperature ${ }^{1} \mathrm{H}$ MAS NMR spectra of ${ }^{17} \mathrm{O}$-enriched OA-grafted nanorods were recorded using a Varian NMR HXY probe, and spinning at $16 \mathrm{kHz}$. A Hahn-echo spectrum was recorded using a $4 \mu \mathrm{s} 90^{\circ}$ pulse. Up to 128 transients were acquired with a recycle delay of 2 to $4 \mathrm{~s}$. Spectra were referenced to adamantane at $1.8 \mathrm{ppm}$.

All solid state NMR spectra are fitted and presented using the DMfit software. ${ }^{4}$

\section{A4) GIPAW-DFT calculations}

The unit cell parameters were set to the single-crystal XRD parameters ${ }^{5-6}$ and kept fixed during geometry optimizations to ensure consistency between experimental and optimized structures. Proton or all atomic positions were then optimized using the VASP (Vienna Ab-initio Simulation Package) $\operatorname{code}^{7}$ based on the Kohn-Sham Density Functional Theory (DFT) and using a plane-wave pseudopotential approach. The NMR parameters were then calculated within Kohn-Sham DFT using the QUANTUM-ESPRESSO code. ${ }^{8}$ The PBE generalized gradient approximation ${ }^{9}$ was used and the valence electrons were described by norm-conserving pseudopotentials ${ }^{10}$ in the Kleinman Bylander form. ${ }^{10}$ The wave functions were expanded on a plane wave basis set with a kinetic energy cut-off of 80 Ry. The integral over the first Brillouin zone was performed using a Monkhorst-Pack $2 \times 2 \times 2$ k-point 
grid for the charge density and chemical shift tensor calculation. The shielding tensor was computed using the Gauge-Including Projector Augmented Wave (GIPAW) approach, ${ }^{11}$ which enables the reproduction of the results of a fully converged all-electron calculation. The isotropic chemical shift $\delta_{\text {iso }}$ is defined as $\delta_{\text {iso }}=\left[\sigma_{\text {iso }}-\sigma_{\text {iso }}(\right.$ ref $\left.)\right]$, where $\sigma_{\text {iso }}$ is the isotropic magnetic shielding and $\sigma_{\text {iso }}($ ref $)$ is the isotropic magnetic shielding of the same nucleus in a reference compound. In the present case, the fit of the linear correlation between the experimental $\delta_{\text {iso }}$ and the calculated $\sigma_{\text {iso }}$ values of ${ }^{17} \mathrm{O}$ for $\mathrm{Na}_{2} \mathrm{SiO}_{3}, \alpha$ $\mathrm{Na}_{2} \mathrm{Si}_{2} \mathrm{O}_{5}, \alpha$ - and $\gamma$-glycine, and $\alpha-\mathrm{SrSiO}_{3}$ enabled the determination of the relation between $\delta_{\text {iso }}$ and calculated $\sigma_{\text {iso }}$ for the ${ }^{17} \mathrm{O}$ nucleus, as described previously. ${ }^{12}$ Diagonalization of the symmetric part of the calculated tensor then provides its principal components $\sigma_{11}, \sigma_{22}, \sigma_{33}$ from which the chemical shift components $\delta_{11}, \delta_{22}, \delta_{33}$ can be calculated. $\delta_{11}, \delta_{22}$ and $\delta_{33}$ are defined such as $\left|\delta_{33}-\delta_{\text {iso }}\right| \geq\left|\delta_{11}-\delta_{\text {iso }}\right| \geq$ $\left|\delta_{22}-\delta_{\text {iso }}\right|$, and $\delta_{\text {iso }}=1 / 3\left(\delta_{11}+\delta_{22}+\delta_{33}\right)$. The principal components $\mathrm{V}_{\mathrm{xx}}, \mathrm{V}_{\mathrm{yy}}$, and $\mathrm{V}_{\mathrm{zz}}$ of the electric field gradient (EFG) tensor defined as $\left|V_{z z}\right| \geq\left|V_{x x}\right| \geq\left|V_{y y}\right|$ are obtained by diagonalization of the tensor. The quadrupolar interaction can then be characterized by the quadrupolar coupling constant $\mathrm{C}_{\mathrm{Q}}$ and the asymmetry parameter $\eta_{\mathrm{Q}}$, which are defined as: $\mathrm{C}_{\mathrm{Q}}=\mathrm{eQ} \mathrm{V}_{\mathrm{zz}} / \mathrm{h}$ and $\eta_{\mathrm{Q}}=\left(\mathrm{V}_{\mathrm{yy}}-\mathrm{V}_{\mathrm{xx}}\right) / \mathrm{V}_{\mathrm{zz}}(\mathrm{e}$ is the proton charge, $\mathrm{h}$ Planck's constant and $\mathrm{Q}$ the quadrupole moment of the considered nucleus). The experimental value of the quadrupole moment of ${ }^{17} \mathrm{O}\left(\mathrm{Q}=-25 \times 10^{-30} \mathrm{~m}^{2}\right)$ was used to calculate $\mathrm{C}_{\mathrm{Q}}$. 


\section{B) Synthesis and characterization of ${ }^{17} \mathrm{O}$ and ${ }^{18} \mathrm{O}$-labeled stearic and oleic acids}

\section{B1) Stearic acid (SA)}

B1-a) Optimized labeling protocol

Stearic acid (92.2 mg, $0.32 \mathrm{mmol}, 1.0 \mathrm{eq})$ and CDI ( $57.8 \mathrm{mg}, 0.36 \mathrm{mmol}, 1.1 \mathrm{eq})$ were introduced into a Retsch MM400 stainless steel grinding jar (10 mL inner volume) containing two stainless steel beads (10 mm diameter). The jar was closed and subjected to grinding for 30 minutes in the MM400 mixer mill operated at $25 \mathrm{~Hz}$. Potassium carbonate $(44.8 \mathrm{mg}, 0.32 \mathrm{mmol}, 1.0 \mathrm{eq})$ and ${ }^{18} \mathrm{O}$-labeled water $(97.1 \%, 17.5 \mu \mathrm{L}, 0.97 \mathrm{mmol}, 3.0 \mathrm{eq})$ were then added subsequently into the jar, and the mixture was subjected to further grinding for 180 minutes at $30 \mathrm{~Hz}$. To help recover the product, non-labeled water $(1 \mathrm{~mL})$ was added into the jar, and the content was subjected to grinding for 2 minutes at $25 \mathrm{~Hz}$. Then, the suspension was transferred to a beaker (together with a sufficient amount of non-labeled water $(10 \mathrm{~mL})$ used here to rinse the jar). The medium was then acidified under stirring to $\mathrm{pH} \sim 1$ with an aqueous solution of $\mathrm{HCl}(6 \mathrm{M}, 12$ drops) and extracted with ethyl acetate $(1 \times 20 \mathrm{~mL}, 3 \times 10 \mathrm{~mL})$. Combined organic phases were washed with $\mathrm{HCl}(1 \mathrm{M}, 15 \mathrm{~mL})$, dried over $\mathrm{Na}_{2} \mathrm{SO}_{4}$, filtered, and finally dried under vacuum. The product was collected as a white microcrystalline solid. Average yield $(\mathrm{n}=3)$ : $77 \pm 2 \mathrm{mg}, 83 \pm 2 \%$.

For the ${ }^{17} \mathrm{O}$-labeling, $90.4 \%{ }^{17} \mathrm{O}$-labeled water $(17.5 \mu \mathrm{L}, 3.0$ eq.) was used at the hydrolysis step. Yield ( $\mathrm{n}=1): 78 \mathrm{mg}, 85 \%$.

For the scale-up, stearic acid (555 mg, $1.95 \mathrm{mmol}, 1.0 \mathrm{eq})$ and CDI (348,7 mg, $2.15 \mathrm{mmol}$, 1.1 eq) were introduced into a Fristch P7 stainless steel grinding jar ( $20 \mathrm{~mL}$ inner volume), and eighty stainless steel beads ( $5 \mathrm{~mm}$ diameter) were added. The jar was closed and subjected to grinding in the P7 planetary mill for two cycles of 10 minutes at $500 \mathrm{rpm}$, with a break of $30 \mathrm{~min}$ between each cycle. Anhydrous potassium carbonate $(269.5 \mathrm{mg}, 1.95 \mathrm{mmol}, 1.0 \mathrm{eq})$ and ${ }^{18} \mathrm{O}-$ labeled water $(99.3 \%, 104 \mu \mathrm{L}$, $5.85 \mathrm{mmol}, 3.0 \mathrm{eq}$ ) were then added subsequently into the jar, and the mixture was subjected to further grinding for 60 minutes at $700 \mathrm{rpm}$. To help recover the product, non-labeled water $(6 \mathrm{~mL})$ was added into the jar, and the content was subjected to grinding for 1 minute at $500 \mathrm{rpm}$. Then, the suspension was transferred to an Erlenmeyer flask, using non-labeled water and ethyl acetate to rinse the jar and lid ( $\sim 3 \times 20 \mathrm{~mL}$ of each in total, alternating between both solvents). The medium was acidified under stirring to $\mathrm{pH} \sim 1$ with an aqueous solution of $\mathrm{HCl}(6 \mathrm{M}, \sim 3.3 \mathrm{~mL}$ or 75 drops $)$ and extracted with ethyl acetate $(1 \times 40 \mathrm{~mL}, 3 \times 30 \mathrm{~mL})$. Combined organic phases were washed with $\mathrm{HCl}(1 \mathrm{M}, 40 \mathrm{~mL})$, dried over $\mathrm{Na}_{2} \mathrm{SO}_{4}$, filtered, and finally dried under vacuum to yield the product as white microcrystalline solid. Average yield $(\mathrm{n}=3): 529 \pm 7 \mathrm{mg}, 95 \pm 1 \%$.

Further details on the optimization of the hydrolysis step in MM400 and P7 labeling schemes are provided in section B1-d. 
Figure B1S1: ATR-IR analysis of the starting material, final product, and reaction intermediates. The dashed line shows that the $\mathrm{C}=\mathrm{O}$ stretching frequency of ${ }^{18} \mathrm{O} /{ }^{17} \mathrm{O}$-enriched product is shifted to lower wavenumbers in comparison with non-labeled precursor.

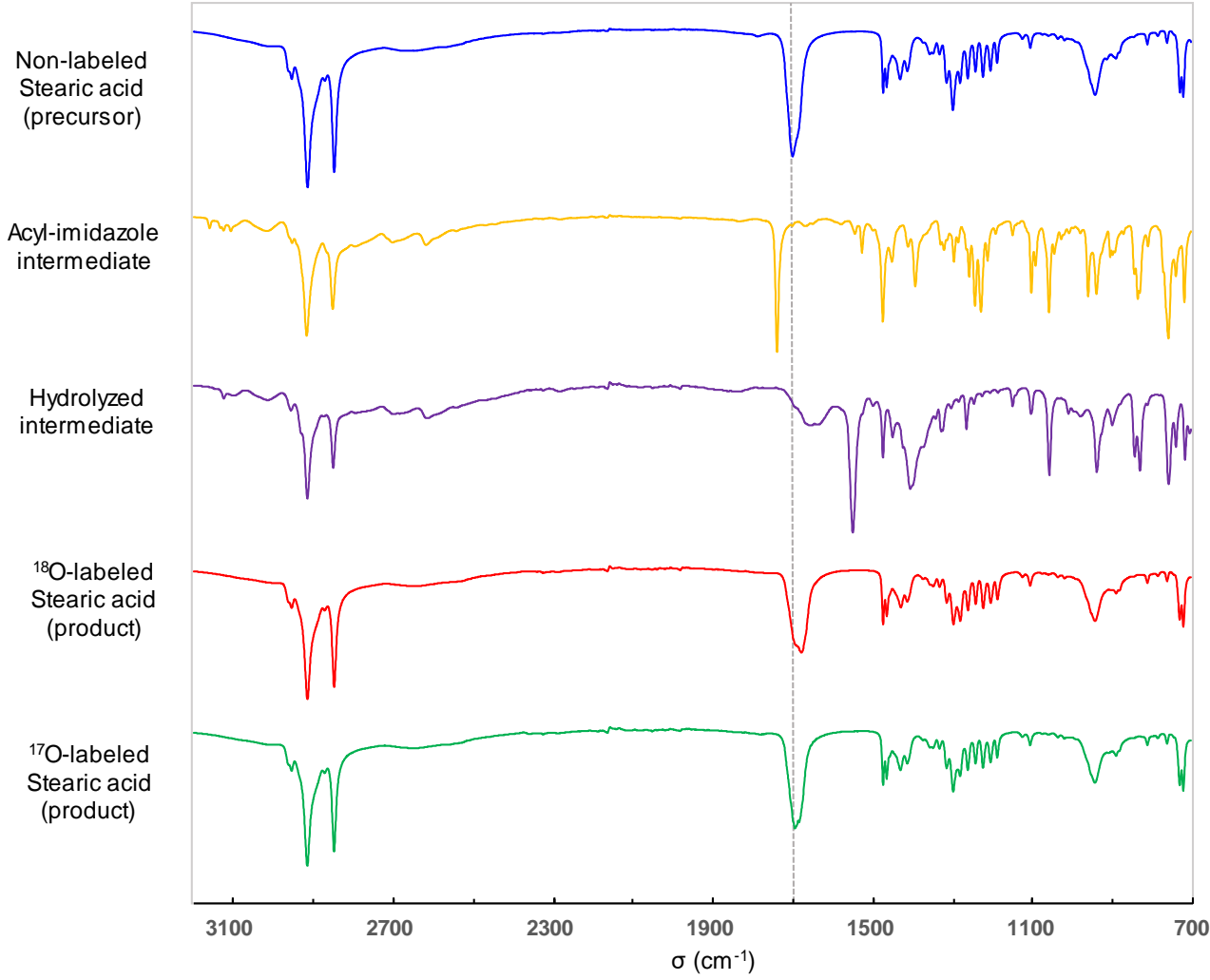


Figure B1S2: MS analyses of the non-labeled precursor in comparison to the ${ }^{18} \mathrm{O}$-enriched product. Average enrichment per carboxylic oxygen determined by MS: $44.1 \pm 1.1 \%(n=3)$, enrichment yield: $\sim 90 \%$.

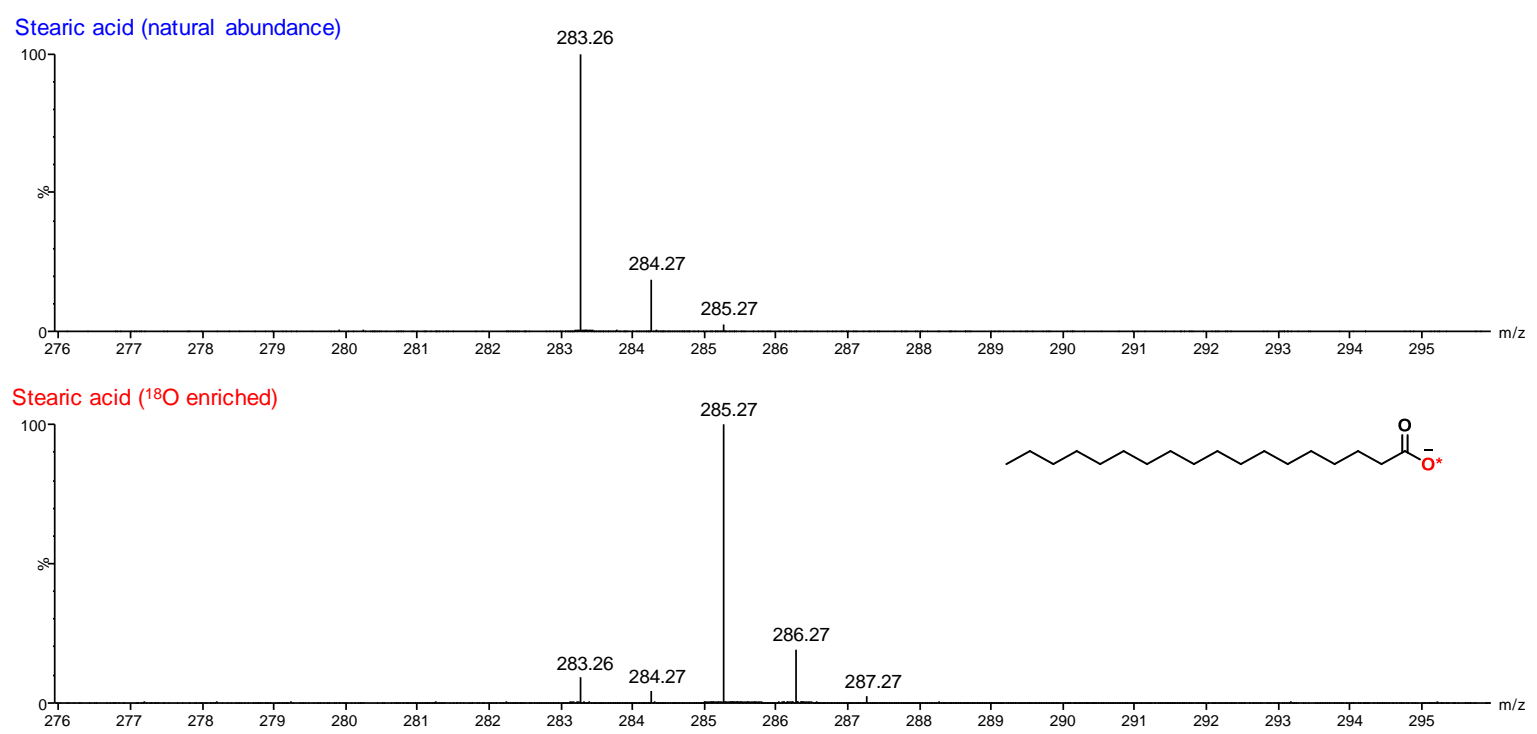

Figure B1S3: LC analyses of the non-labeled precursor in comparison to the ${ }^{18} \mathrm{O}$-enriched product. The small peak with a retention time of 4.75 min belongs to a palmitic acid impurity present in the starting non-enriched reagent.

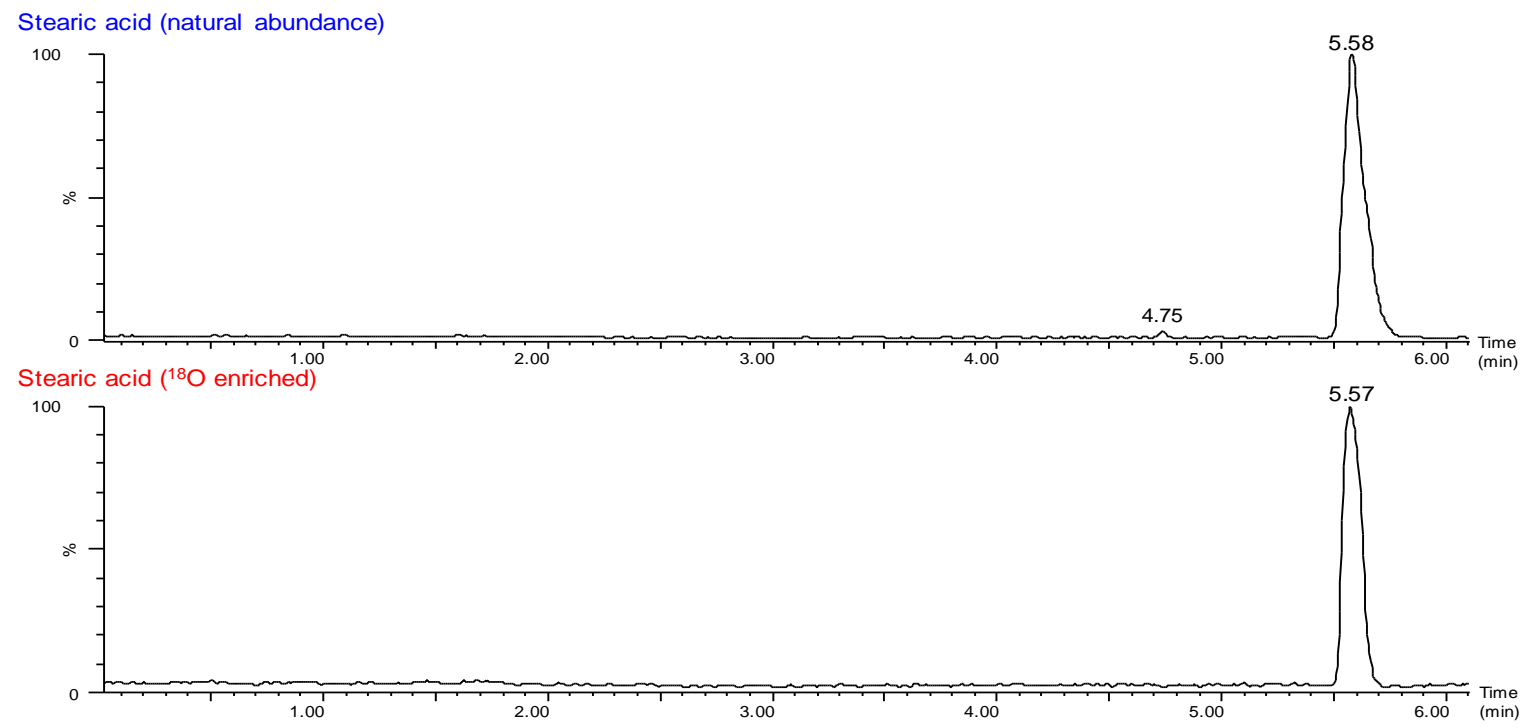


Figure B1S4: ${ }^{1} \mathrm{H}$ NMR spectra of the non-labeled precursor in comparison to the ${ }^{18} \mathrm{O}$-enriched product (DMSO- $d_{6}$, $600 \mathrm{MHz}$; solvent peaks are crossed out).

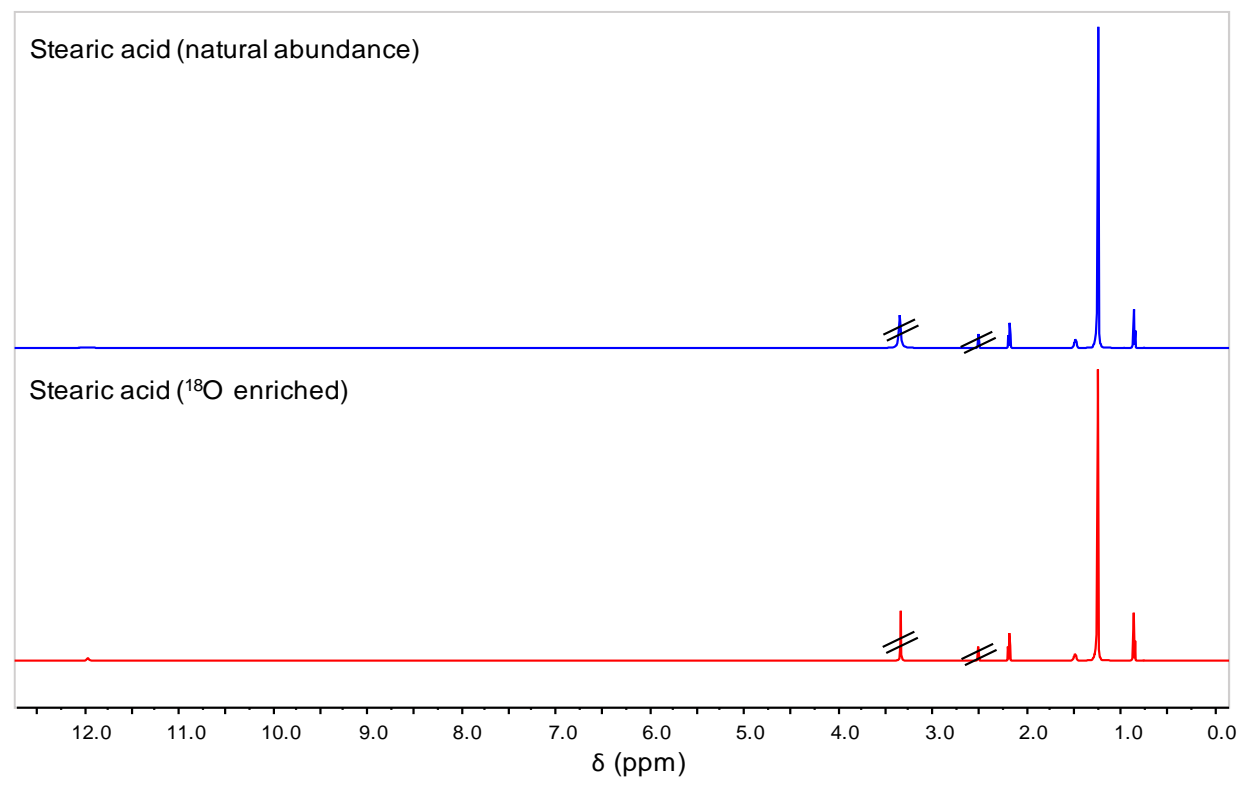

Figure B1S5: ${ }^{13} \mathrm{C}$ NMR spectra of the non-labeled precursor in comparison to the ${ }^{18} \mathrm{O}$-enriched product (DMSO-d6, $600 \mathrm{MHz}$; solvent peaks are crossed out).

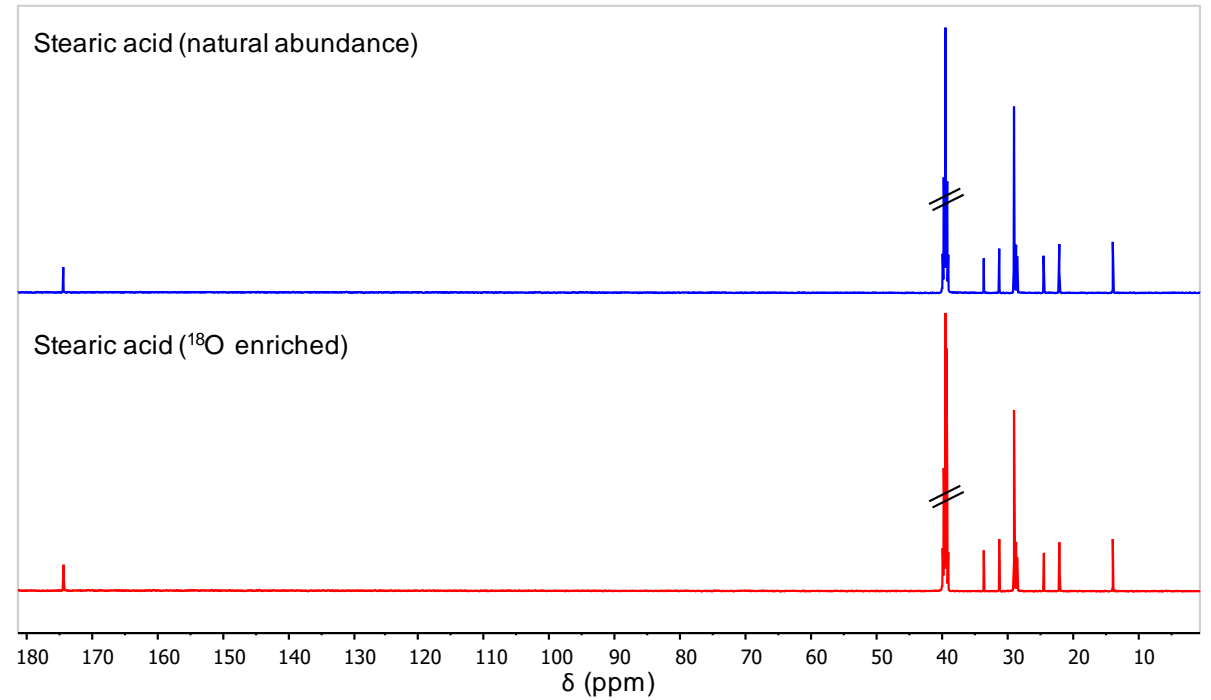


Figure B1S6: XRD powder pattern of the non-labeled precursor in comparison to the ${ }^{18} \mathrm{O}$-enriched product.

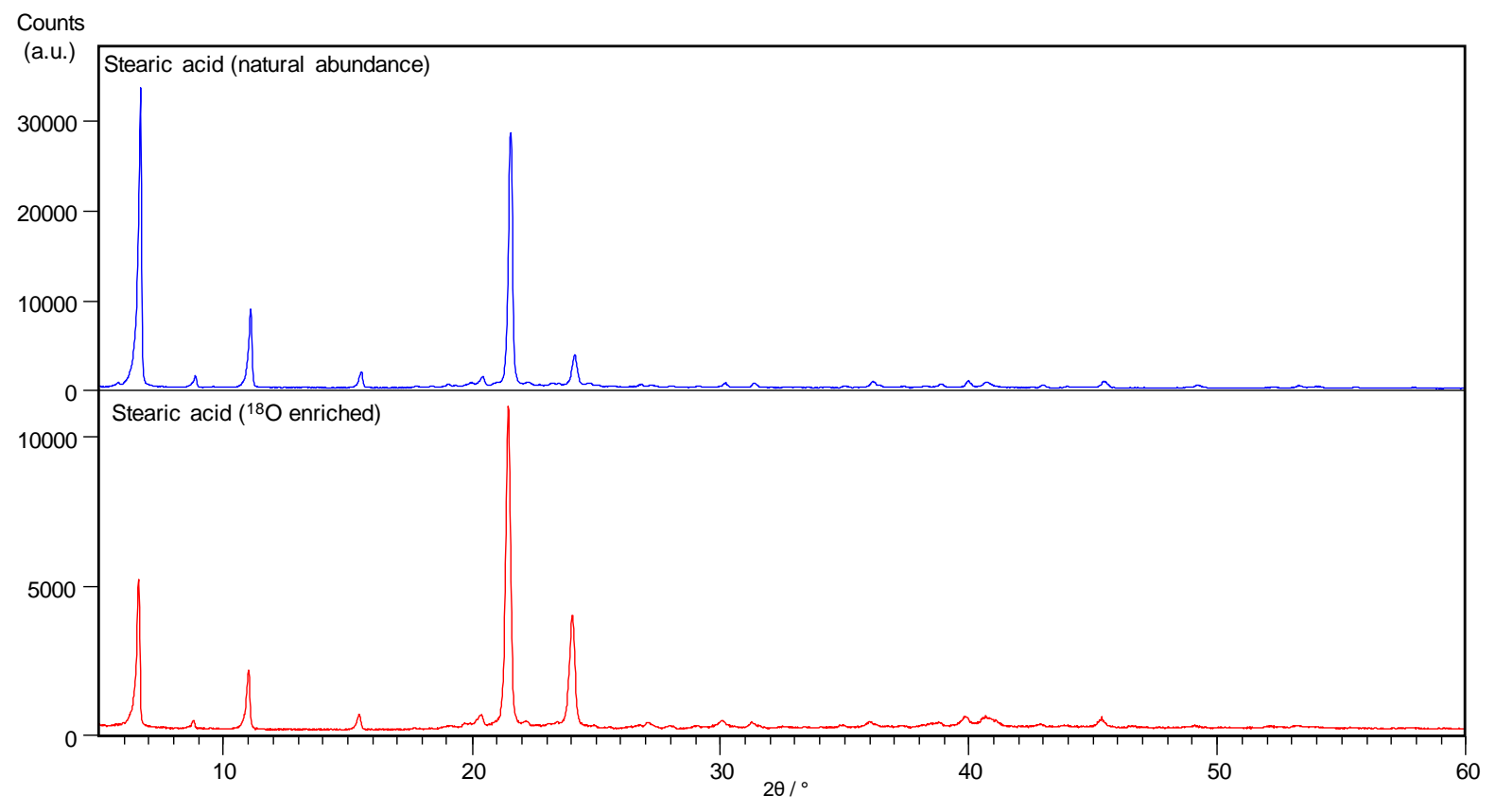

Figure B1S7: ${ }^{13} \mathrm{C}$ NMR study of the ${ }^{18} \mathrm{O}$-isotope effect on the ${ }^{13} \mathrm{C}$-carboxylic resonance in solution NMR. The non-labeled precursor is compared to the ${ }^{18} \mathrm{O}$-enriched product, both having been mixed in different ratios, as indicated above each spectrum (DMSO- $\left.d_{6}, 600 \mathrm{MHz}\right)$.

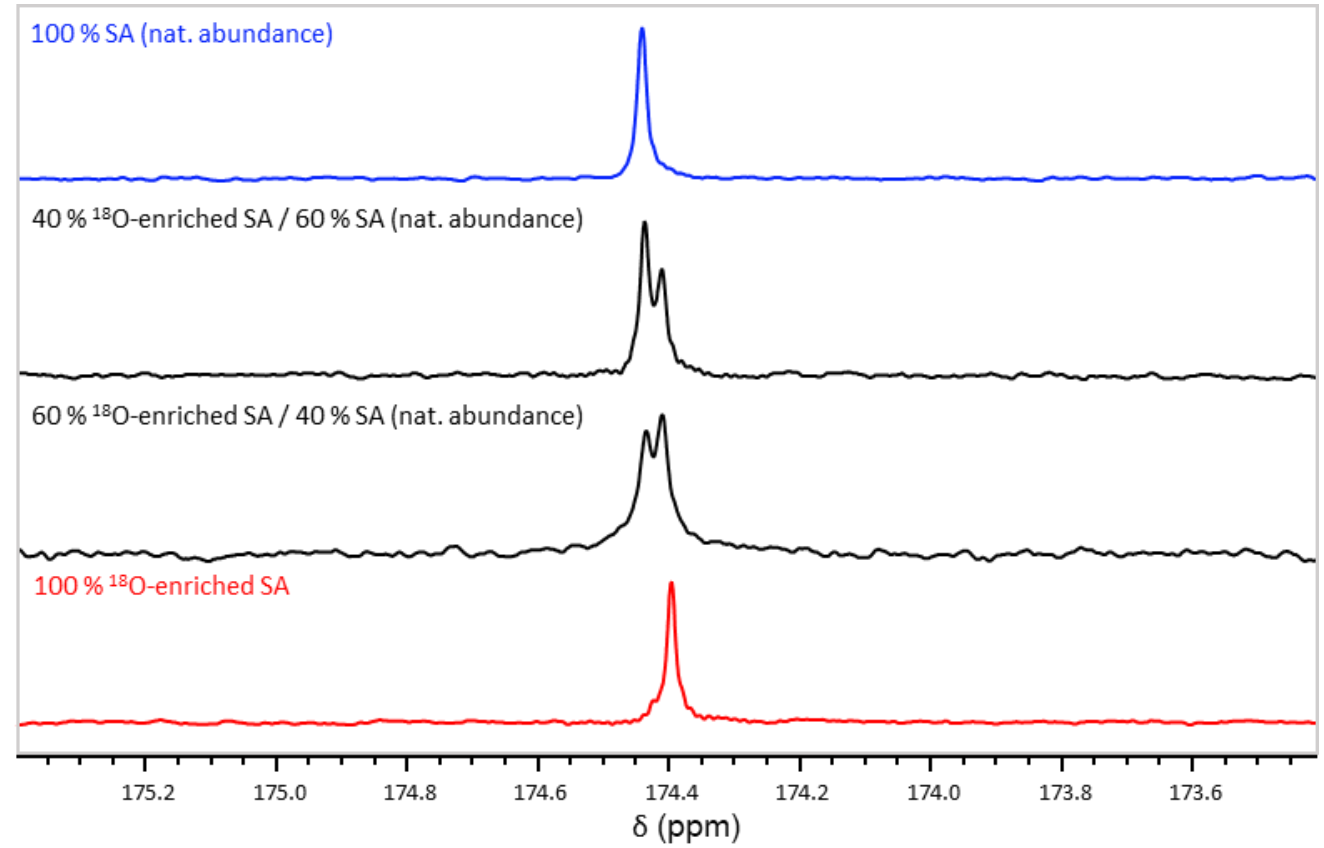


Figure B1S8: MS analyses of the non-labeled precursor in comparison to the ${ }^{17} \mathrm{O}$-enriched product. Average enrichment per carboxylic oxygen determined by MS: $35.9 \pm 0.3 \%(n=1)$, enrichment yield: $\sim 79 \%$.

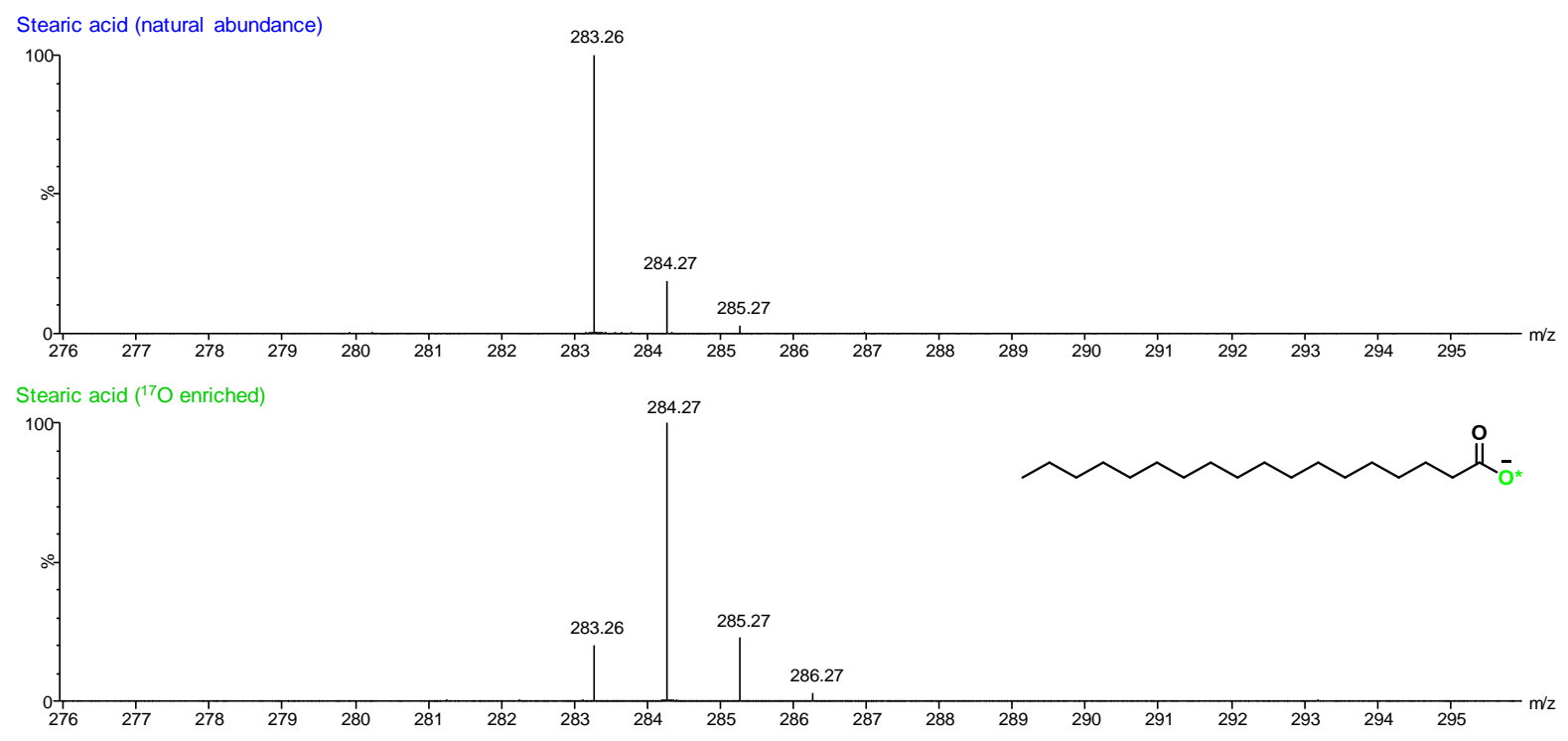

Figure B1S9: LC analyses of the non-labeled precursor in comparison to the ${ }^{17} \mathrm{O}$-enriched product. The small peak with a retention time of 4.75 min belongs to a palmitic acid impurity present in the starting non-enriched reagent.

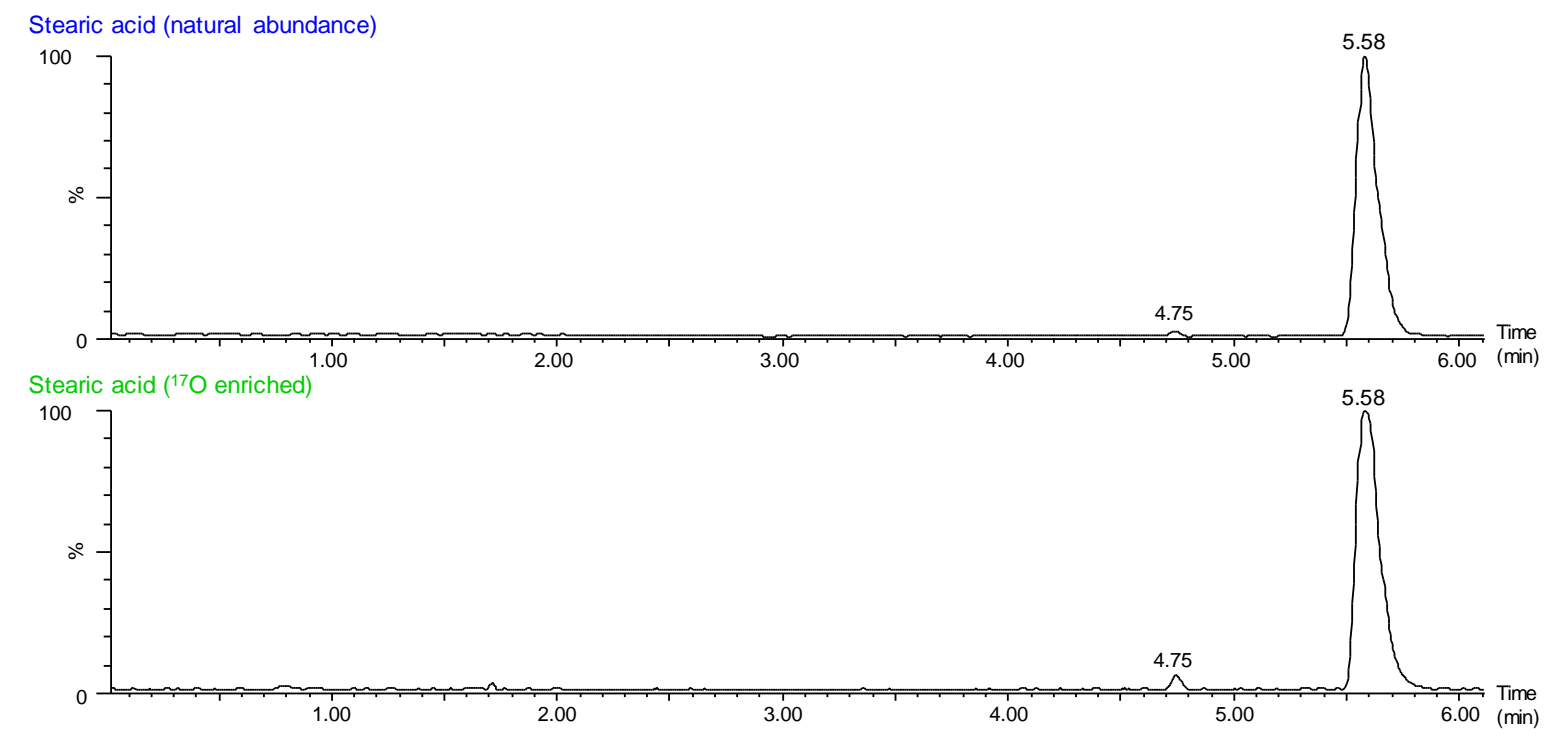


Figure B1S10: ${ }^{1} \mathrm{H}$ NMR spectra of the non-labeled precursor in comparison to the ${ }^{17} \mathrm{O}$-enriched product (DMSO- $d_{6}, 600 \mathrm{MHz}$; solvent peaks are crossed out).

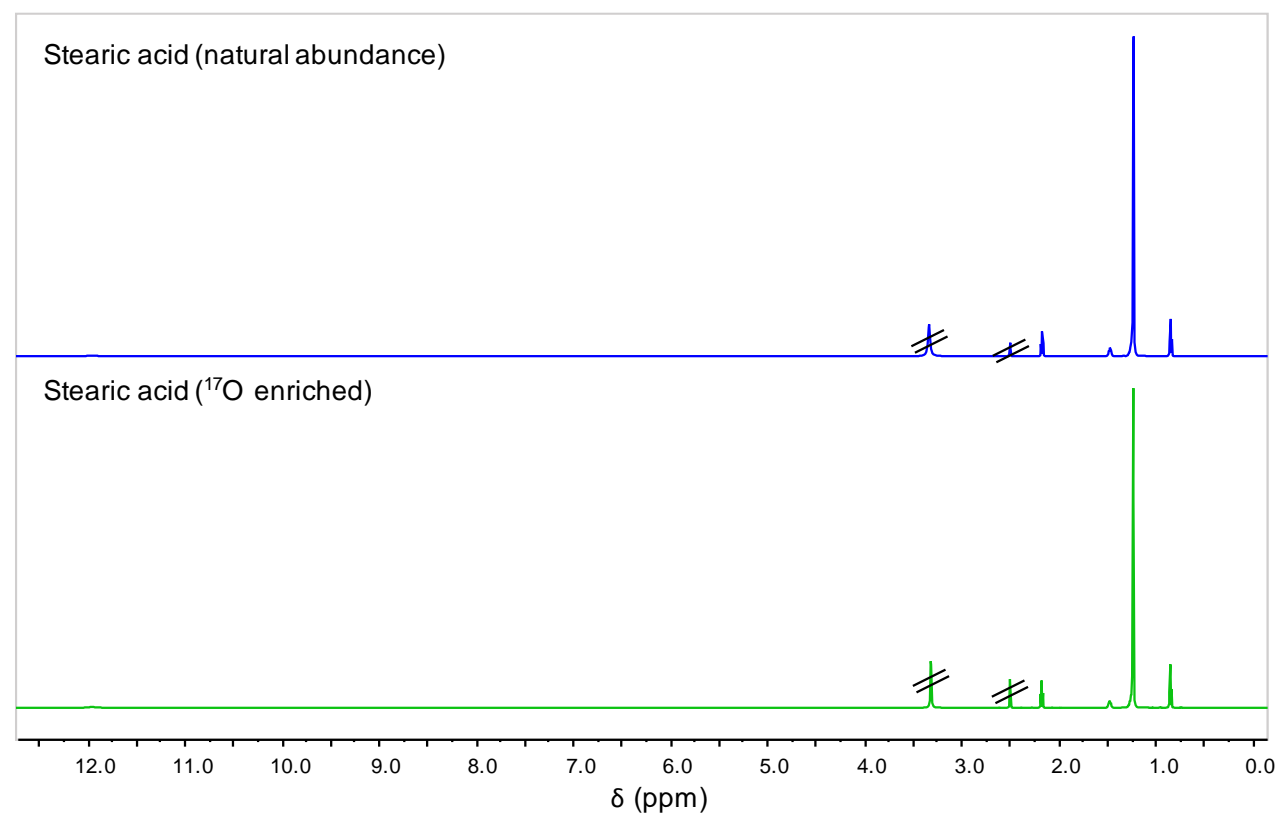

Figure B1S11: ${ }^{13} \mathrm{C}$ NMR spectra of the non-labeled precursor in comparison to the ${ }^{17} \mathrm{O}$-enriched product (DMSO- $d_{6}, 600 \mathrm{MHz}$; solvent peaks are crossed out).

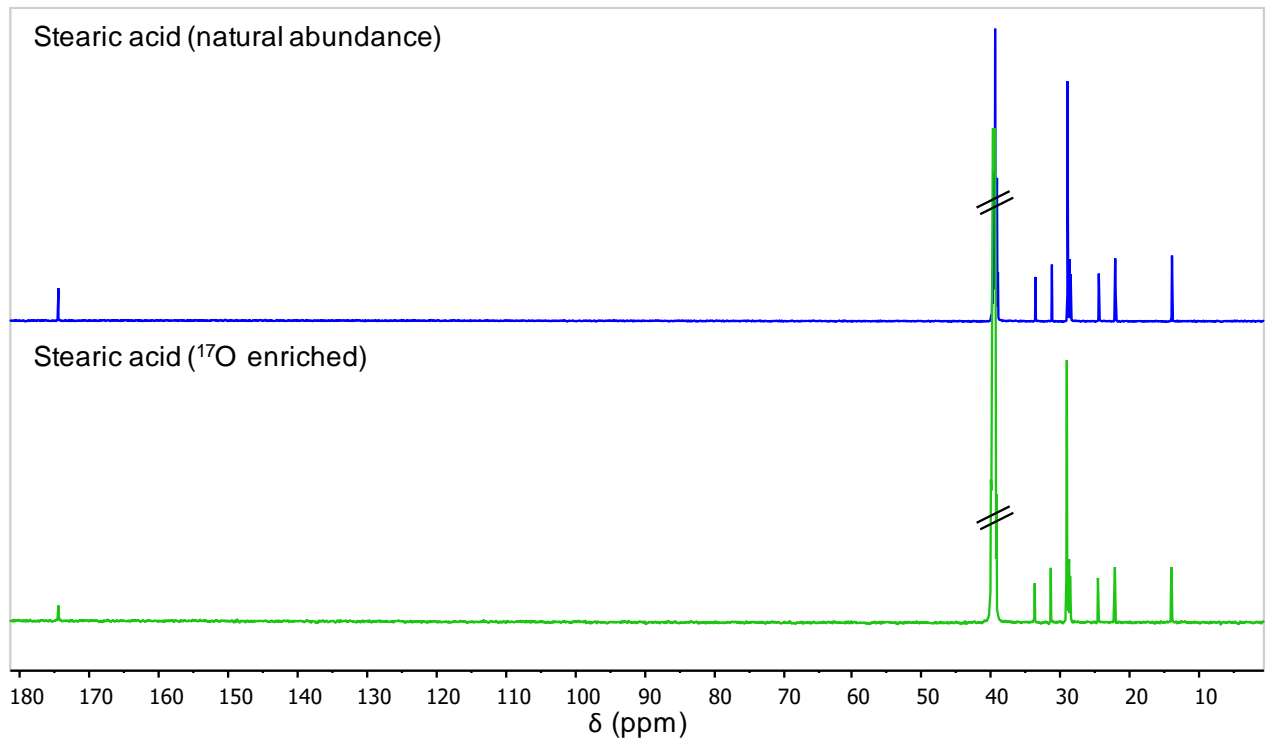


Figure B1S12: XRD powder pattern of the non-labeled precursor in comparison to the ${ }^{17} \mathrm{O}$-enriched product.

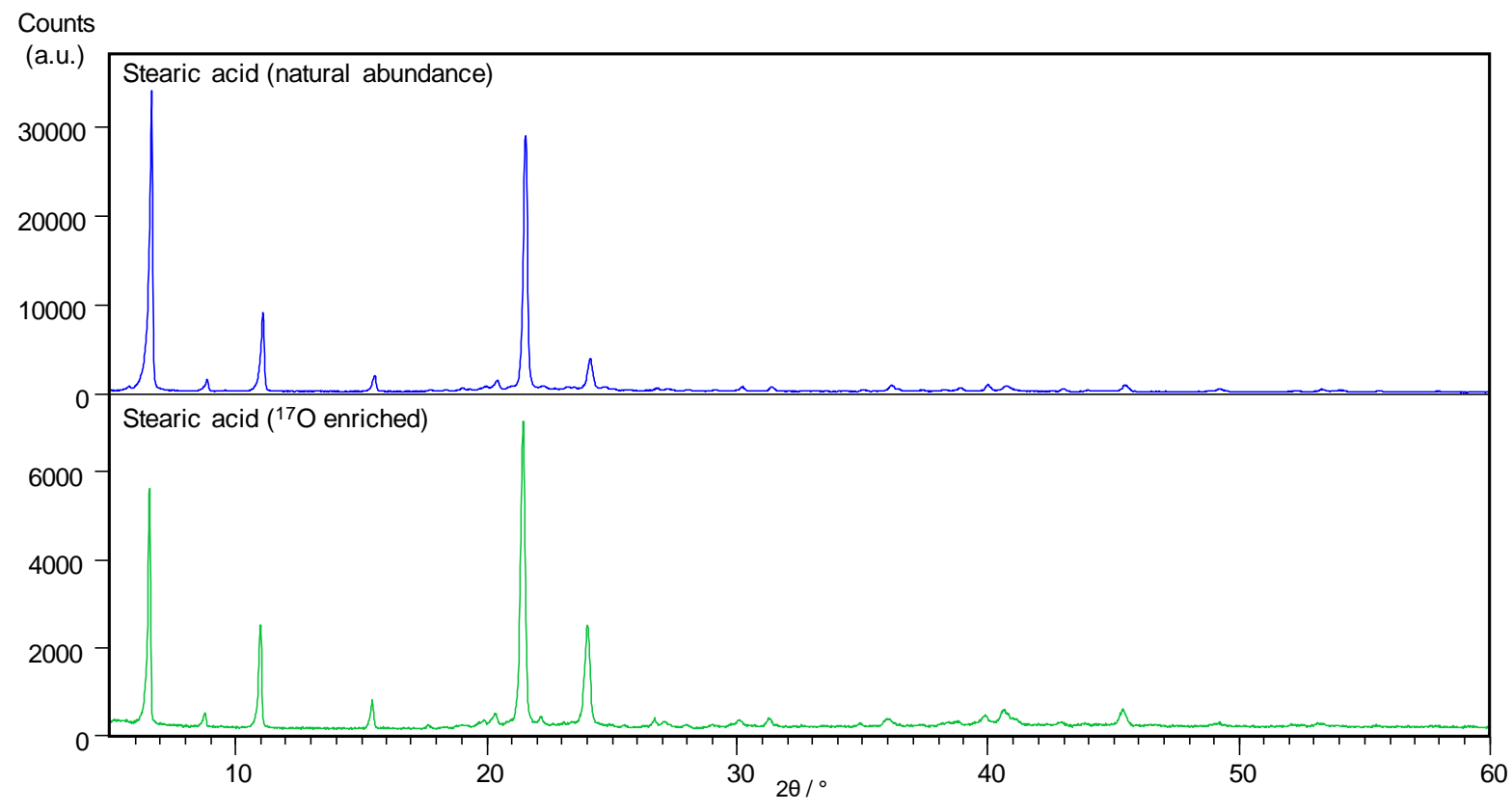


Table B1S1: Optimization of the hydrolysis step for the small-scale synthesis of enriched SA (MM400 mixer mill; $10 \mathrm{~mL}$ inner-volume jar containing two $10 \mathrm{~mm}$ diameter beads; stainless steel).

\begin{tabular}{|c|c|c|c|c|c|c|}
\hline Test & $\mathbf{n}_{(\mathbf{e q})}\left(\mathbf{H}_{2}{ }^{*} \mathbf{O}\right)$ & $\mathbf{n}_{(\mathrm{eq})}\left(\mathbf{K}_{\mathbf{2}} \mathbf{C O}_{\mathbf{3}}\right)$ & $\begin{array}{c}\text { Milling time } \\
(\mathbf{h})\end{array}$ & $\begin{array}{c}\text { Milling } \\
\text { frequency } \\
(\mathbf{H z})\end{array}$ & Yield (\%) & $\begin{array}{c}\text { Enrichment } \\
\text { yield (\%) }\end{array}$ \\
\hline 1 & 3.0 & 0 & $>5.5 \mathrm{~h}^{\mathrm{a}}$ & 30 & N.D. $^{\mathrm{b}}$ & N.M. $^{\mathrm{c}}$ \\
\hline 2 & 3.0 & 1.0 & $3.0 \mathrm{~h}$ & 30 & $82-84$ & $91-94$ \\
\hline 3 & 2.0 & 1.0 & $3.5 \mathrm{~h}$ & 30 & 82 & 85 \\
\hline 4 & 2.0 & 2.0 & $3.0 \mathrm{~h}$ & 30 & 81 & N.M. $^{{ }^{\mathrm{c}}}$ \\
\hline
\end{tabular}

In absence of $\mathrm{K}_{2} \mathrm{CO}_{3}$ base (test \#1), the hydrolysis time exceeded $5.5 \mathrm{~h}$, despite the use of 3 equivalents of $\mathrm{H}_{2} * \mathrm{O}$ in the hydrolysis step. By adding 1 equivalent of $\mathrm{K}_{2} \mathrm{CO}_{3}$ during the hydrolysis step (test \#2), the milling time could be reduced to only 3 hours, and the enriched molecule was isolated with good synthetic and enrichment yields. When trying to further reduce the number of equivalents of $\mathrm{H}_{2} * \mathrm{O}$ in presence of 1 equivalent of $\mathrm{K}_{2} \mathrm{CO}_{3}$ (test \#3), the milling time had to be re-increased to $3.5 \mathrm{~h}$, and the overall enrichment yield of the isolated product was lower. Addition of a second equivalent of base only slightly reduced the milling time (test \#4).

Overall, the optimal milling conditions which were chosen, allowing the best enrichment and synthetic yields to be reached in minimal time, are those of test \#2. These conditions were found to be reproducible.

Table B1S2: Optimization of the milling conditions during the hydrolysis step in larger-scale syntheses of enriched SA (P7 planetary mill; $20 \mathrm{~mL}$ inner-volume jar containing $5 \mathrm{~mm}$ diameter beads; stainless steel). Tests \#1-5 (grey lines) correspond to syntheses performed starting from $\sim 310 \mathrm{mg}$ of stearic acid reagent. Test \#6 (blue line) corresponds to tests performed starting from $\sim 555 \mathrm{mg}$ of stearic acid reagent.

\begin{tabular}{|c|c|c|c|c|c|c|c|}
\hline Test & $\begin{array}{c}\text { Rotation } \\
\text { speed } \\
\text { (rpm) }\end{array}$ & $\begin{array}{c}\text { Number of } \\
\text { milling } \\
\text { beads }\end{array}$ & $\begin{array}{c}\text { Effective } \\
\text { milling time } \\
\text { (h) }\end{array}$ & $\begin{array}{l}\text { Hydrolysis } \\
\text { step } \\
\text { (estimated } \\
\text { by IR) }\end{array}$ & $\begin{array}{c}\text { Medium } \\
\text { homogeneity } \\
\text { (estimated } \\
\text { by IR) }\end{array}$ & Yield (\%) & $\begin{array}{c}\text { Enrichment } \\
\text { yield }(\%)\end{array}$ \\
\hline 1 & 500 & 80 & $2 \mathrm{~h}^{\mathrm{a}}$ & incomplete & homogeneous & $96^{c}$ & 67 \\
\hline 2 & 500 & 80 & $3 \mathrm{~h}^{\mathrm{b}}$ & incomplete & homogeneous & $95^{\mathrm{c}}$ & 84 \\
\hline 3 & 800 & 80 & $1 \mathrm{~h}$ & incomplete & heterogeneous & N.D. ${ }^{d}$ & N.M. $^{\mathrm{e}}$ \\
\hline 4 & 700 & 80 & $1 \mathrm{~h}$ & complete & homogeneous & $95 \pm 3^{f}$ & $88 \pm 3^{f}$ \\
\hline 5 & 800 & 50 & $1 \mathrm{~h}$ & incomplete & heterogeneous & 89 & 77 \\
\hline 6 & 700 & 80 & $1 \mathrm{~h}$ & complete & homogeneous & $95 \pm 1^{f}$ & $92 \pm 2^{f}$ \\
\hline
\end{tabular}

${ }^{a}$ Four cycles of 15 min, with a 30 min break between each cycle), followed by 1 cycle of 60 min

Traces of ics of 60 min, with a 30 min break between each cycle

Traces of imidazolium in the product

N.D. $=$ Not determined

${ }^{\mathrm{e}} \mathrm{N} . \mathrm{M} .=$ Not measured (non-enriched water was used)

${ }^{f}$ Average value over 3 independent experiments $(n=3)$

Larger-scale experiments were all performed using the optimal relative stoichiometries between reagents established in the MM400 (Table B1S1, test \#2). As reported in Table B1S2, using the planetary mill, the milling conditions of the hydrolysis step also required optimization. Tests were first performed on an intermediate scale ( $\sim 310 \mathrm{mg}$ of stearic acid reagent, tests \#1 to 5), before switching to larger quantities $(\sim 555 \mathrm{mg}$ of stearic acid reagent, test \#6). At $500 \mathrm{rpm}$, the hydrolysis was found to be incomplete, even after 3 hours of milling (Table B1S2, tests \#1 and 2). Using a higher rotation speed of 800 rpm (test \#3), although a higher hydrolysis rate was globally achieved, the mixing of reagents was 
found to be heterogeneous, based on IR analyses. This could be explained by a "rolling effect" occurring during the milling, as can be seen in Figure B1S13 (a). In order to counter this, two options were looked into: ${ }^{13}$ reducing the rotation speed (test \#4) or the number of beads (test \#5). The former solution was found to be the most efficient, as shown in Table B1S2 (test \#4) and Figure B1S13 (b), and was used in subsequent scale-up labeling tests for stearic acid. Indeed, using the same conditions, it was possible to reproducibly perform the labeling starting from $555 \mathrm{mg}$ of stearic acid, as shown in Table B1S2 (test \#6) and Figure B1S13 (c).

It is worth noting that experiments were performed here using only one of the two P7 reactors. Had both reactors been used, it would have been possible to double the amount of enriched stearic acid produced (and hence obtain $\sim 1 \mathrm{~g}$ of enriched product).

Figure B1S13: Photo of the reaction mixture at the end of the hydrolysis step a/ at $800 \mathrm{rpm}$ (Table B1S2, test \#3, $\sim 310 \mathrm{mg}$ of stearic acid reagent); b/ at $700 \mathrm{rpm}$ (Table B1S2, test \#4, 310 $\mathrm{mg}$ of stearic acid reagent); and $\mathbf{c} /$ at $700 \mathrm{rpm}$ (Table B1S2, test \#6, 555 mg of stearic acid reagent).

a/

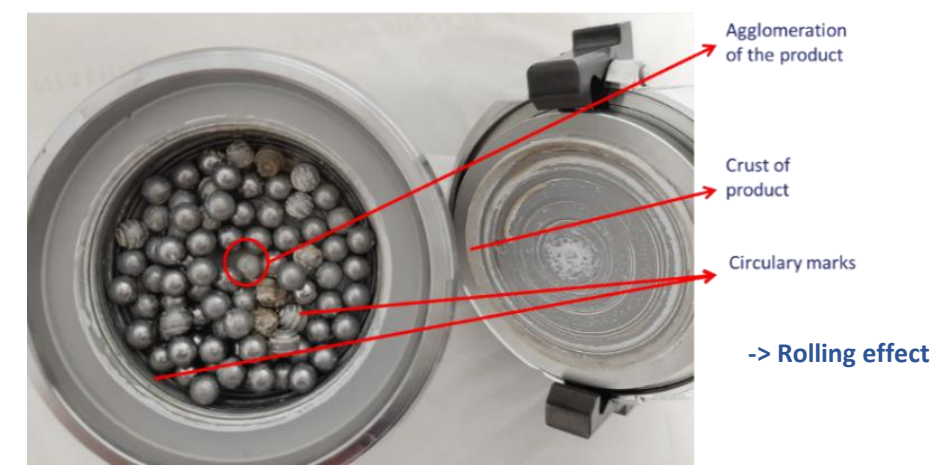

b/

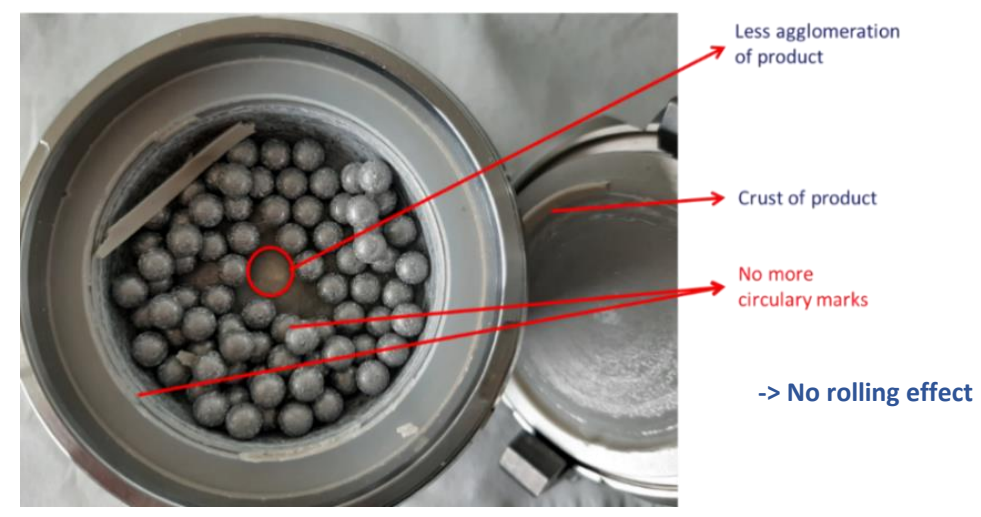

cl

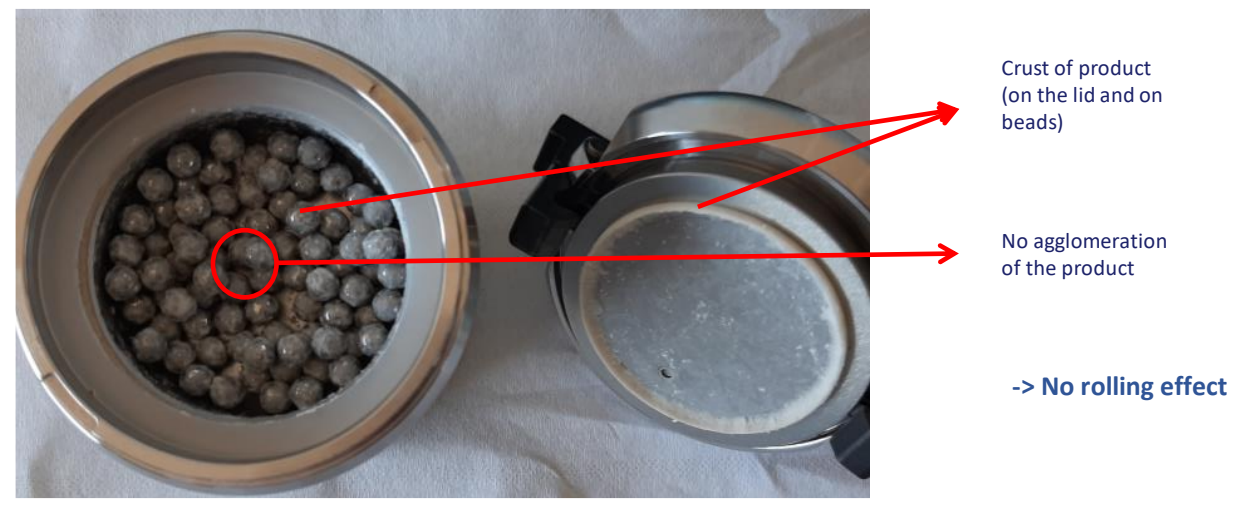


Stearic acid phases, which had been labeled in ${ }^{17} \mathrm{O}$ or ${ }^{18} \mathrm{O}$ (using $\sim 90 \%{ }^{17} \mathrm{O}$ labeled $\mathrm{H}_{2}{ }^{*} \mathrm{O}$ and $97 \%{ }^{18} \mathrm{O}$-labeled $\mathrm{H}_{2}{ }^{*} \mathrm{O}$, respectively) were packed in a small vial under air. Then the vial was closed, parafilmed, and stored either in the freezer $\left({ }^{17} \mathrm{O}\right.$-enriched stearic acid) or on the bench in the lab $\left({ }^{18} \mathrm{O}\right.$ enriched stearic acid). Samples were then re-analyzed after 1 year of storage (Table B1S3).

Table B1S3: Measured enrichment levels of stearic acid after 1 year of storage (average enrichment per carboxylic oxygen, as determined by MS).

\begin{tabular}{|l|c|c|}
\hline & \multicolumn{2}{|c|}{ Enrichment level [\%] } \\
\hline Fatty acid & $\mathbf{t}_{\mathbf{0}}$ & $\mathbf{t}_{\mathbf{0}}+\mathbf{1}$ year \\
\hline Stearic acid- ${ }^{17} \mathrm{O}$ & 36.0 & 36.0 \\
\hline Stearic acid- ${ }^{18} \mathrm{O}$ & 44.0 & 44.0 \\
\hline
\end{tabular}




\section{B2) ${ }^{13} \mathrm{C}$-Stearic acid $\left({ }^{13} \mathrm{C}-\mathrm{SA}\right)$}

\section{B2-a) Optimized labeling protocol}

${ }^{13} \mathrm{C}$-Stearic acid $(92.3 \mathrm{mg}, 0.32 \mathrm{mmol}, 1.0 \mathrm{eq})$ and CDI $(57.7 \mathrm{mg}, 0.36 \mathrm{mmol}, 1.1 \mathrm{eq})$ were introduced into a stainless steel grinding jar (10 mL inner volume) containing two stainless steel beads (10 mm diameter). The jar was closed and subjected to grinding for 30 minutes in the MM400 mixer mill operated at $25 \mathrm{~Hz}$. Anhydrous potassium carbonate $(44.7 \mathrm{mg}, 0.32 \mathrm{mmol}, 1.0 \mathrm{eq})$ and ${ }^{18} \mathrm{O}$-labeled water $(97.1 \%, 17.5 \mu \mathrm{L}, 0.97 \mathrm{mmol}, 3.0 \mathrm{eq})$ were then added subsequently into the jar, and the mixture was subjected to further grinding for 180 minutes at $30 \mathrm{~Hz}$. To help recover the product, non-labeled water $(1 \mathrm{~mL})$ was added into the jar, and the content was subjected to grinding for 2 minutes at $25 \mathrm{~Hz}$. Then, the suspension was transferred to a beaker (together with a sufficient amount of non-labeled water (15 mL) used here to rinse the jar). The medium was acidified to $\mathrm{pH} \sim 1$ with an aqueous solution of $\mathrm{HCl}(6 \mathrm{M}, 12$ drops $)$ and extracted with ethyl acetate $(1 \times 20 \mathrm{~mL}, 3 \times 10 \mathrm{~mL})$. Combined organic phases were washed with $\mathrm{HCl}(1 \mathrm{M}, 15 \mathrm{~mL})$, dried over $\mathrm{Na}_{2} \mathrm{SO}_{4}$, filtered, and finally dried under vacuum to yield the product as white microcrystalline solid. Yield $(\mathrm{n}=1): 81 \mathrm{mg}, 89 \%$.

For the ${ }^{17} \mathrm{O}$-labeling, $90.4 \%$ water $(17.5 \mu \mathrm{L}, 3.0$ eq. $)$ was used at the hydrolysis step. Average yield $(\mathrm{n}=3): 86 \pm 4 \mathrm{mg}, 92 \pm 2 \%$.

Figure B2S1: ATR-IR analysis of the starting material, final product, and reaction intermediates. The dashed line shows that the $\mathrm{C}=\mathrm{O}$ stretching frequency of ${ }^{18} \mathrm{O} /{ }^{17} \mathrm{O}$-enriched product is lower in comparison with non-labeled precursor.

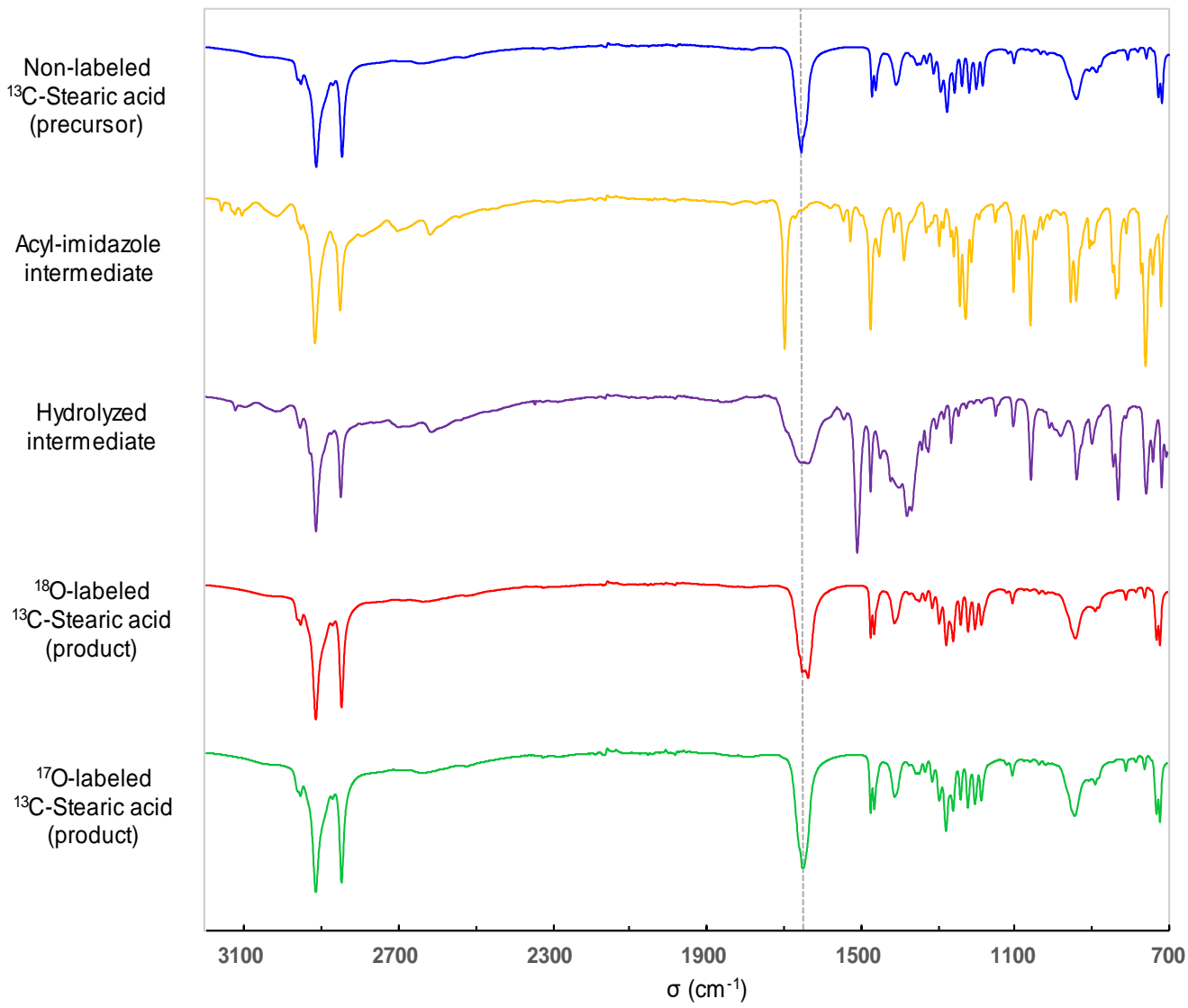


Figure B2S2: MS analyses of the non-labeled precursor in comparison to the ${ }^{18} \mathrm{O}$-enriched product. Average enrichment per carboxylic oxygen determined by MS: $44.2 \pm 0.3 \%(n=1)$, enrichment yield: $\sim 91 \%$.

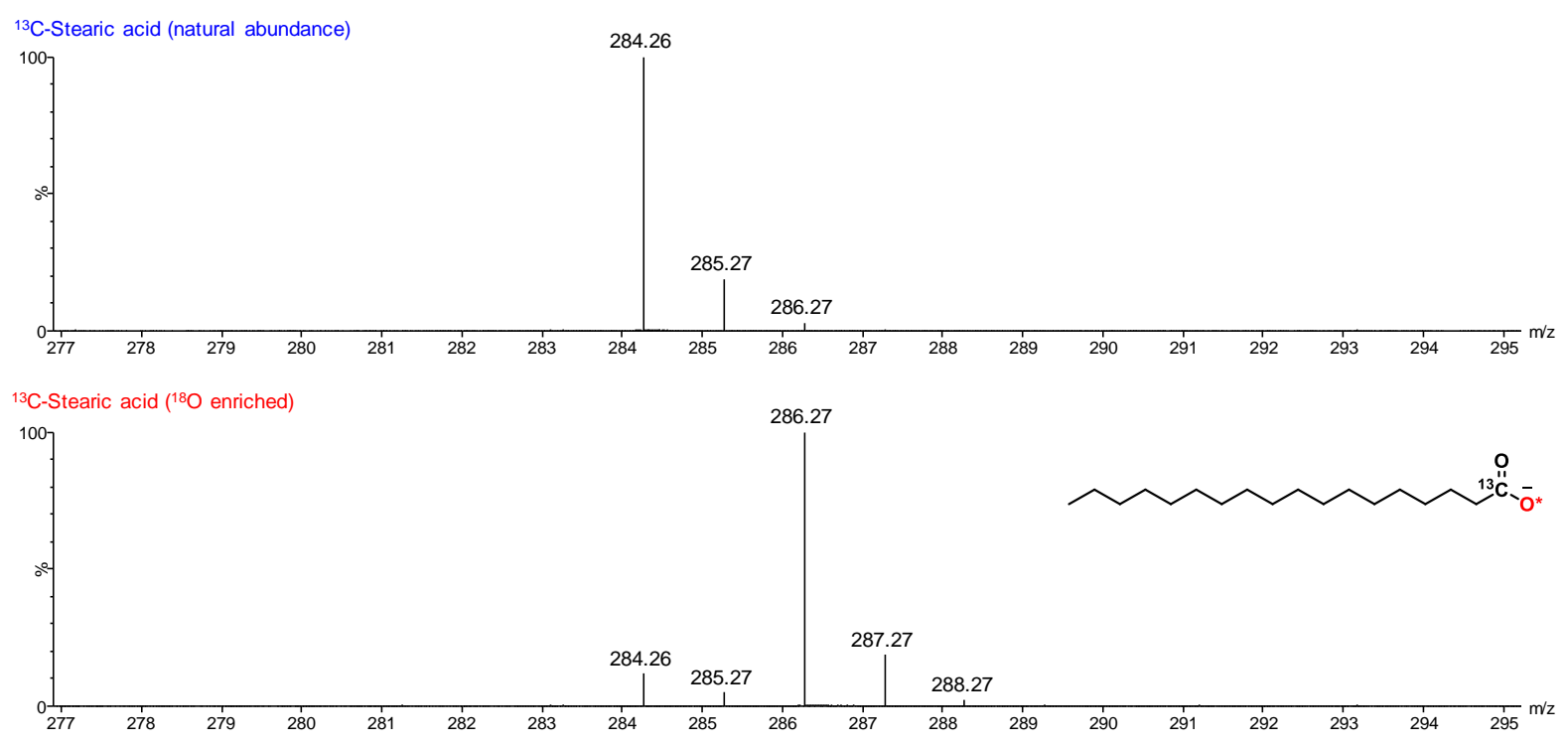

Figure B2S3: LC analyses of the non-labeled precursor in comparison to the ${ }^{18} \mathrm{O}$-enriched product.

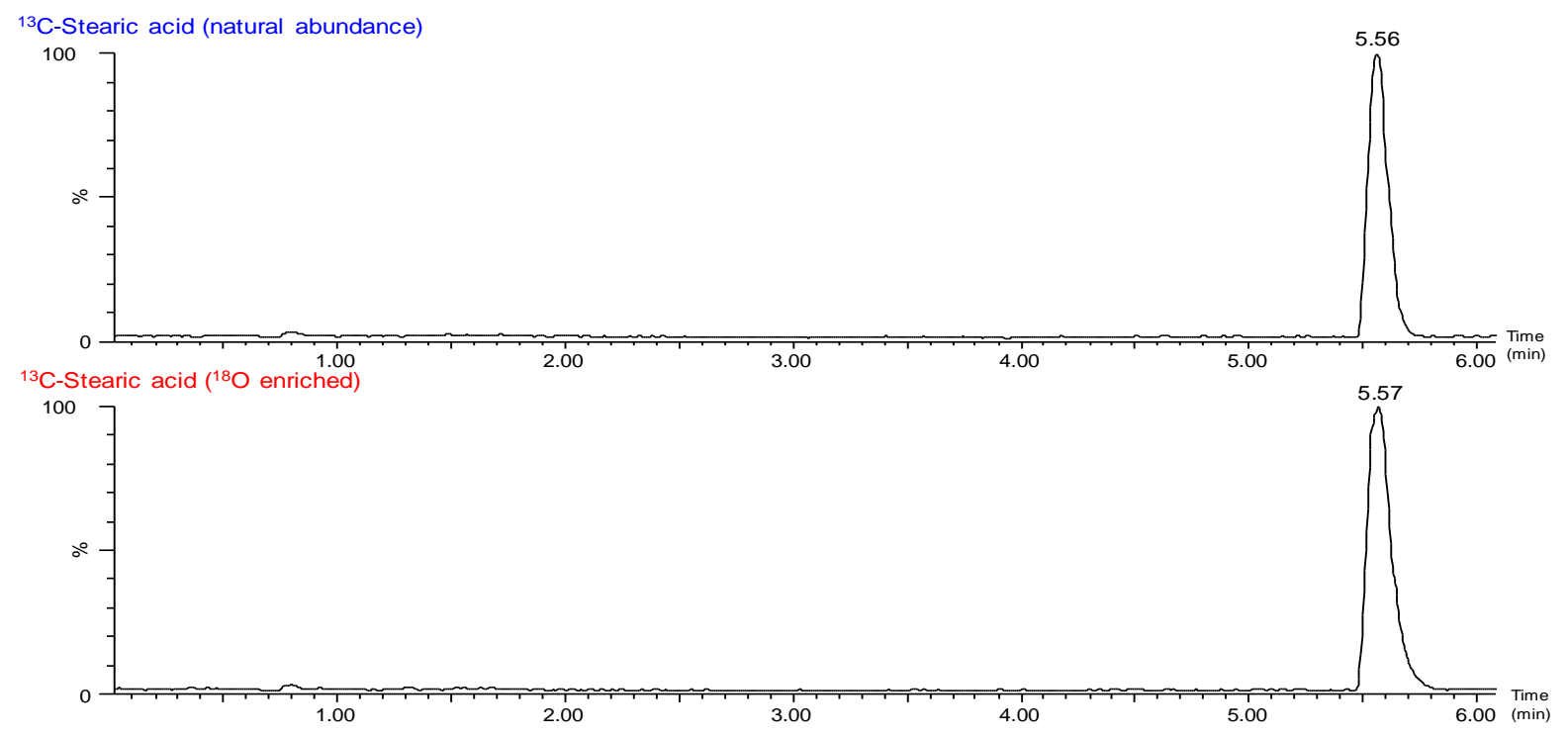


Figure B2S4: ${ }^{1} \mathrm{H}$ NMR spectra of the non-labeled precursor in comparison to the ${ }^{18} \mathrm{O}$-enriched product (DMSO- $d_{6}$, $600 \mathrm{MHz}$; solvent peaks are crossed out).

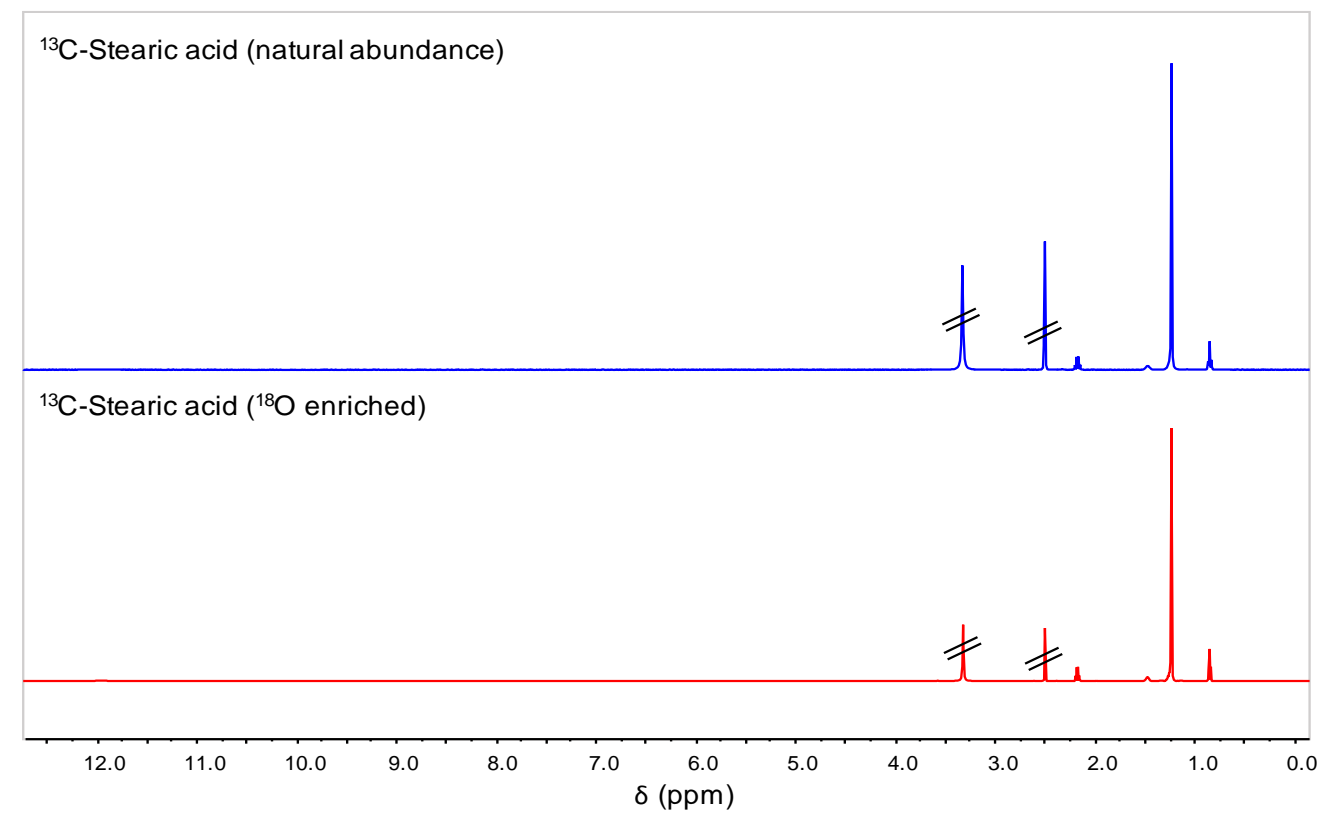

Figure B2S5: ${ }^{13} \mathrm{C}$ NMR spectra of the non-labeled precursor in comparison to the ${ }^{18} \mathrm{O}$-enriched product (DMSO- $d_{6}, 600 \mathrm{MHz}$; solvent peaks are crossed out).

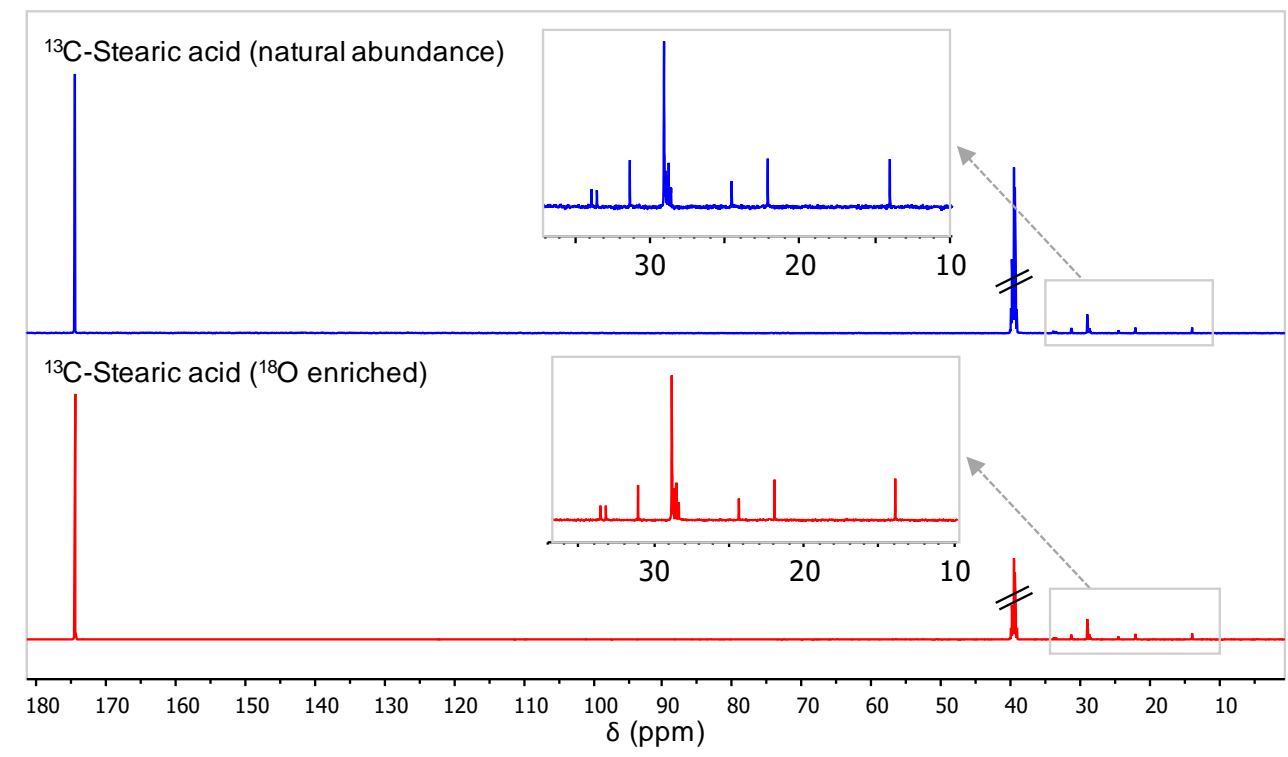


Figure B2S6: MS analyses of the non-labeled precursor in comparison to the ${ }^{17} \mathrm{O}$-enriched product. Average enrichment per carboxylic oxygen determined by MS: $35.9 \pm 1.5 \%(n=3)$, enrichment yield: $\sim 79 \%$.

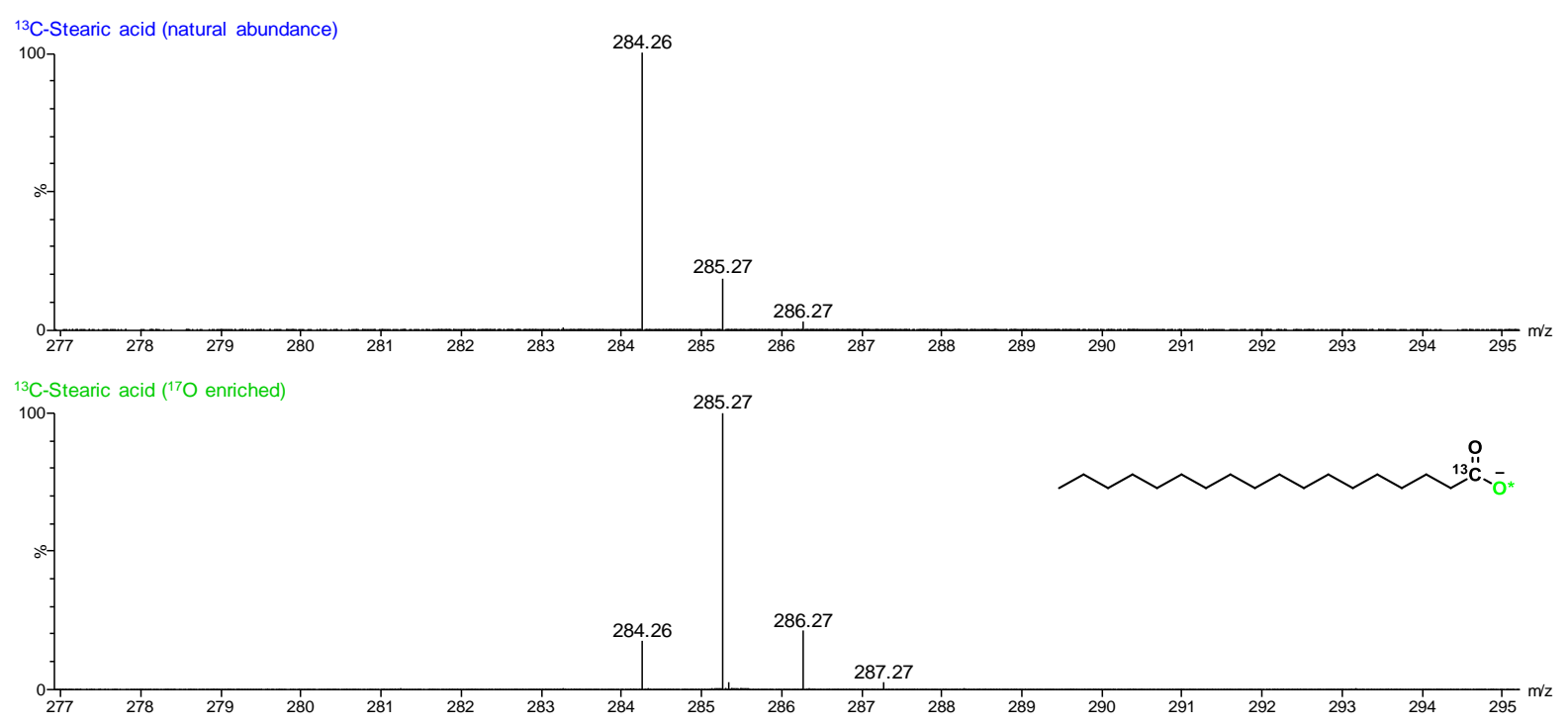

Figure B2S7: LC analyses of the non-labeled precursor in comparison to the ${ }^{17} \mathrm{O}$-enriched product.

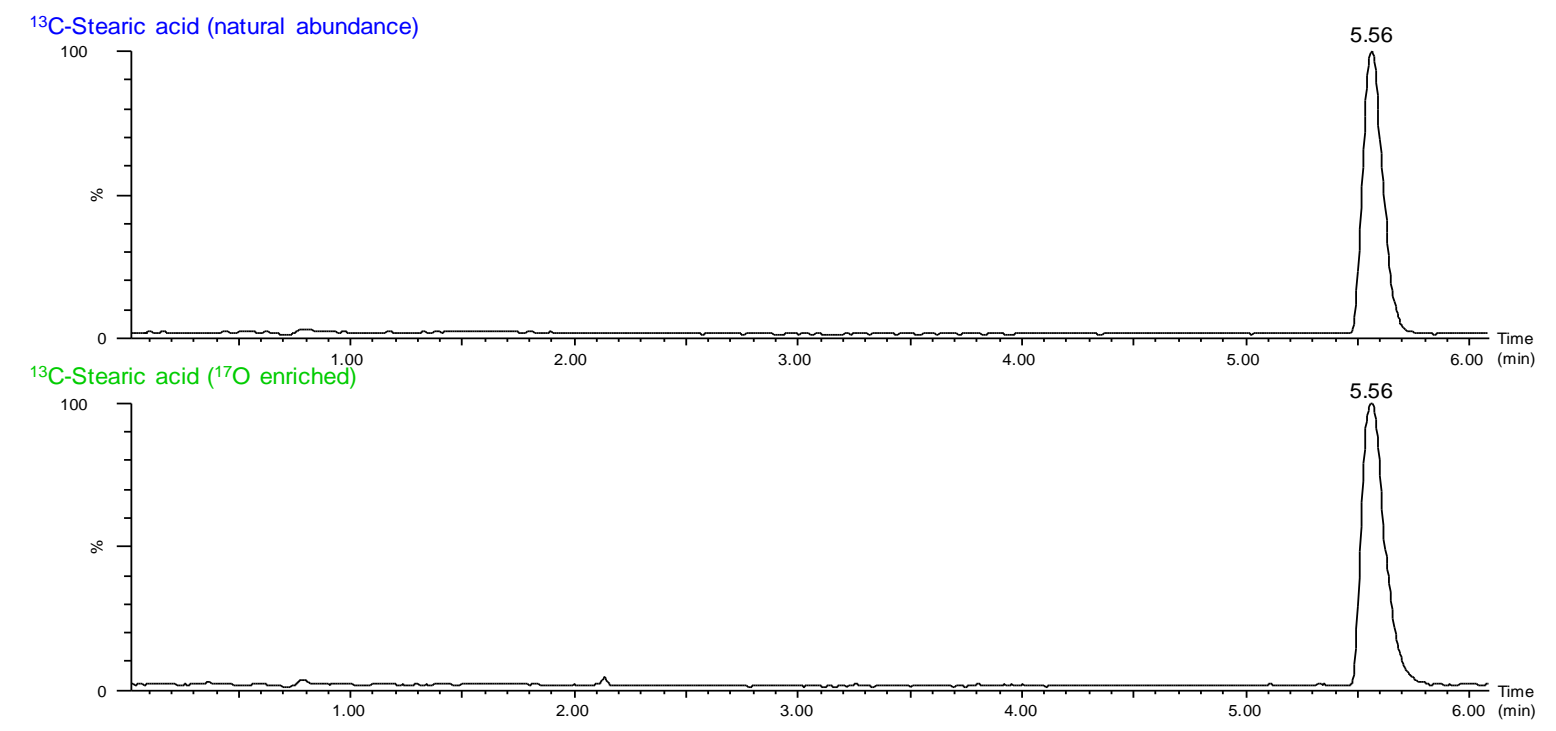


Figure B2S8: ${ }^{1} \mathrm{H}$ NMR spectra of the non-labeled precursor in comparison to the ${ }^{17} \mathrm{O}$-enriched product (DMSO- $d_{6}$, $600 \mathrm{MHz}$; solvent peaks are crossed out).

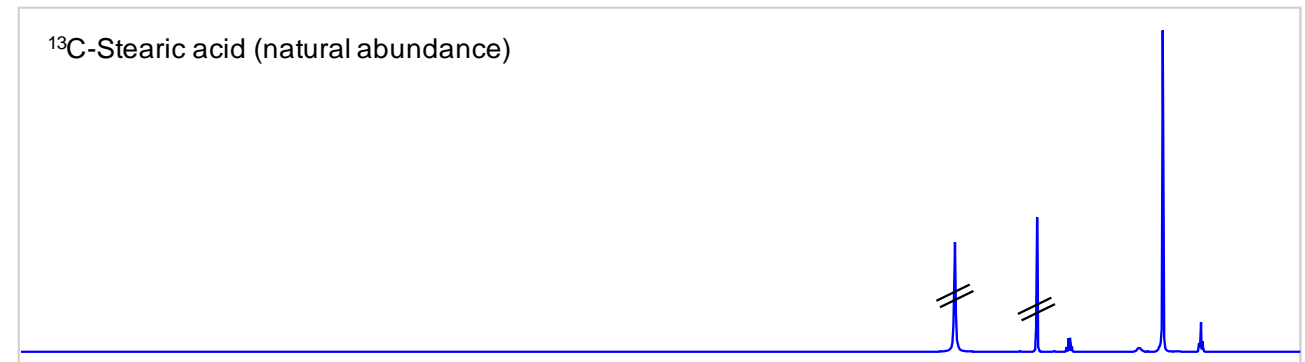

${ }^{13} \mathrm{C}$-Stearic acid $\left({ }^{17} \mathrm{O}\right.$ enriched)

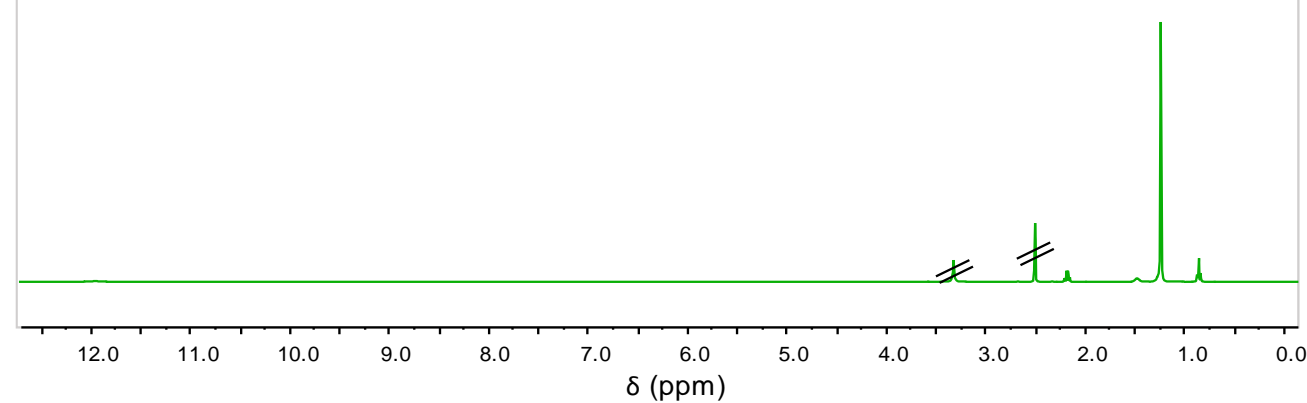

Figure B2S9: ${ }^{13} \mathrm{C}$ NMR spectra of the non-labeled precursor in comparison to the ${ }^{17} \mathrm{O}$-enriched product (DMSO- $d_{6}, 600 \mathrm{MHz}$; solvent peaks are crossed out).

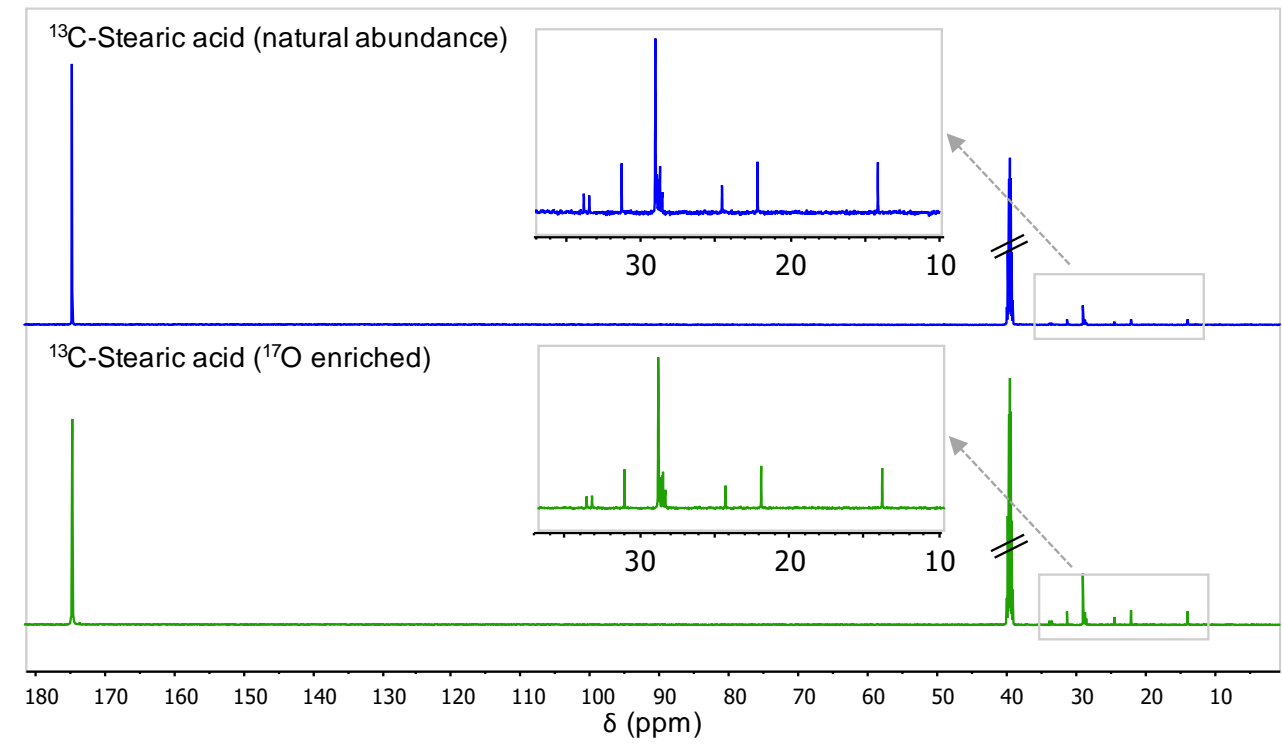


Figure B2S10: ${ }^{17} \mathrm{O}$ MAS NMR spectrum of ${ }^{17} \mathrm{O}$ - and ${ }^{13} \mathrm{C}$-labeled SA (black) and its fit (dashed red line), considering the presence of $\mathrm{C}=\mathrm{O}$ (green) and $\mathrm{C}-\mathrm{OH}$ (purple) contributions.

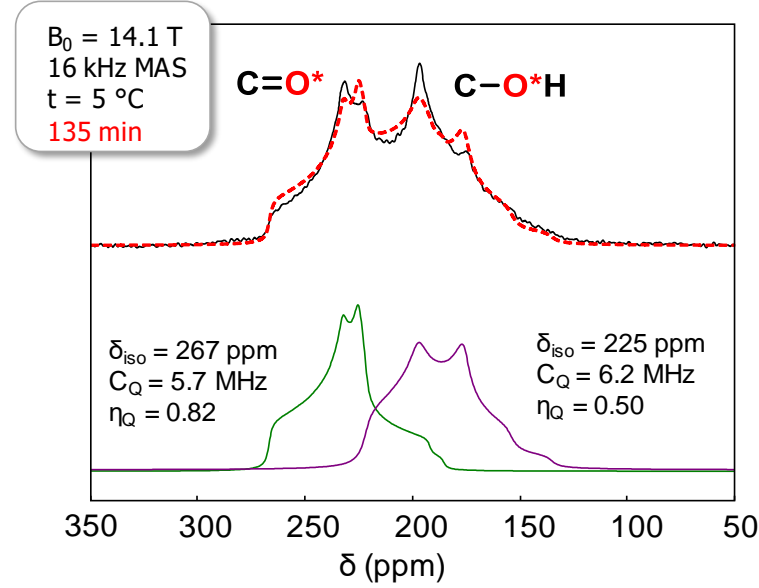




\section{B3) Oleic acid (OA)}

\section{B3-a) Optimized labeling protocol}

Oleic acid (92 mg, $0.33 \mathrm{mmol}, 1.0 \mathrm{eq})$ and CDI ( $58 \mathrm{mg}, 0.36 \mathrm{mmol}, 1.1 \mathrm{eq})$ were introduced into the stainless steel grinding jar $(10 \mathrm{~mL}$ inner volume) containing two stainless steel beads $(10 \mathrm{~mm}$ diameter). The jar was closed and subjected to grinding for 30 minutes in the MM400 mixer mill operated at $25 \mathrm{~Hz} .{ }^{18} \mathrm{O}$-labeled water $(97.1 \%, 12 \mu \mathrm{L}, 0.66 \mathrm{mmol}, 2.0 \mathrm{eq})$ was then added into the jar, and the mixture was subjected to further grinding for 60 minutes at $25 \mathrm{~Hz}$. To help recover the product, nonlabeled water $(1 \mathrm{~mL})$ was added into the jar, and the content was subjected to grinding for 2 minutes at $25 \mathrm{~Hz}$. Then, the content was transferred to a beaker (together with a sufficient amount of non-labeled water (13-15 mL), used here to rinse the jar). The medium was acidified to $\mathrm{pH} \sim 1$ with an aqueous solution of $\mathrm{HCl}(6 \mathrm{M}, 14-18$ drops) and extracted with ethyl acetate $(1 \times 20 \mathrm{~mL}, 2 \times 10 \mathrm{~mL})$. Combined organic phases were dried over $\mathrm{Na}_{2} \mathrm{SO}_{4}$, filtered and finally dried under vacuum giving the product as a colorless oil. Average yield $(\mathrm{n}=3): 84 \pm 1 \mathrm{mg}, 91 \pm 2 \%$.

For the ${ }^{17} \mathrm{O}$-labeling, $39.3 \%$ or $90.4 \%$ enriched water $(12 \mu \mathrm{L}, 2.0$ eq. $)$ was used at the hydrolysis step. Average yield $(\mathrm{n}=2): 83 \pm 1 \mathrm{mg}, 90 \pm 2 \%$.

For the scale-up, a $50 \mathrm{~mL}$ stainless steel jar with eight stainless steel beads (10 mm diameter) was used. Oleic acid (1.2 g, $4.3 \mathrm{mmol}, 1.0 \mathrm{eq})$ and CDI ( $0.8 \mathrm{~g}, 4.7 \mathrm{mmol}, 1.1 \mathrm{eq})$ were introduced into the jar and reacted for $15 \mathrm{~min}$ in the MM400 mixer mill operated at $25 \mathrm{~Hz}$. For hydrolysis, $90 \% \mathrm{H}_{2}{ }^{17} \mathrm{O}$ $(154 \mu \mathrm{L}, 8.5 \mathrm{mmol}, 2 \mathrm{eq}$ ) was added and reaction took place for $30 \mathrm{~min}$ at $25 \mathrm{~Hz}$. To recover the product, $50 \mathrm{~mL}$ of non-labeled water and $5 \mathrm{~mL}$ of ethyl acetate were used to rinse the jar and transfer the content to a beaker. The medium was acidified to $\mathrm{pH} \sim 1$ with an aqueous solution of $\mathrm{HCl}(6 \mathrm{M}, 2.5 \mathrm{~mL})$ and extracted with ethyl acetate $(4 \times 15 \mathrm{~mL})$. Combined organic phases were dried over $\mathrm{Na}_{2} \mathrm{SO}_{4}$, filtered and finally dried under vacuum. The product was isolated as a colorless oil. Average yield $(n=2)$ : $1.10 \pm 0.02 \mathrm{~g}, 92 \pm 2 \%$.

Figure B3S1: ATR-IR analysis of the starting material, final product, and reaction intermediates. The dashed line shows that the $\mathrm{C}=\mathrm{O}$ vibration frequency of the ${ }^{18} \mathrm{O} /{ }^{17} \mathrm{O}$-enriched product is lower in comparison with the nonlabeled precursor.

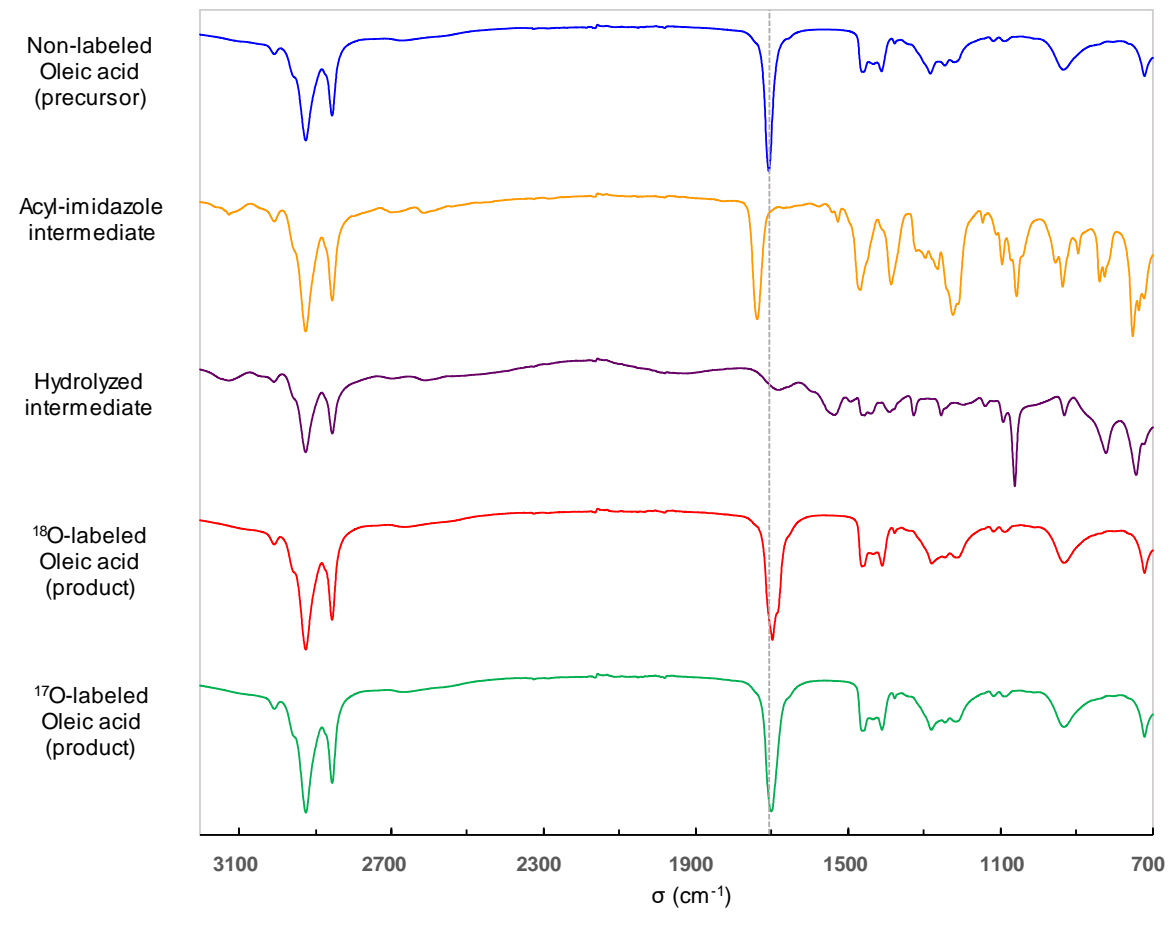


Figure B3S2: MS analyses of the non-labeled precursor in comparison to the ${ }^{18} \mathrm{O}$-enriched product. Average enrichment per carboxylic oxygen determined by MS: $43.8 \pm 1.5 \%(n=3)$, enrichment yield: $\sim 90 \%$.

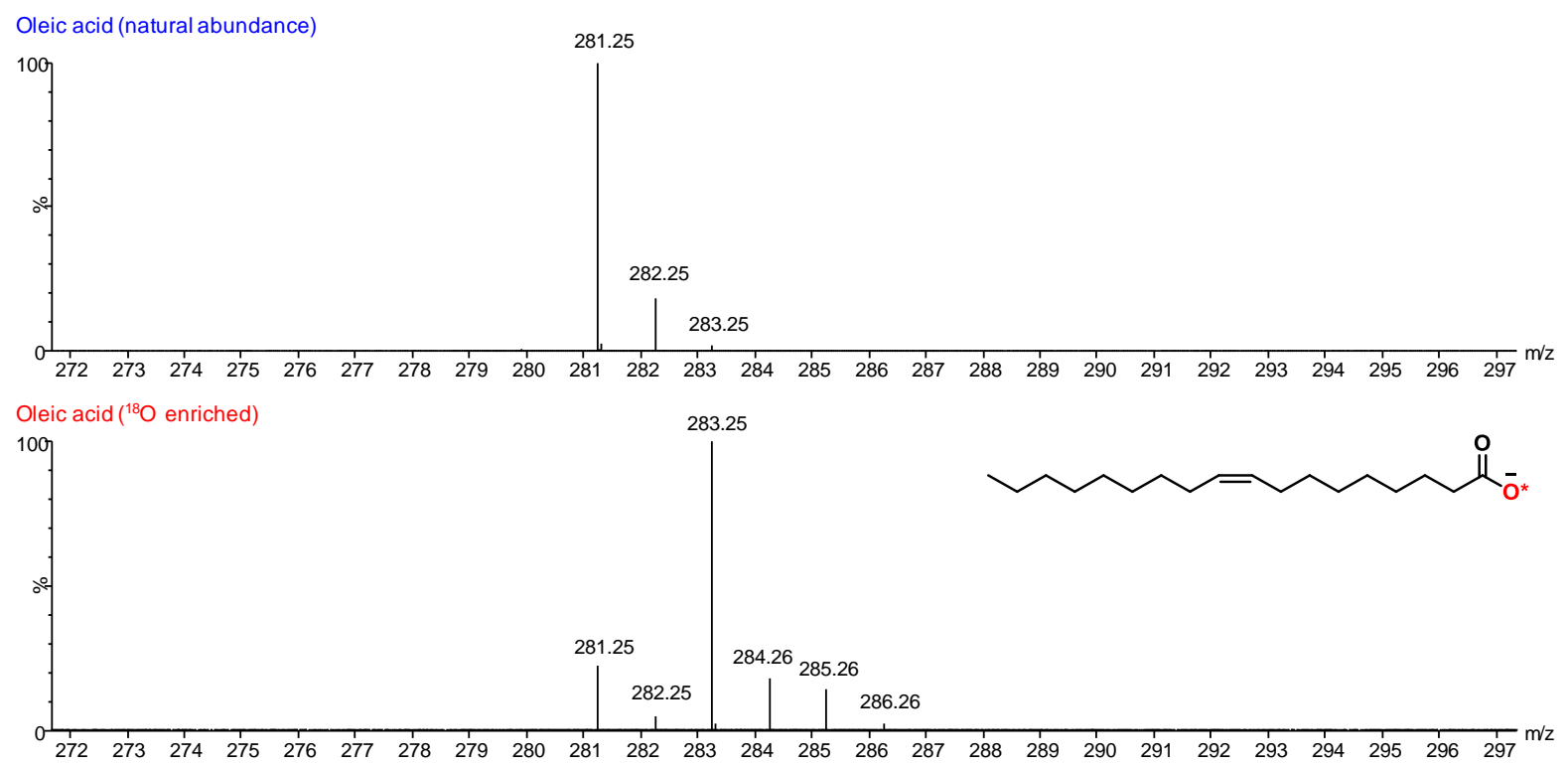

Figure B3S3: LC analyses of the non-labeled precursor in comparison to the ${ }^{18} \mathrm{O}$-enriched product.

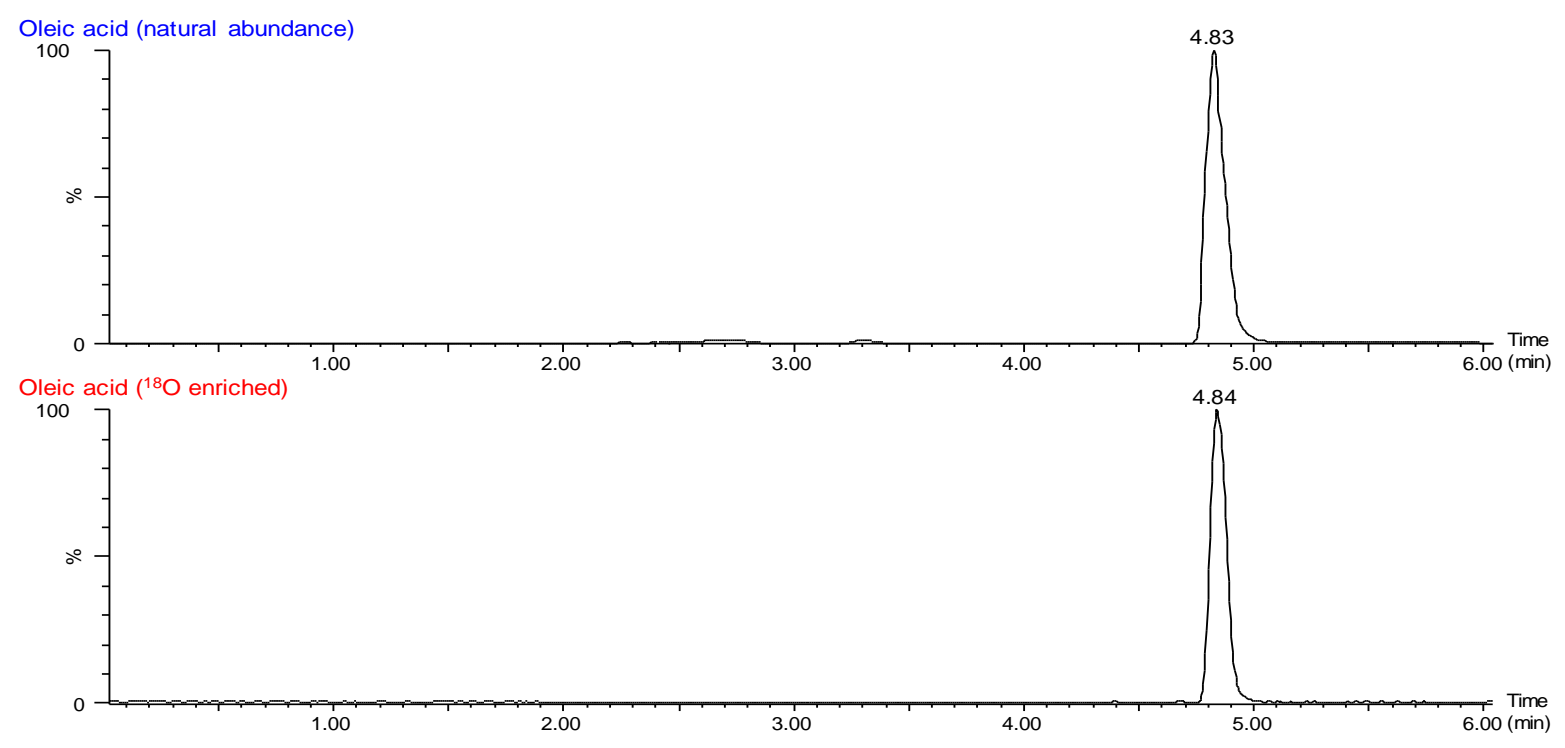


Figure B3S4: ${ }^{1} \mathrm{H}$ NMR spectra of the non-labeled precursor in comparison to the ${ }^{18} \mathrm{O}$-enriched product (DMSO- $d_{6}$, $600 \mathrm{MHz}$; solvent peaks are crossed out).

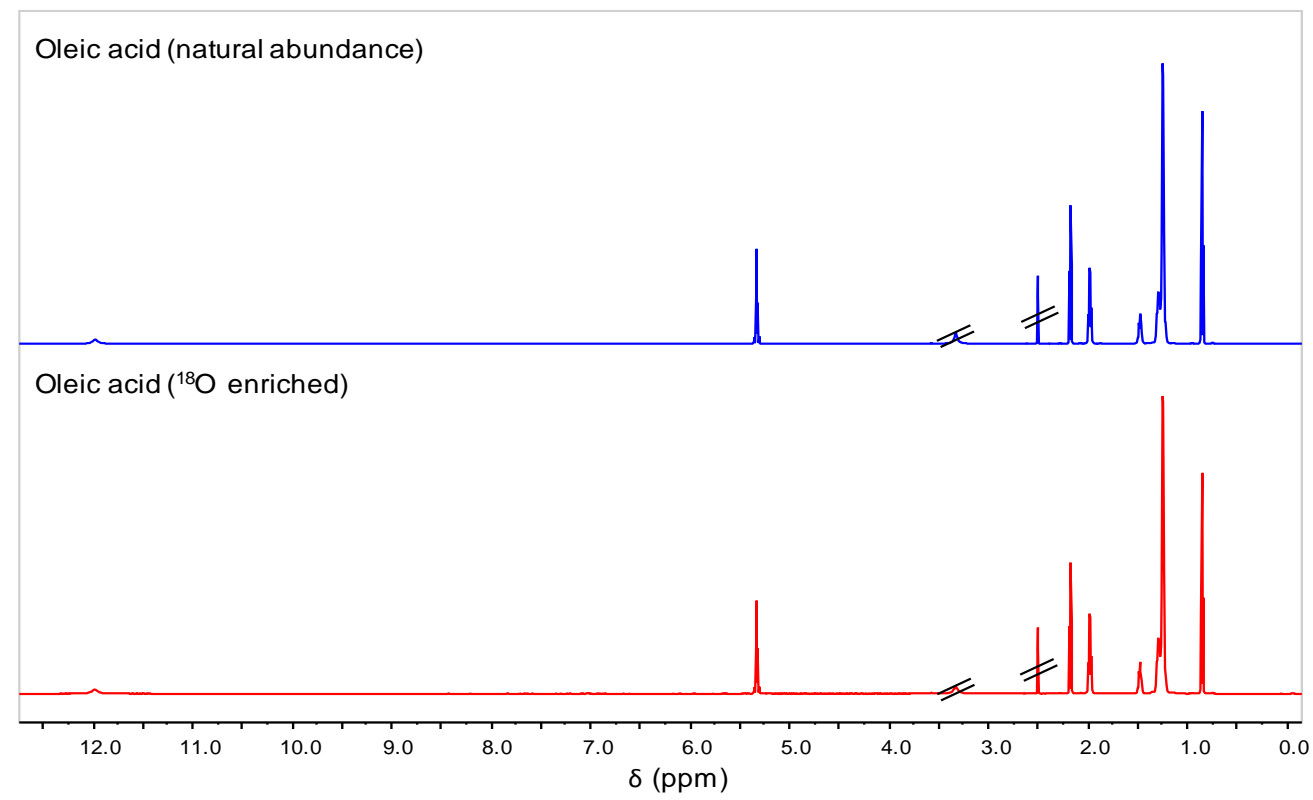

Figure B3S5: ${ }^{13} \mathrm{C}$ NMR spectra of the non-labeled precursor in comparison to the ${ }^{18} \mathrm{O}$-enriched product (DMSO- $d_{6}, 600 \mathrm{MHz}$; solvent peaks are crossed out).

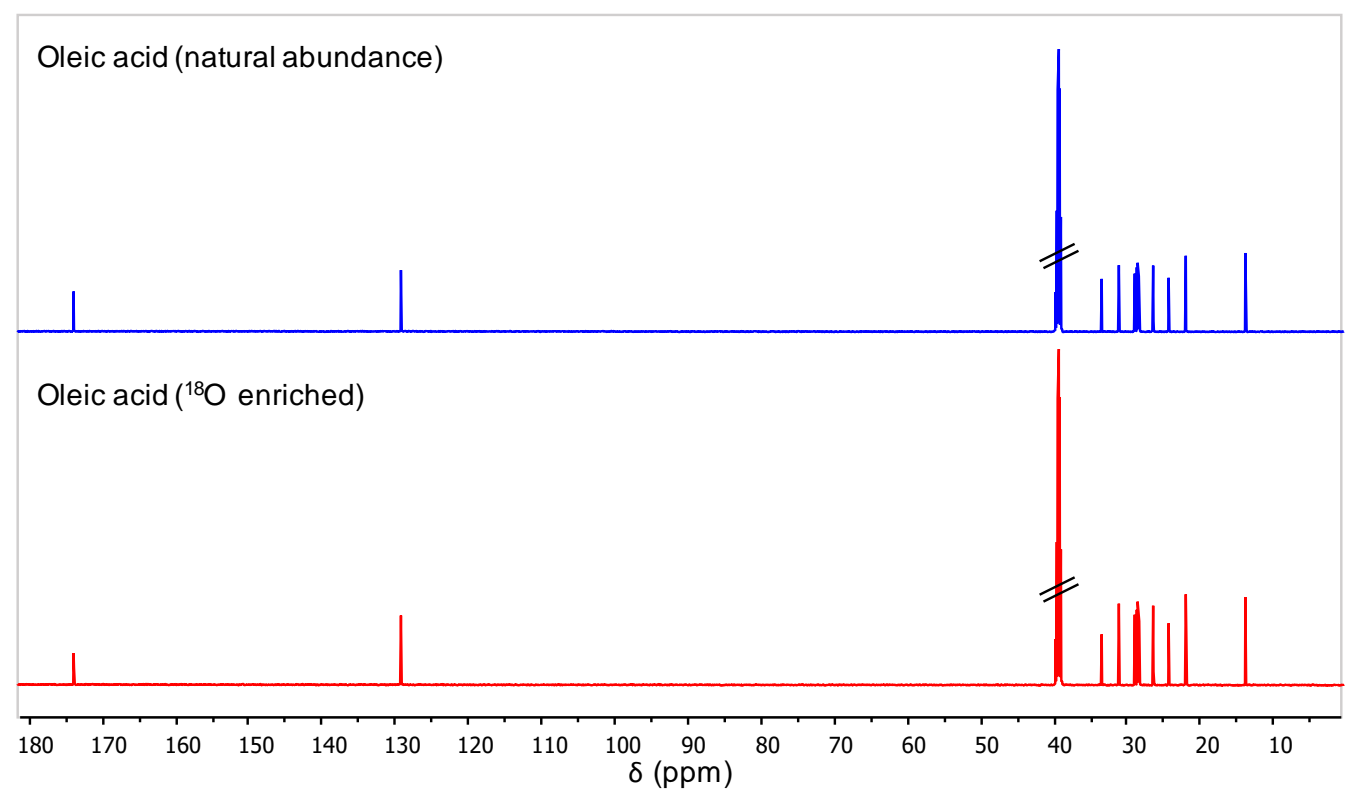


Figure B3S6: ${ }^{13} \mathrm{C}$ NMR study of the ${ }^{18} \mathrm{O}$-isotope effect on the ${ }^{13} \mathrm{C}$-carboxylic resonance in solution NMR. The non-labeled precursor is compared to the ${ }^{18} \mathrm{O}$-enriched product, both having been mixed in different ratios, as indicated above each spectrum (DMSO- $d_{6}, 600 \mathrm{MHz}$ ).

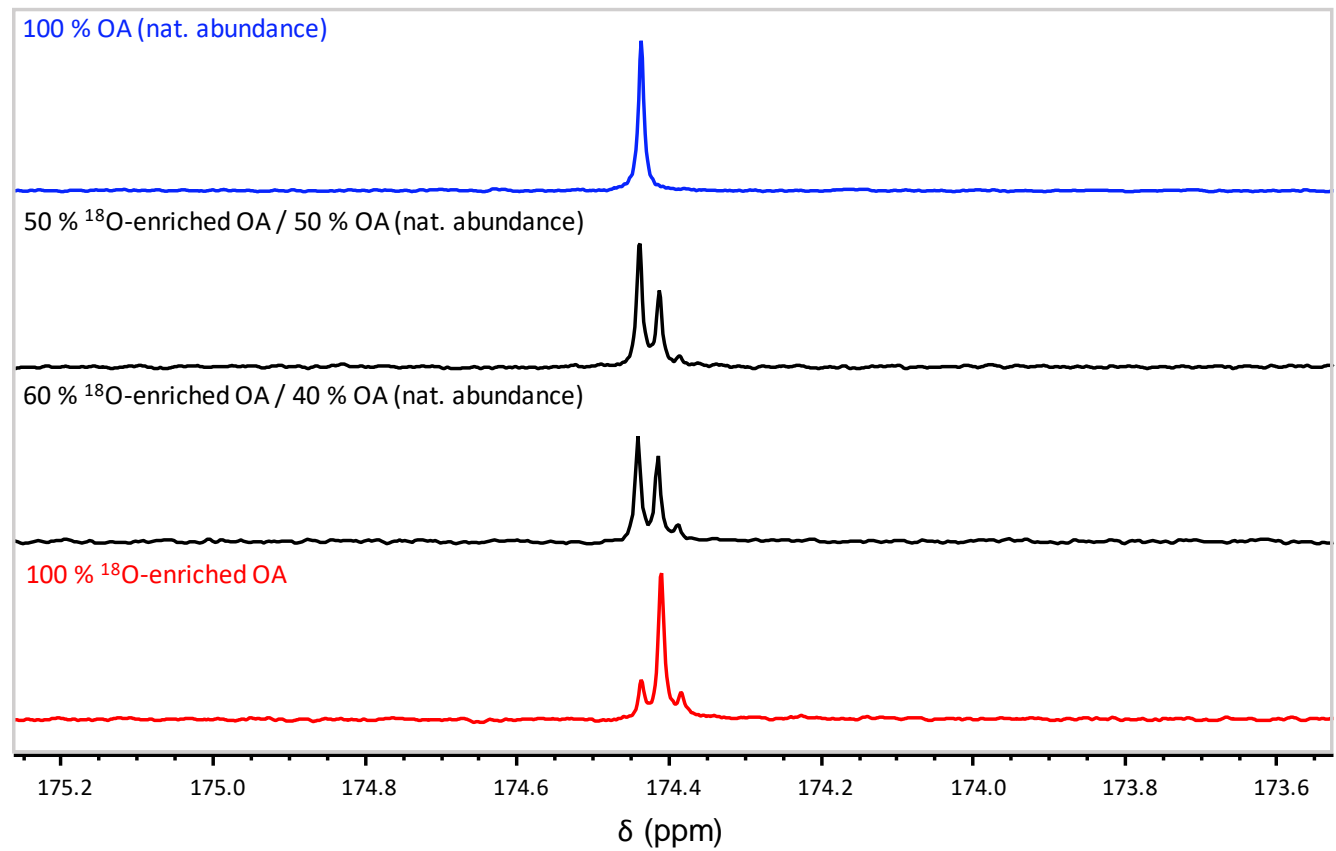


Figure B3S7: MS analyses of the non-labeled precursor in comparison to the ${ }^{17} \mathrm{O}$-enriched product (scale-up synthesis). Average enrichment per carboxylic oxygen determined by MS: $37.4 \pm 0.3 \%(\mathrm{n}=2)$, enrichment yield: $\sim 82 \%$.
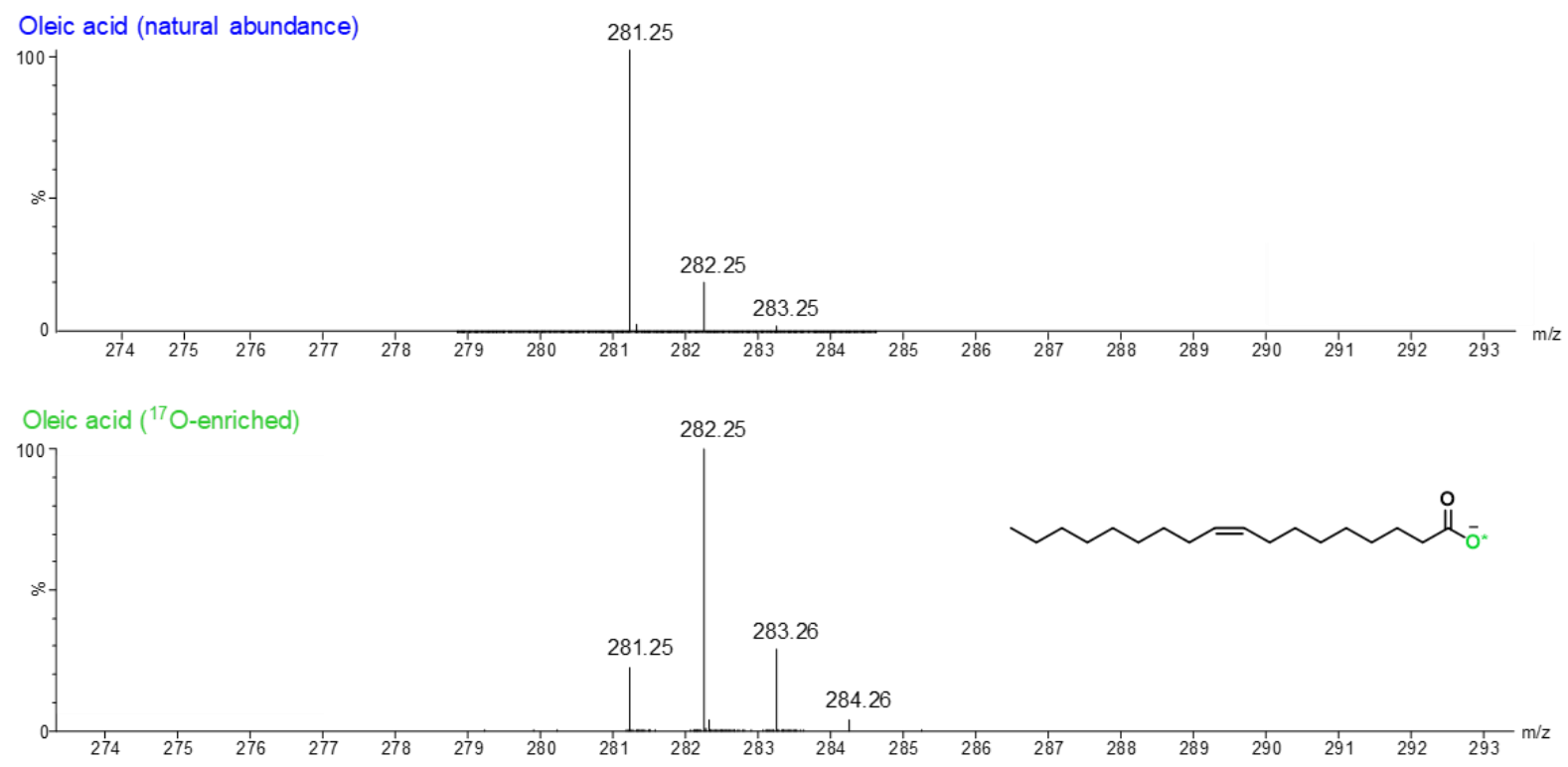

Figure B3S8: LC analyses of the non-labeled precursor in comparison to the ${ }^{17} \mathrm{O}$-enriched product.

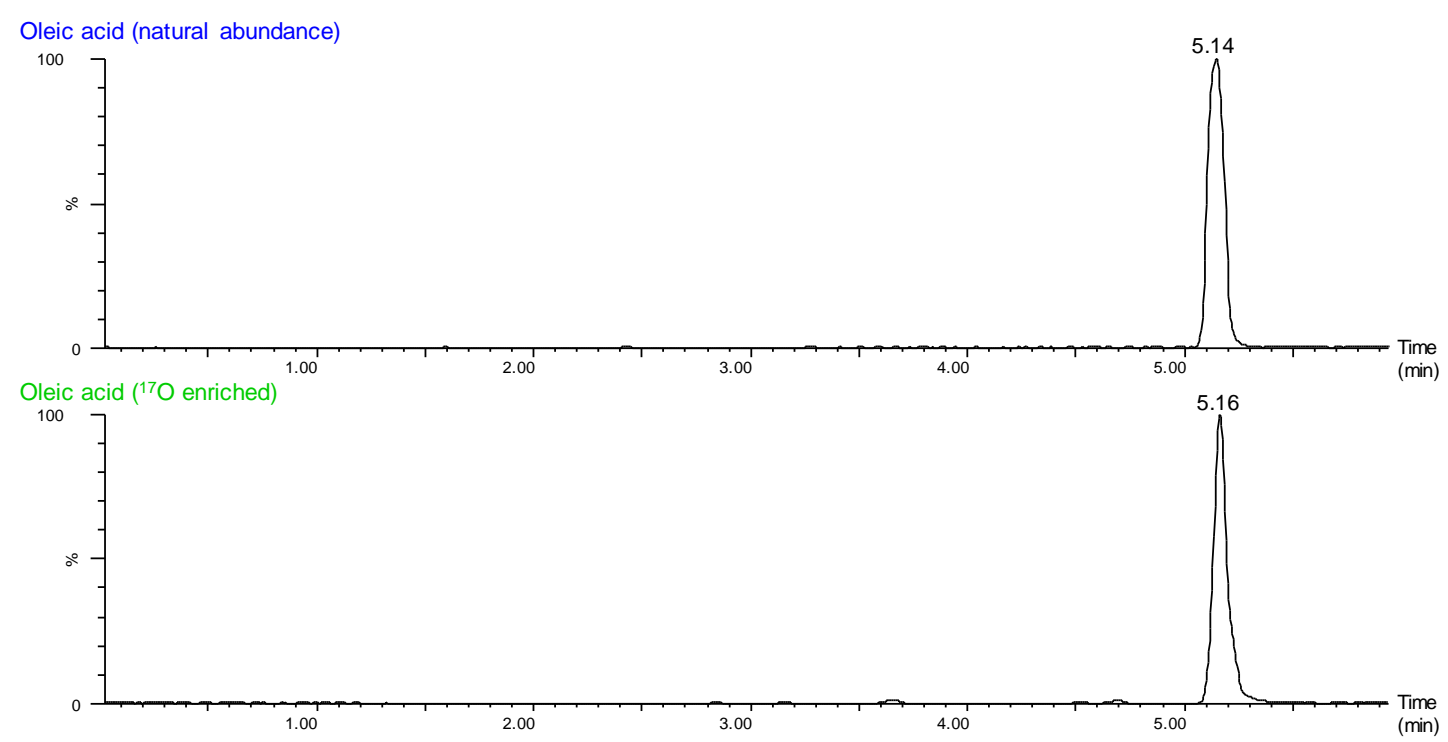


Figure B3S9: ${ }^{1} \mathrm{H}$ NMR spectra of the non-labeled precursor in comparison to the ${ }^{17} \mathrm{O}$-enriched product (DMSO- $d_{6}$, $600 \mathrm{MHz}$; solvent peaks are crossed out).

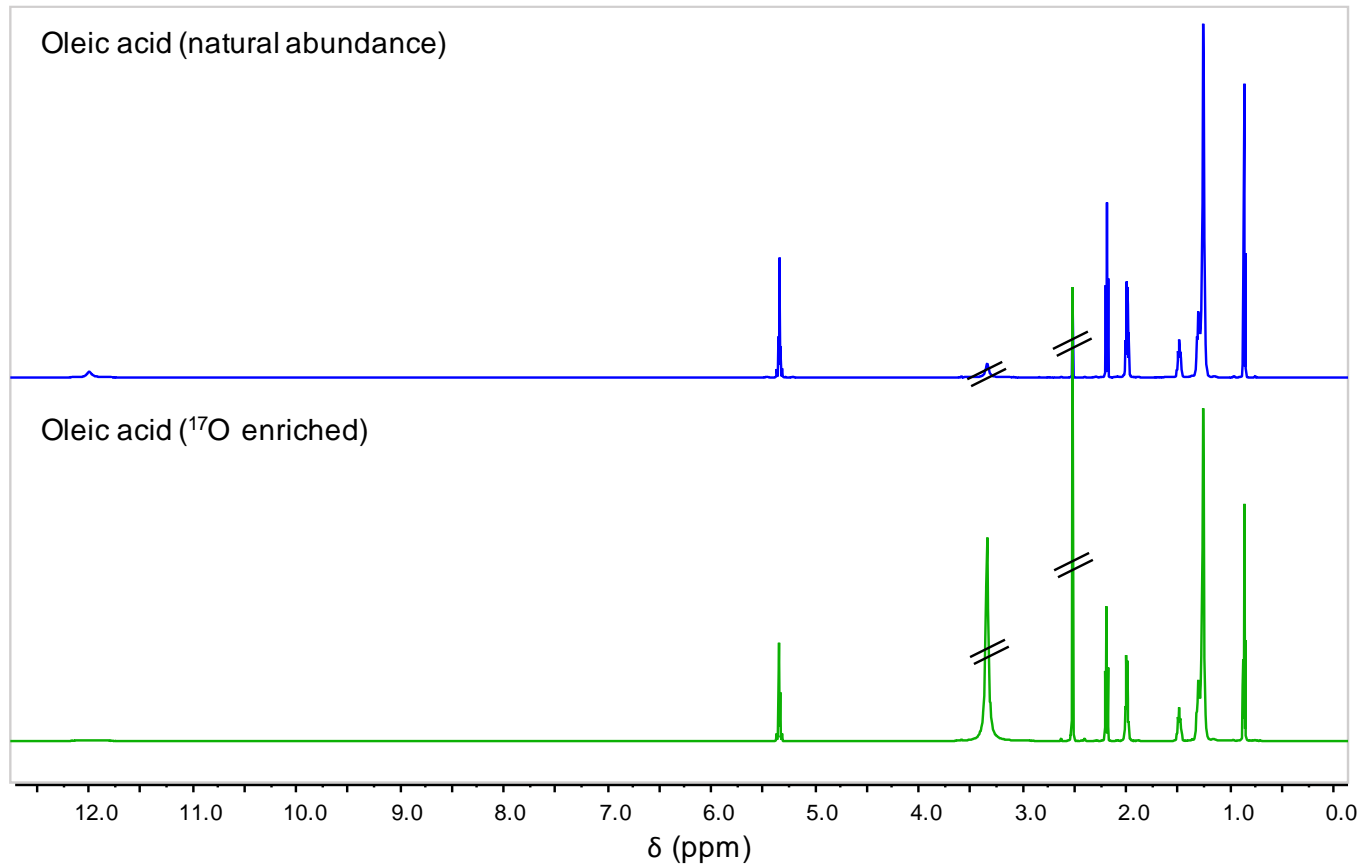

Figure B3S10: ${ }^{13} \mathrm{C}$ NMR spectra of the non-labeled precursor in comparison to the ${ }^{17} \mathrm{O}$-enriched product (DMSO-d, $600 \mathrm{MHz}$; solvent peaks are crossed out).

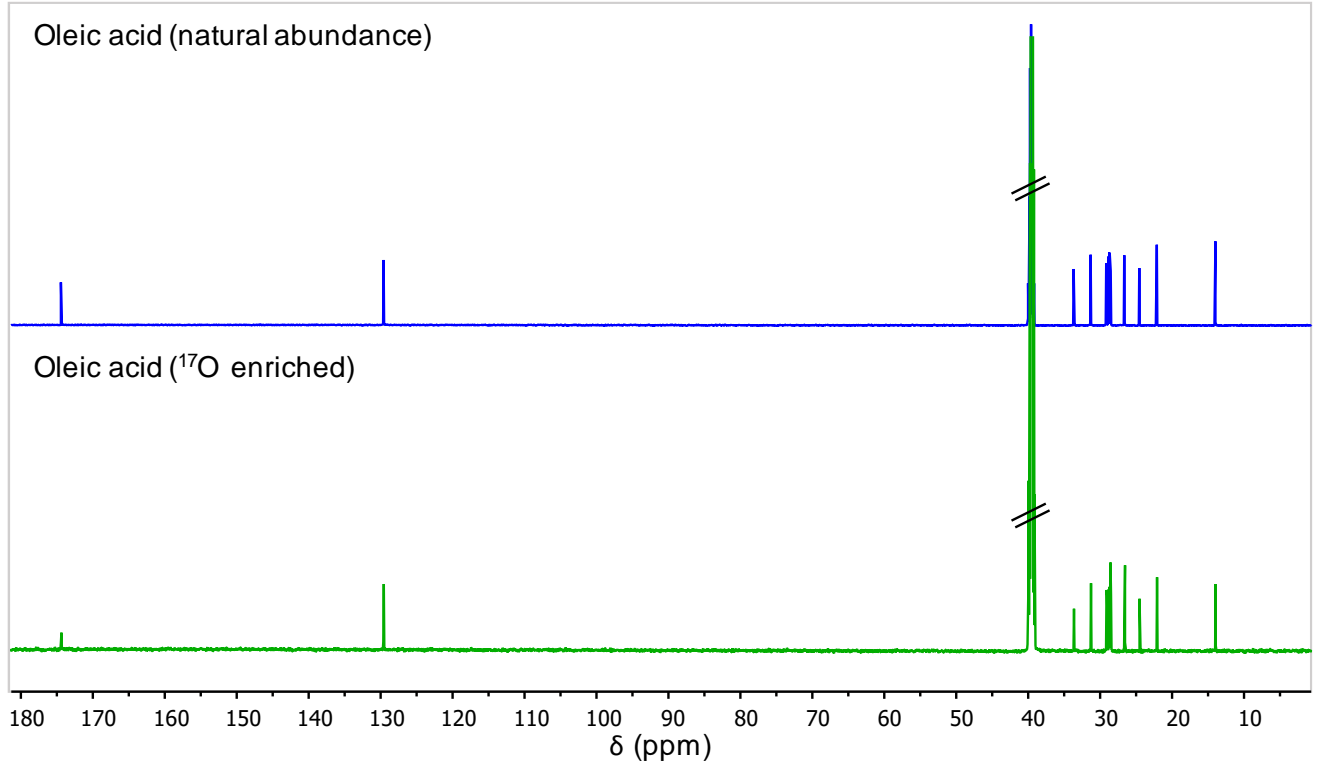


Oleic acid phases, which had been labeled in ${ }^{17} \mathrm{O}$ or ${ }^{18} \mathrm{O}$ (using here $\sim 40 \%{ }^{17} \mathrm{O}$ labeled $\mathrm{H}_{2}{ }^{*} \mathrm{O}$ and $97 \%{ }^{18} \mathrm{O}$-labeled $\mathrm{H}_{2}{ }^{*} \mathrm{O}$ for the hydrolysis steps, respectively) were packed in a small vial under air. Then the vial was closed, parafilmed, and stored either in a fridge $\left({ }^{17} \mathrm{O}\right.$-enriched oleic acid $)$ or a freezer $\left({ }^{18} \mathrm{O}-\right.$ enriched oleic acid). Samples were then re-analyzed by MS after 1 year of storage (Table B3S1).

Table B3S1: Measured enrichment levels of oleic acid after 1 year of storage (average enrichment per carboxylic oxygen, as determined by MS).

\begin{tabular}{|l|c|c|}
\hline & \multicolumn{2}{|c|}{ Enrichment level [\%] } \\
\hline Fatty acid & $\mathbf{t}_{\mathbf{0}}$ & $\mathbf{t}_{\mathbf{0}}+\mathbf{1}$ year \\
\hline Oleic acid- ${ }^{17} \mathrm{O}$ & 18.6 & 18.7 \\
\hline Oleic acid- ${ }^{18} \mathrm{O}$ & 45.4 & 45.4 \\
\hline
\end{tabular}




\section{C/ Synthesis and characterization of Zn-Oleate (Zn-OA)}

\section{C1) Optimized synthetic protocol}

Oleic acid labeled in oxygen-17 (83 mg, $0.3 \mathrm{mmol}, 2.0 \mathrm{eq})$ and sodium hydroxide (12 mg, $0.3 \mathrm{mmol}, 2.0 \mathrm{eq})$ were introduced successively into a stainless steel grinding jar (10 mL inner volume) containing two stainless steel beads (10 $\mathrm{mm}$ diameter). The jar was closed and subjected to grinding for 10 minutes in the MM400 mixer mill operated at $25 \mathrm{~Hz}$. Zinc chloride $(20 \mathrm{mg}, 0.15 \mathrm{mmol}, 1.0 \mathrm{eq}$ ) was then added into the jar, and the mixture was subjected to further grinding for 15 minutes at $25 \mathrm{~Hz}$. The light grey powder was recovered from the jar and dried under vacuum. Average mass recovered $(n=2)$ : $95 \pm 12 \mathrm{mg}$. The sample was stored in the freezer to avoid potential structural changes, prior to any further analyses or ageing tests.

The OA precursor used here in the synthesis of $\mathrm{Zn}$-oleate had an average ${ }^{17} \mathrm{O}$-enrichment per carboxylic oxygen of $\sim 19 \%$, because it had been prepared using $\sim 39.3 \%{ }^{17} \mathrm{O}$-enriched water.

Figure C1S1: ATR-IR analysis of zinc oleate synthesis using mechanochemistry.

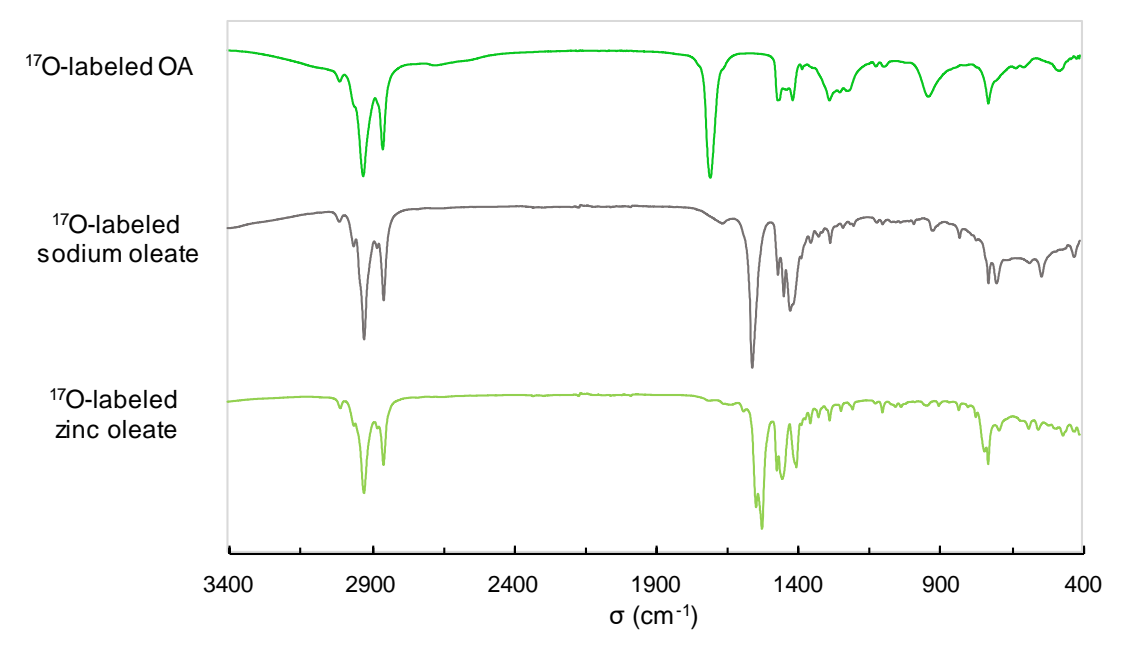

\section{C2) Structural analyses}

Figure C2S1: X-ray diffraction powder pattern of the recovered ${ }^{17} \mathrm{O}$-enriched Zn-oleate product. " **" symbols correspond to the $\mathrm{NaCl}$ by-product (see discussion in section $\mathrm{C} 3$ ).

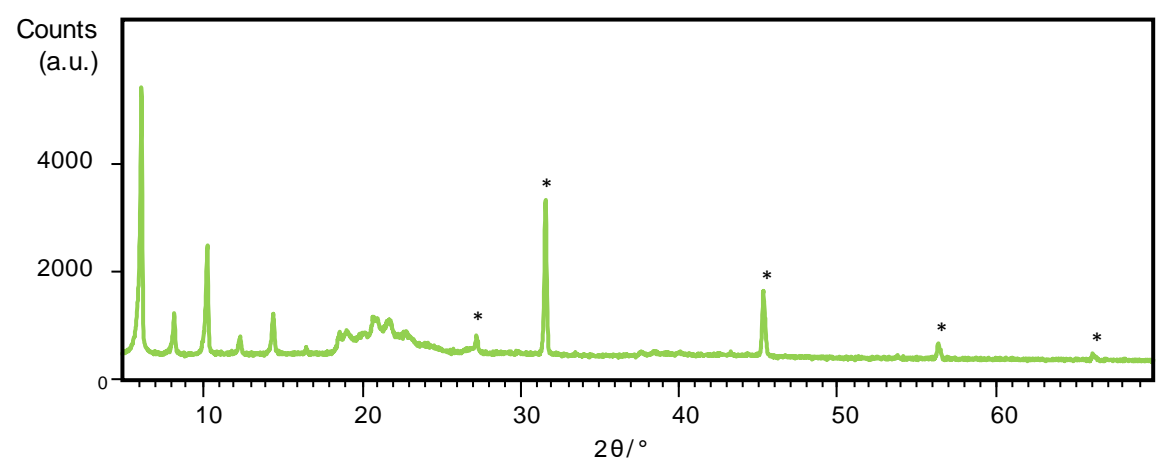


Figure C2S2: Multinuclear solid state NMR study of the recovered ${ }^{17} \mathrm{O}$-enriched Zn-oleate product at $14.1 \mathrm{~T}: \mathrm{a} /{ }^{13} \mathrm{C}$ CPMAS NMR (inset: expansion of the $\alpha-\mathrm{CH}_{2}$ region; see main text for the expansion of the carboxylate region), b/ ${ }^{17} \mathrm{O}$ MAS NMR, c/ ${ }^{23} \mathrm{Na}$ MAS NMR (see discussion in section C3). Acquisition conditions can be found in section A3. "*” symbols correspond to spinning sidebands.
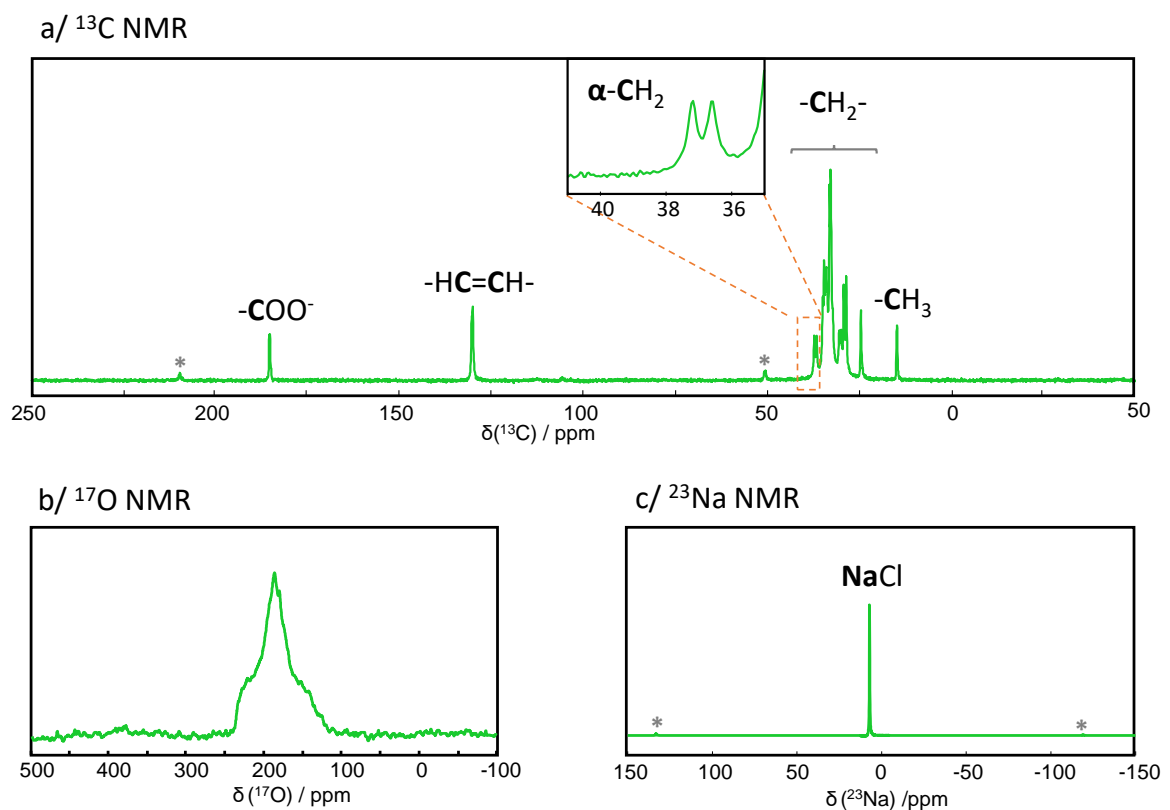

\section{C3) Discussion on the synthesis and structural analyses}

\section{C3-a) New synthetic protocol for Zn-oleate using mechanochemistry}

According to the literature, $\mathrm{Zn}$-oleate can be prepared by various routes, including $(i)$ by reaction of $\mathrm{ZnCl}_{2}$ with sodium oleate (which can be formed in situ from oleic acid and $\mathrm{NaOH}$ ) in solution, ${ }^{14-20}$ (ii) by reaction of oleic acid with $\mathrm{Zn}$-acetate, ${ }^{21}$ or (iii) by reaction of $\mathrm{Zn}(\mathrm{Et})_{2}$ and oleic acid. ${ }^{22}$

Here, we developed a new synthetic protocol for Zn-oleate using ball-milling, which is described in section $\mathrm{C} 1$. It consisted in first forming the sodium carboxylate salt, by reacting the fatty acid in presence of 1 equivalent of $\mathrm{NaOH}$ for 10 minutes at $25 \mathrm{~Hz}$ in a mixer mill. $\mathrm{Zn}$-oleate was then obtained by adding 0.5 equivalents of $\mathrm{ZnCl}_{2}$ into the jar, milling for $15 \mathrm{~min}$ at $25 \mathrm{~Hz}$, and then drying the sample under vacuum. Both reaction steps could be followed by IR spectroscopy (see supporting information, Figure C1S1). One advantage of this procedure is that the ball-milling steps are rapid and performed under mild conditions, meaning that there is no risk to lose the isotopic label of the oleic acid during them.

With this ball-milling synthetic procedure, the recovered material is a mixture of the $\mathrm{Zn}$-oleate salt and $\mathrm{NaCl}$, as shown by X-ray diffraction (see supporting information, Figure C2S1). No attempt was made to wash off the $\mathrm{NaCl}$, as its presence in the material was actually found to be advantageous for characterization purposes (especially for solid state NMR). Indeed, it allows the sample to have a more powdery texture, making it more easy to manipulate than the pasty/waxy precipitates which can be isolated for metal soap phases. ${ }^{20}$ It is worth noting that the ${ }^{23} \mathrm{Na}$ solid state NMR spectrum of the product recovered after ball-milling only shows the distinct sharp signature of crystalline $\mathrm{NaCl}$ (see supporting information, Figure $\mathrm{C} 2 \mathrm{~S} 2-\mathrm{c}$ ), but no other sodium environments, which proves that this phase is not a mixed $\mathrm{Na}, \mathrm{Zn}$ oleate salt.

Attempts to synthesize Zn-oleate by ball-milling, starting from oleic acid and $\mathrm{ZnO}$ precursors directly were also performed. Although the formation of Zn-oleate could be achieved in some cases, syntheses were more difficult to reproduce, and yields were generally lower, the product being difficult to remove from the reactor due to its waxy texture. Hence, this second synthetic route was not pursued. 
Figure C3S1: ATR-IR spectra of Zn-oleate phases prepared by ball-milling, using non-labeled (top) and ${ }^{17} \mathrm{O}$-enriched (bottom) oleic acid. The wavenumbers of the IR bands which shift upon enrichment are indicated on the spectra.

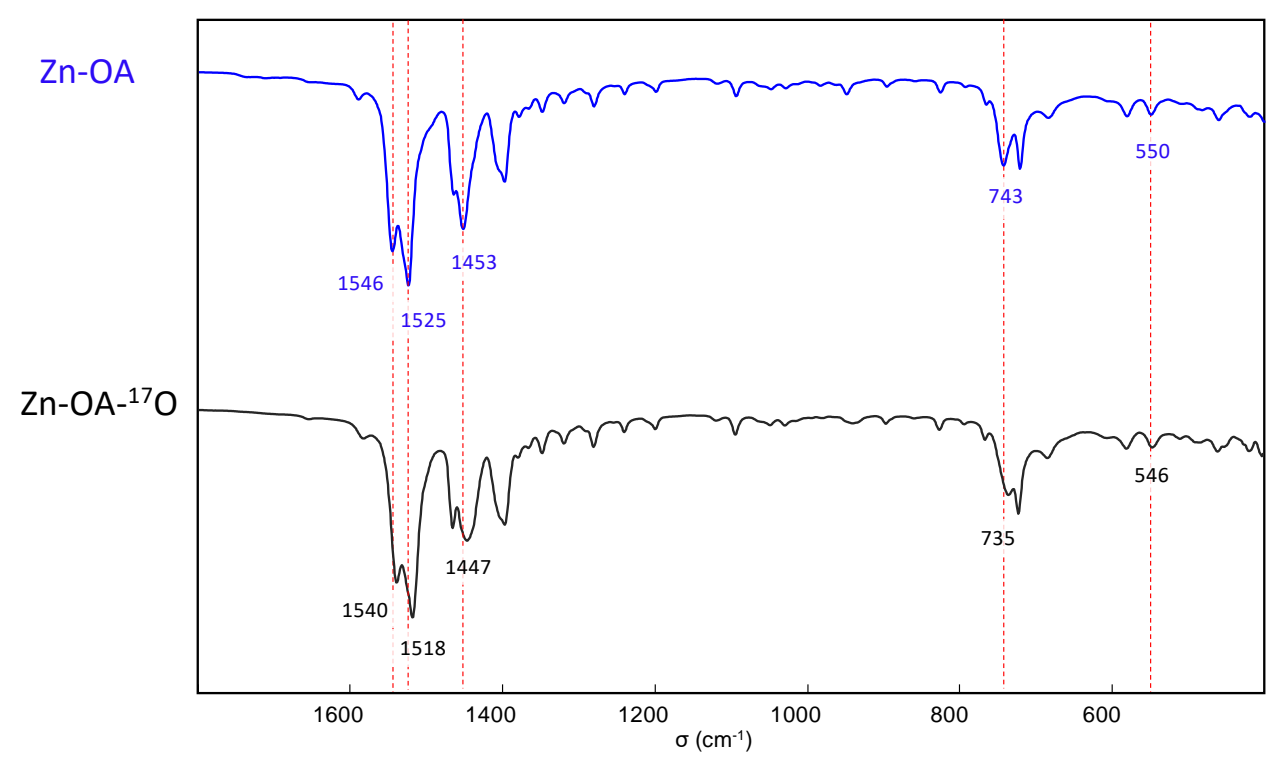

\section{Carboxylate stretching region}

In previous IR studies of $\mathrm{Zn}$-oleate, the following assignments can be found :23-24

- 1548 and $1526 \mathrm{~cm}^{-1}: v_{\mathrm{a}}(\mathrm{COO})$ vibration modes,

- 1407 and $1398 \mathrm{~cm}^{-1}: v_{\mathrm{s}}(\mathrm{COO})$ vibration modes,

- 1467 and $1455 \mathrm{~cm}^{-1}: \delta\left(\mathrm{CH}_{2}\right)$ vibration modes.

We observed that in the $\mathrm{C}=\mathrm{O}$ stretching region, the bands which shift upon ${ }^{17} \mathrm{O}$ labeling are those at 1546, 1525 and $1453 \mathrm{~cm}^{-1}$. In contrast, no shift or broadening is observed in the band centered at $1466 \mathrm{~cm}^{-1}$, nor in the composite band at $\sim 1398 \mathrm{~cm}^{-1}$. Hence, based on the IR-band shifts we observed after oxygen-isotopic labeling, we propose the following new assignments in this region :

- 1546 and $1525 \mathrm{~cm}^{-1}: v_{\mathrm{a}}(\mathrm{COO})$ vibration modes,

- $1453 \mathrm{~cm}^{-1}$ (broad): $v_{\mathrm{s}}(\mathrm{COO})$ vibration modes,

-1466 and $1398 \mathrm{~cm}^{-1}: \delta\left(\mathrm{CH}_{2}\right)$ vibration modes.

It is worth noting that the re-assignment of the $1453 \mathrm{~cm}^{-1}$ band to a $v_{\mathrm{s}}(\mathrm{COO})$ vibration mode is actually consistent with an IR and Raman study of $\mathrm{Zn}$-acetate. ${ }^{25}$

\section{Low frequency region $\left(400-800 \mathrm{~cm}^{-1}\right)$}

In the low frequency region, the bands which shift upon ${ }^{17} \mathrm{O}$ labeling are those at 743 and $550 \mathrm{~cm}^{-1}$, which had not been assigned previously for $\mathrm{Zn}$-oleate. ${ }^{23}$ Here, the shifts observed after enrichment show that they both correspond to carboxylate vibration modes. By analogy to studies on $\mathrm{Zn}$-acetate and $\mathrm{Zn}$-stearate, they can be assigned to carboxylate bending and rocking modes, respectively. ${ }^{25}$ 
Figure C3S2: Ultra-high field ${ }^{17} \mathrm{O}$ MAS NMR spectrum of ${ }^{17} \mathrm{O}$-labeled Zn-oleate at $35.2 \mathrm{~T}$ : comparison of the experimental spectrum (black) and of a possible fit (red dashed line), which was performed considering the presence of 2 types of oxygen sites in a 3:1 ratio (purple and green lines). The full spectrum showing spinning sidebands is to the left, and a zoom into the central part of the spectrum to the right. Fits were performed using the int2QUAD option in the DMFit program (and hence CSA and Euler angles are defined as implemented in this program). ${ }^{4}$ Spectral acquisition conditions can be found in Table A3S2 (supporting information).
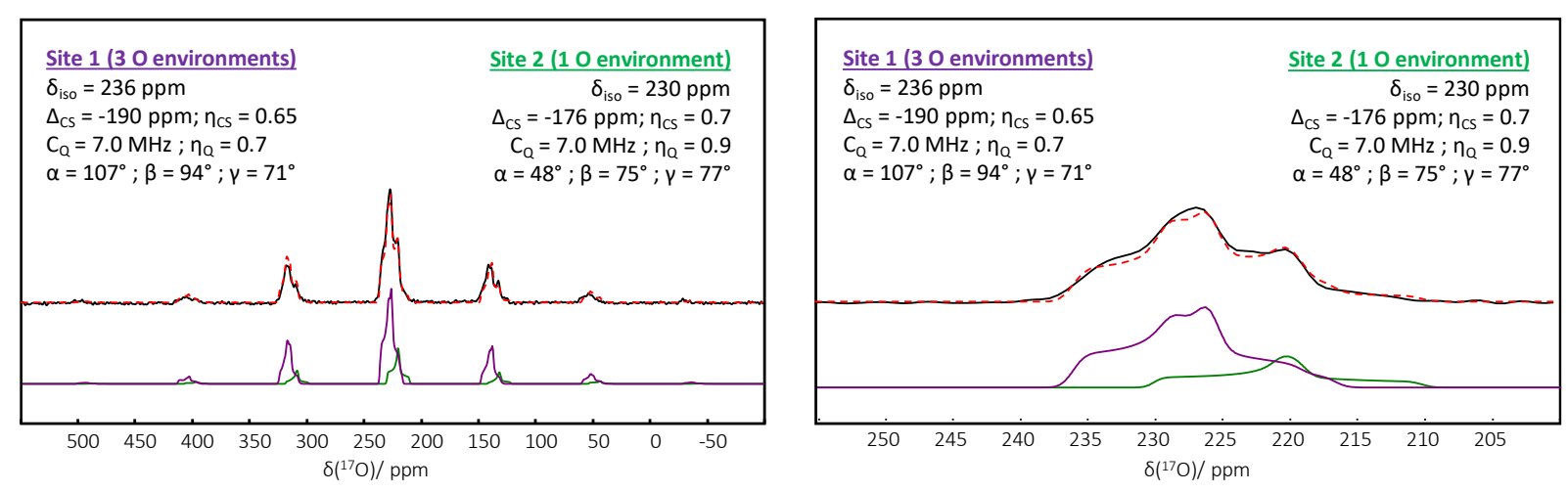

The fits shown above were carried out using $\delta_{\text {iso }}, \Delta_{\mathrm{CS}}, \eta_{\mathrm{CS}}, \mathrm{C}_{\mathrm{Q}}$ and $\eta_{\mathrm{Q}}$ values which are globally consistent with $(i)$ the slices extracted from the high-resolution 3QMAS analysis, and (ii) the GIPAWDFT calculations performed on Zn-carboxylates adopting similar coordination modes (see section C3$\mathrm{d}$ below). However, further analyses under static conditions at different fields would be needed to confirm / refine the fitted parameters, especially for the high-frequency component of the spectrum, which results from the overlap of 3 different carboxylate oxygens (as described in the main text), which do not necessarily have all ${ }^{17} \mathrm{O}$ NMR parameters and Euler angles identical. This is however beyond the purpose of the current study. 


\section{C3-d) GIPAW-DFT calculations of NMR parameters in Zn-carboxylates}

Investigations performed so far have shown that the ${ }^{17} \mathrm{O}$ isotropic shifts of carboxylate groups in coordination polymers and MOFs vary depending on the binding mode of the oxygen atoms $\left(\mu_{1}-\mathrm{O}\right.$, $\left.\mu_{2}-\mathrm{O} \ldots\right)$, the nature of the metal to which they are bound $\left(\mathrm{Al}^{3+}, \mathrm{Ga}^{3+}, \mathrm{Sc}^{3+}, \mathrm{Zr}^{4+}, \mathrm{Mg}^{2+} \ldots\right)$, and the presence of additional water molecules in close proximity to the carboxylate function. ${ }^{26-27}$ Hence, it appeared difficult to rationalize the difference in shift observed between the two ${ }^{17} \mathrm{O}$ sites of $\mathrm{Zn}$-oleate by analogy to previously published studies on coordination compounds or MOFs. A computational study was thus performed to determine the sensitivity of ${ }^{17} \mathrm{O}$ NMR parameters to the local environment of oxygen in Zn-carboxylate crystalline phases in which the ligands adopt a bidentate bridging mode, with each carboxylate oxygen linked to one $\mathrm{Zn}^{2+}$ ion only, like for $\mathrm{Zn}$-oleate.

The two structures used in the computational study were $\mathrm{Zn}$-pentanoate and Zn-octanoate. ${ }^{5-6} \mathrm{In}$ both cases, prior to the GIPAW-DFT calculations of NMR parameters, ${ }^{11}$ the geometry was optimized by DFT using the VASP software package, ${ }^{7}$ keeping the cell parameters fixed, and relaxing either $\mathrm{H}$ positions only, or all atomic positions. Calculated ${ }^{17} \mathrm{O} \delta_{\text {iso }}, \mathrm{C}_{\mathrm{Q}}$ and $\eta_{\mathrm{Q}}$ values are shown in Table $\mathrm{C} 3 \mathrm{~S} 1$, together with the ${ }^{13} \mathrm{C}$ chemical shifts of the carboxylate groups. The plot of $\delta_{\text {iso }}\left({ }^{17} \mathrm{O}\right)$ as a function of $\mathrm{d}(\mathrm{Zn} . . . \mathrm{O})$ for H-relaxed and fully relaxed models of Zn-pentanoate and Zn-octanoate is shown in Figure C3S3. Moreover, the CSA parameters calculated for H-relaxed models of $\mathrm{Zn}$-pentanoate and $\mathrm{Zn}$ octanoate are shown in Table C3S2.

Table C3S1. GIPAW DFT-calculated ${ }^{17} \mathrm{O}$ NMR parameters and ${ }^{13} \mathrm{C}$ chemical shifts (for the carboxylate), for $\mathrm{Zn}$-pentanoate and Zn-octanoate.

\begin{tabular}{|c|c|c|c|}
\hline & $\delta_{\text {iso/ppm }}$ & $\mathrm{CQ}_{\mathrm{Q}} / \mathrm{MHz}$ & १Q \\
\hline \multicolumn{4}{|c|}{ Zn-pentanoate (H-relaxed) } \\
\hline 01 & 231.6 & 6.92 & 0.99 \\
\hline $\mathbf{O 2}$ & 239.1 & 6.98 & 0.90 \\
\hline $\mathbf{O 3}$ & 233.7 & -6.81 & 0.90 \\
\hline 04 & 236.9 & 6.48 & 0.92 \\
\hline C1 & 183.5 & & \\
\hline C6 & 181.6 & & \\
\hline \multicolumn{4}{|c|}{ Zn-pentanoate (all relaxed) } \\
\hline O1 & 250.3 & -7.20 & 0.89 \\
\hline $\mathbf{O 2}$ & 262.1 & 6.73 & 0.94 \\
\hline $\mathbf{O 3}$ & 255.3 & -7.02 & 0.80 \\
\hline 04 & 263.4 & -6.35 & 0.96 \\
\hline $\mathrm{C} 1$ & 190.7 & & \\
\hline C6 & 190.1 & & \\
\hline \multicolumn{4}{|c|}{ Zn-octanoate (H-relaxed) } \\
\hline 011 & 233.6 & -7.09 & 0.95 \\
\hline 012 & 241.1 & 6.79 & 0.77 \\
\hline O21 & 246.7 & 6.22 & 0.95 \\
\hline $\mathbf{O 2 2}$ & 235.8 & -6.83 & 0.87 \\
\hline C11 & 182.8 & & \\
\hline $\mathrm{C} 21$ & 184.1 & & \\
\hline \multicolumn{4}{|c|}{ Zn-octanoate (all relaxed) } \\
\hline 011 & 248.5 & -7.24 & 0.91 \\
\hline 012 & 267.2 & 6.80 & 0.88 \\
\hline 021 & 265.6 & -6.29 & 0.97 \\
\hline $\mathbf{O 2 2}$ & 255.8 & -6.96 & 0.79 \\
\hline C11 & 191.4 & & \\
\hline $\mathrm{C} 21$ & 190.6 & & \\
\hline
\end{tabular}

Figure C3S3. Correlation between the calculated ${ }^{17} \mathrm{O}$ isotropic chemical shifts in $\mathrm{Zn}$-pentanoate and $\mathrm{Zn}$-octanoate (H-relaxed and fully-relaxed models), \& the $\mathrm{Zn}$... O distance in the corresponding models.

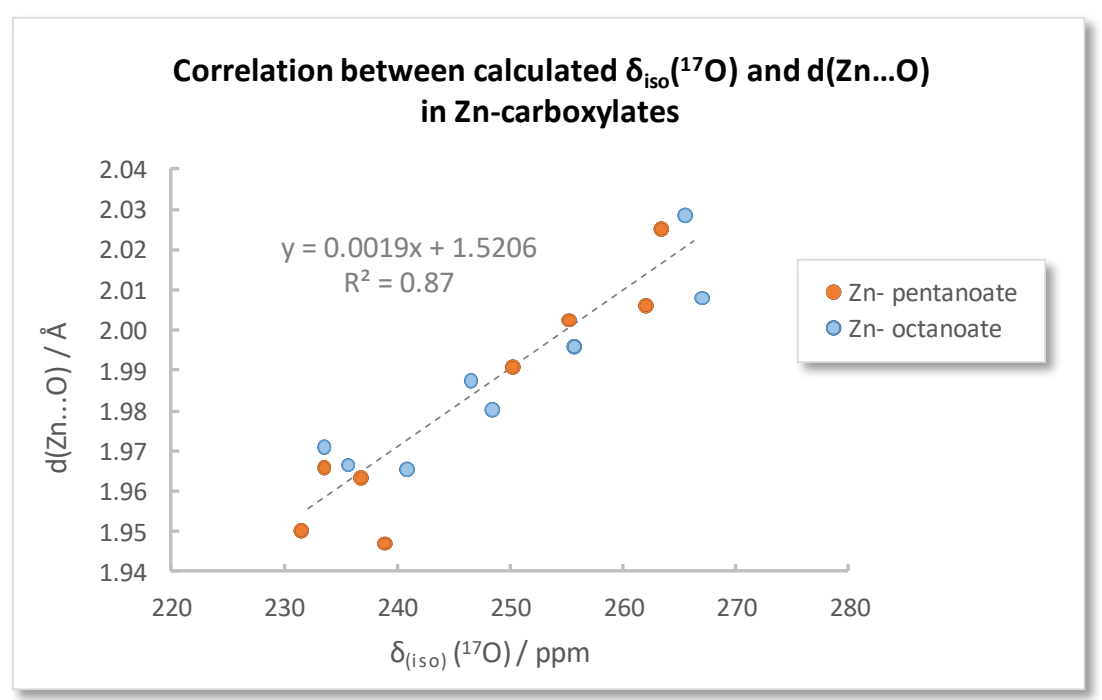


Table C3S2. Complete set of GIPAW DFT-calculated ${ }^{17} \mathrm{O}$ NMR parameters for H-relaxed models of Zn-pentanoate and Zn-octanoate, including Euler angles, as defined for fitting NMR spectra with the DMFit program (int2QUAD model). ${ }^{4}$

\begin{tabular}{|c|c|c|c|c|c|c|c|c|c|}
\hline & $\delta_{\text {iso }} / \mathrm{ppm}$ & $\delta_{11} / \mathrm{ppm}$ & $\delta_{22} / \mathrm{ppm}$ & $\delta_{33} / \mathbf{p p m}$ & $\mathrm{C}_{\mathrm{Q}} / \mathrm{MHz}$ & $\eta_{\mathbf{Q}}$ & $\alpha / /^{\circ}$ & $\beta /{ }^{\circ}$ & $\gamma /{ }^{\circ}$ \\
\hline \multicolumn{10}{|c|}{ Zn-pentanoate (H-relaxed) } \\
\hline 01 & 233.6 & 418.7 & 230.1 & 52.1 & -7.09 & 0.95 & 95 & -125 & 175 \\
\hline $\mathbf{O 2}$ & 241.1 & 393.6 & 290.7 & 38.9 & 6.79 & 0.77 & 0 & 80 & 85 \\
\hline $\mathbf{O 3}$ & 246.7 & 409.4 & 278.7 & 51.9 & 6.22 & 0.95 & 175 & -85 & 95 \\
\hline O4 & 235.8 & 418.4 & 236.2 & 52.8 & -6.83 & 0.87 & -55 & 90 & 95 \\
\hline \multicolumn{10}{|c|}{ Zn-octanoate (H-relaxed) } \\
\hline 011 & 231.6 & 421.6 & 241.5 & 31.6 & 6.92 & 0.99 & 35 & -95 & 85 \\
\hline 012 & 239.1 & 399.6 & 278.1 & 39.5 & 6.98 & 0.90 & 180 & 100 & 85 \\
\hline O21 & 233.7 & 419.4 & 235.4 & 46.2 & -6.81 & 0.90 & 55 & 90 & -90 \\
\hline $\mathbf{O 2 2}$ & 236.9 & 396.4 & 275.6 & 38.7 & 6.48 & 0.92 & 175 & -95 & 85 \\
\hline
\end{tabular}




\title{
D/ Synthesis, characterization and reactivity studies of oleic-acid grafted $\mathrm{ZnO}$ nanorods
}

\author{
D1) Synthesis of OA-grafted $\mathrm{ZnO}$ nanorods (NRs) \\ D1-a) Optimized synthesis of ZnO nanorods
}

$\mathrm{ZnO}$ nanorods (NRs) were prepared by adapting a published method. ${ }^{28-30}$ Glassware used for the synthesis was first washed with $\mathrm{HCl}(1 \mathrm{M})$, and rinsed with distilled water and acetone, and then left to dry at air. Zinc acetate dihydrate (1.9 g, $8.7 \mathrm{mmol}, 1.0$ eq.) was dissolved in $84 \mathrm{~mL}$ of methanol, to which $180 \mu \mathrm{L}$ of demineralized water were added. Potassium hydroxide $(1.0 \mathrm{~g}, 17.8 \mathrm{mmol}, 2.0 \mathrm{eq}$.) was separately dissolved in $46 \mathrm{~mL}$ of methanol, and then added dropwise (during $15 \mathrm{~min}$ ) into the zinc acetate solution, which was heated in an oil bath at $60^{\circ} \mathrm{C}$ and stirred at $750 \mathrm{rpm}$. After $5 \mathrm{~min}$ of addition ( $1 / 3$ of $\mathrm{KOH}$ solution), the reaction mixture turned white. Within 5 minutes after the end of addition, the solution became transparent again. It was stirred in the oil bath for an additional $\sim 2 \mathrm{~h} 30 \mathrm{~min}$ (it turned white again after $1 \mathrm{~h} 30 \mathrm{~min})$. The reaction mixture was then concentrated using a rotary evaporator to $\sim 20-25 \mathrm{~mL}$ volume, and the resulting cloudy solution was left to stir at $250 \mathrm{rpm}$ at $60{ }^{\circ} \mathrm{C}$ overnight ( $\sim 18-19 \mathrm{~h}$, to be more specific). The white reaction mixture was then cooled down to room temperature and centrifuged for $15 \mathrm{~min}$ at $20000 \mathrm{rpm}$. The supernatant was discarded, and the white powder was washed twice using $20 \mathrm{~mL}$ of methanol, followed by centrifugation at $20000 \mathrm{rpm}$ for $15 \mathrm{~min}$, and then dried under vacuum for $2 \mathrm{~h}$. The as-formed nanorods (NRs) were obtained with the aspect of brittle transparent crystals, and stored in the freezer wrapped in aluminum foil. They were ground manually before the different analyses (TEM, XRD, BET, IR, solid state NMR) and the subsequent grafting procedure. Their surface area was found to be $\sim 100 \mathrm{~m}^{2} / \mathrm{g}$ (as measured by $\mathrm{N}_{2}$ adsorption and BET analysis), and the particle size was on average $\sim 32 \pm 7 \mathrm{~nm}$ length and $7 \pm 2 \mathrm{~nm}$ diameter (according to TEM). Average yield $(\mathrm{n}=4): 614 \pm 21 \mathrm{mg}, 85 \pm 3 \%$.

\section{D1-b) Optimized ZnO-NR grafting procedure}

ZnO-NRs (100 mg) were sonicated in $45 \mathrm{~mL}$ of THF for 30-60 min (temperature in the ultrasound bath controlled to be below $30{ }^{\circ} \mathrm{C}$ ). A solution of ${ }^{17} \mathrm{O}$-oleic acid in THF $(\mathrm{c}=0.073 \mathrm{M}, 10.9 \mathrm{mg}$ of $\mathrm{OA}, \mathrm{V}=524 \mu \mathrm{L}$ ) was then added to the suspension of NRs while stirring at $325 \mathrm{rpm}$. The reaction vessel was closed, parafilmed, covered with aluminum foil, and stirred at room temperature overnight $(\sim 17$ $18 \mathrm{~h}$, to be more specific). After reaction, the white suspension was evaporated almost to dryness (leaving $\sim 1 \mathrm{~mL}$ in the flask) using a rotary evaporator. The grafted NRs were then washed twice using $20 \mathrm{~mL}$ of $\mathrm{n}$-hexane, followed by centrifugation at $20000 \mathrm{rpm}$ for $20 \mathrm{~min}$, and finally dried under vacuum for $2 \mathrm{~h}$. NRs were obtained as a white soft waxy solid, and stored in the freezer wrapped in aluminum foil. Average yield $(n=4): 75 \pm 4 \mathrm{mg}$.

A "control" experiment was also performed using the same protocol, but with a solution of nonlabeled oleic acid in THF ( $c=0.073 \mathrm{M}, 10.9 \mathrm{mg}$ of $\mathrm{OA}, \mathrm{V}=527 \mu \mathrm{L})$, which was added to the suspension of NRs in view of the grafting. Average yield $(\mathrm{n}=2): 71 \pm 6 \mathrm{mg}$. 
Figure D1S1: ATR-IR analysis of $\mathrm{ZnO}-\mathrm{NRs}$ before and after the grafting procedure.

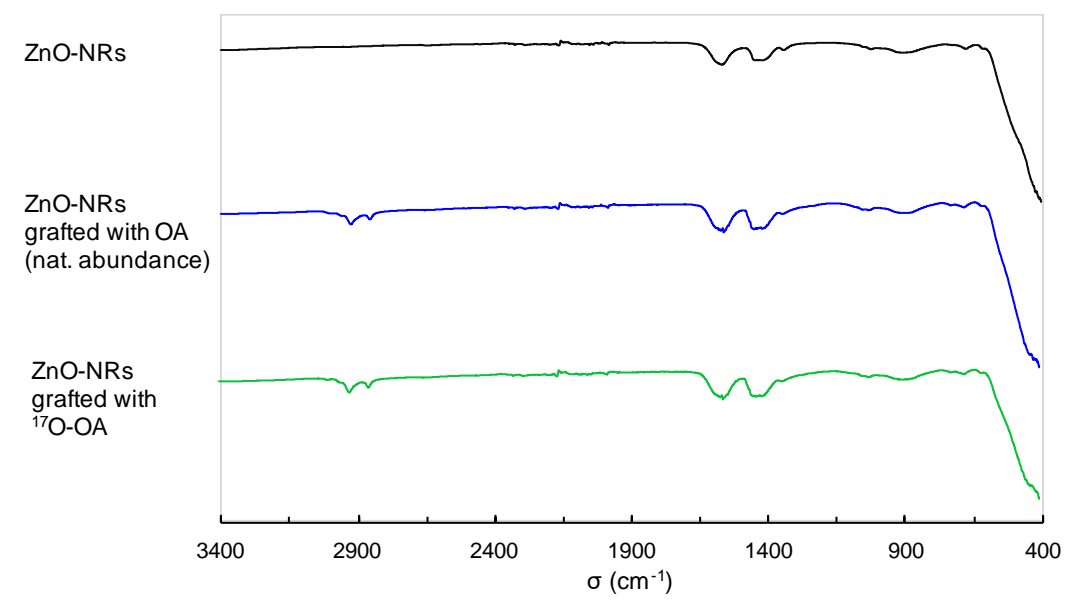

Figure D1S2: XRD analysis of $\mathrm{ZnO}-\mathrm{NRs}$ before and after grafting procedure.

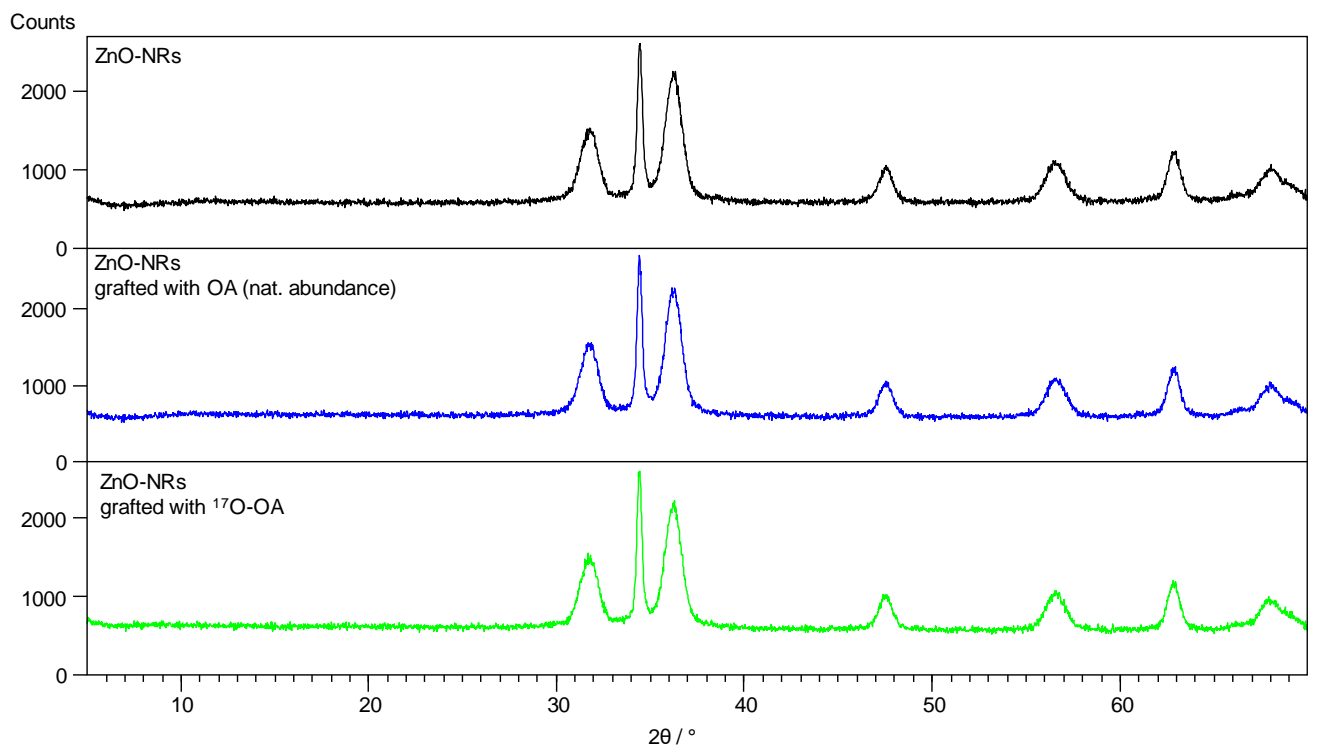

Figure D1S3: TEM analysis of ZnO-NRs: a) bare NRs, b) grafted with OA (nat. abundance), c) grafted with ${ }^{17} \mathrm{O}-$ labeled OA.
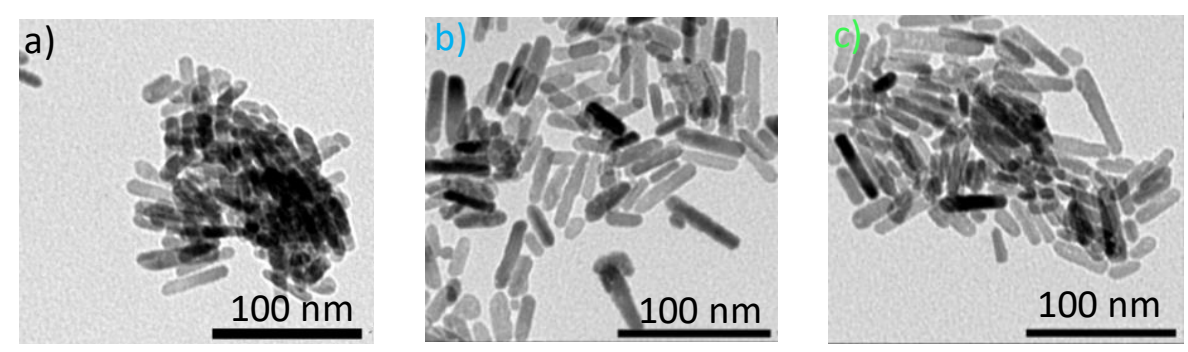
Figure D1S4: XRD analysis of ${ }^{17} \mathrm{O}$-labeled Zn-oleate and ZnO-NRs grafted with ${ }^{17} \mathrm{O}-$ labeled OA (“*” symbols correspond to $\mathrm{NaCl}$, as detailed in section $\mathrm{C} 3$ ).

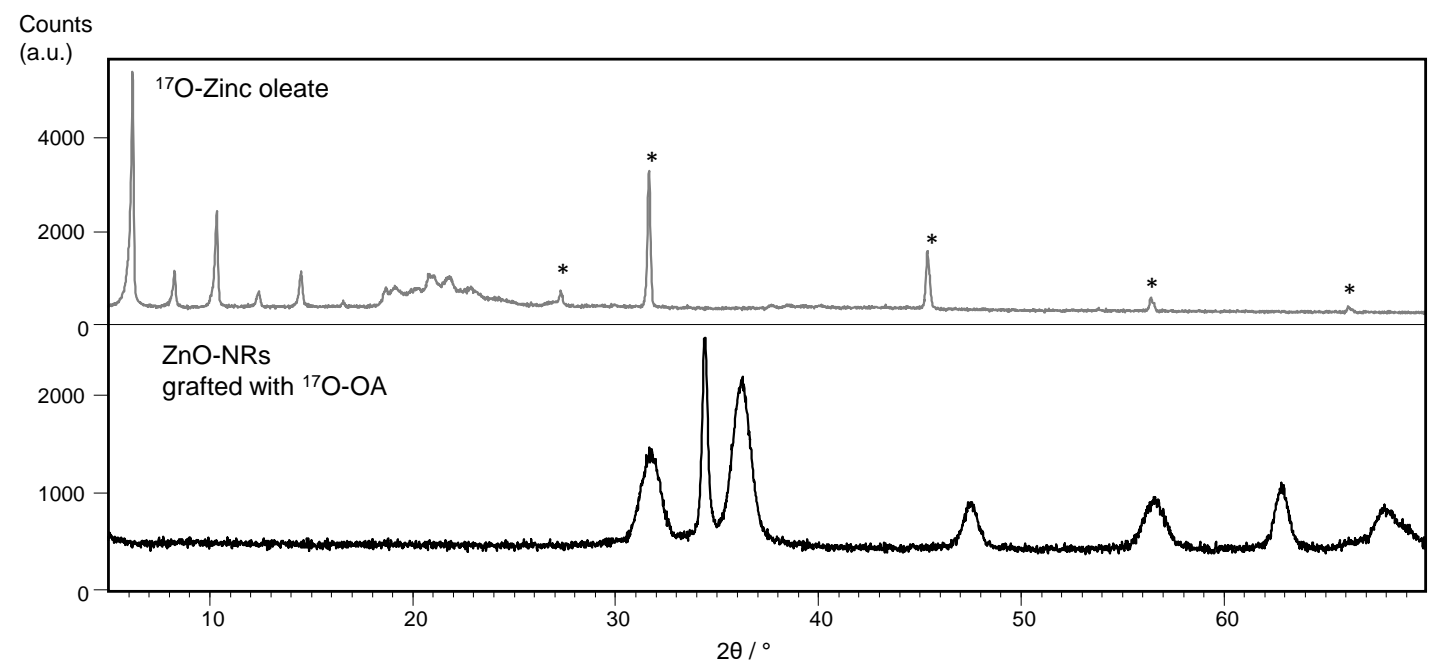

Figure D1S5. Comparison of the IR spectra of ${ }^{17} \mathrm{O}$-labeled oleic acid (green), ${ }^{17} \mathrm{O}$-labeled Zn-oleate (grey), bare ZnO NRs (black), and ZnO NRs grafted with ${ }^{17} \mathrm{O}$-labeled OA (navy). The region shaded in orange shows where $\mathrm{C}=\mathrm{O}$ stretching vibrations are expected, and the dashed red line is characteristic of an acidic $\mathrm{COOH}$ group. The lack of vibration band at $\sim 1700 \mathrm{~cm}^{-1}$ in the grafted nanorods can be seen as evidence of the predominant presence of the deprotonated oleate at the surface, in line with previous IR studies of grafted nanoparticles. ${ }^{31-32}$

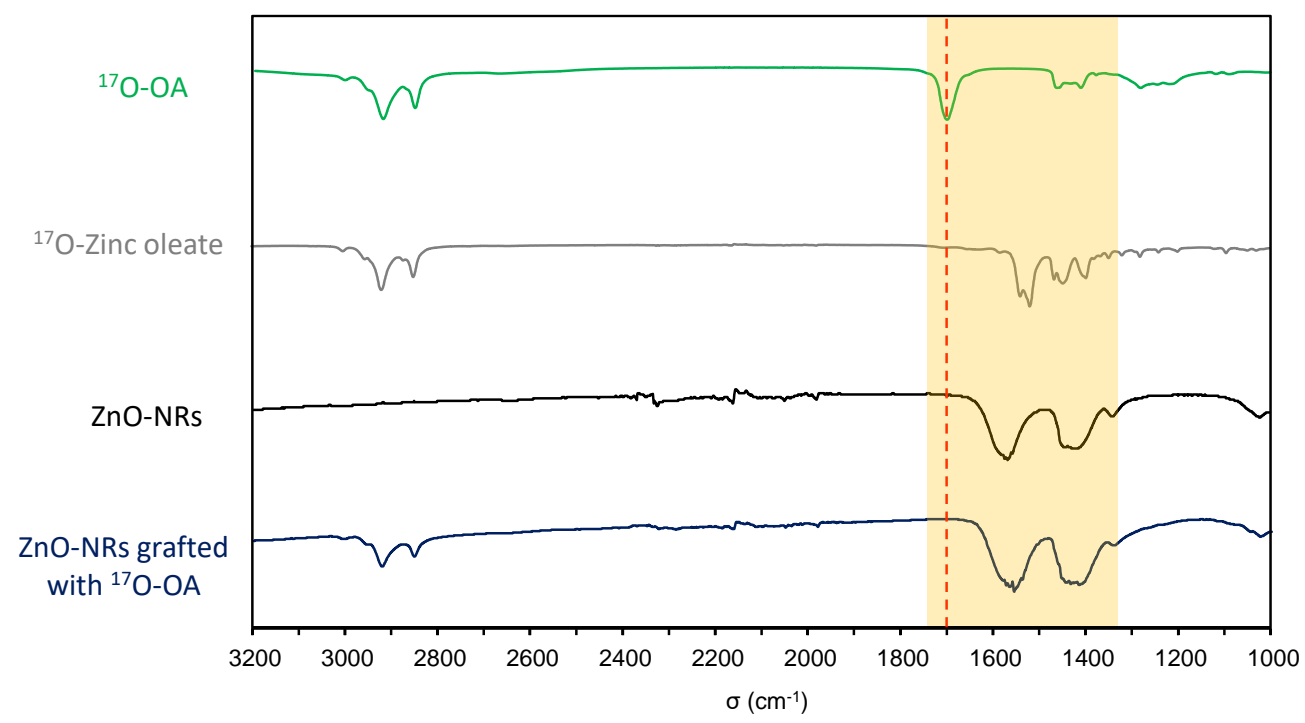


Figure D1S6. Variable-temperature ${ }^{1} \mathrm{H}$ MAS NMR spectra of the ${ }^{17} \mathrm{O}-\mathrm{OA}$ grafted nanorods $\left(\mathrm{B}_{0}=14.1 \mathrm{~T}, 16 \mathrm{kHz}\right.$ spinning speed, Hahn-echo sequence with an echo delay of 4 rotor periods). The shaded grey region corresponds to the chemical shift range where $\mathrm{COOH}$ signals are expected, as shown by comparison to the ${ }^{1} \mathrm{H} \mathrm{NMR}$ spectrum of pure oleic acid, recorded on the same instrument (dashed grey line). (The "*” symbol indicates a background resonance).

Previous studies on the binding of carboxylic acids at the surface of inorganic materials like silica have shown that acidic $\mathrm{COOH}$ protons may only become observable at very low temperatures (below $-40^{\circ} \mathrm{C}$ ), due to dynamic chemical exchanges with other protons in the system. ${ }^{33}$ Here, no $\mathrm{COOH}$ resonance could be resolved at $-100^{\circ} \mathrm{C}$ for the OA-grafted $\mathrm{ZnO} \mathrm{NRs}$, even when using a ${ }^{1} \mathrm{H}$ homonuclear decoupling sequence like DUMBO (data not shown). This suggests the predominance of the deprotonated oleate at the surface of $\mathrm{ZnO}$.

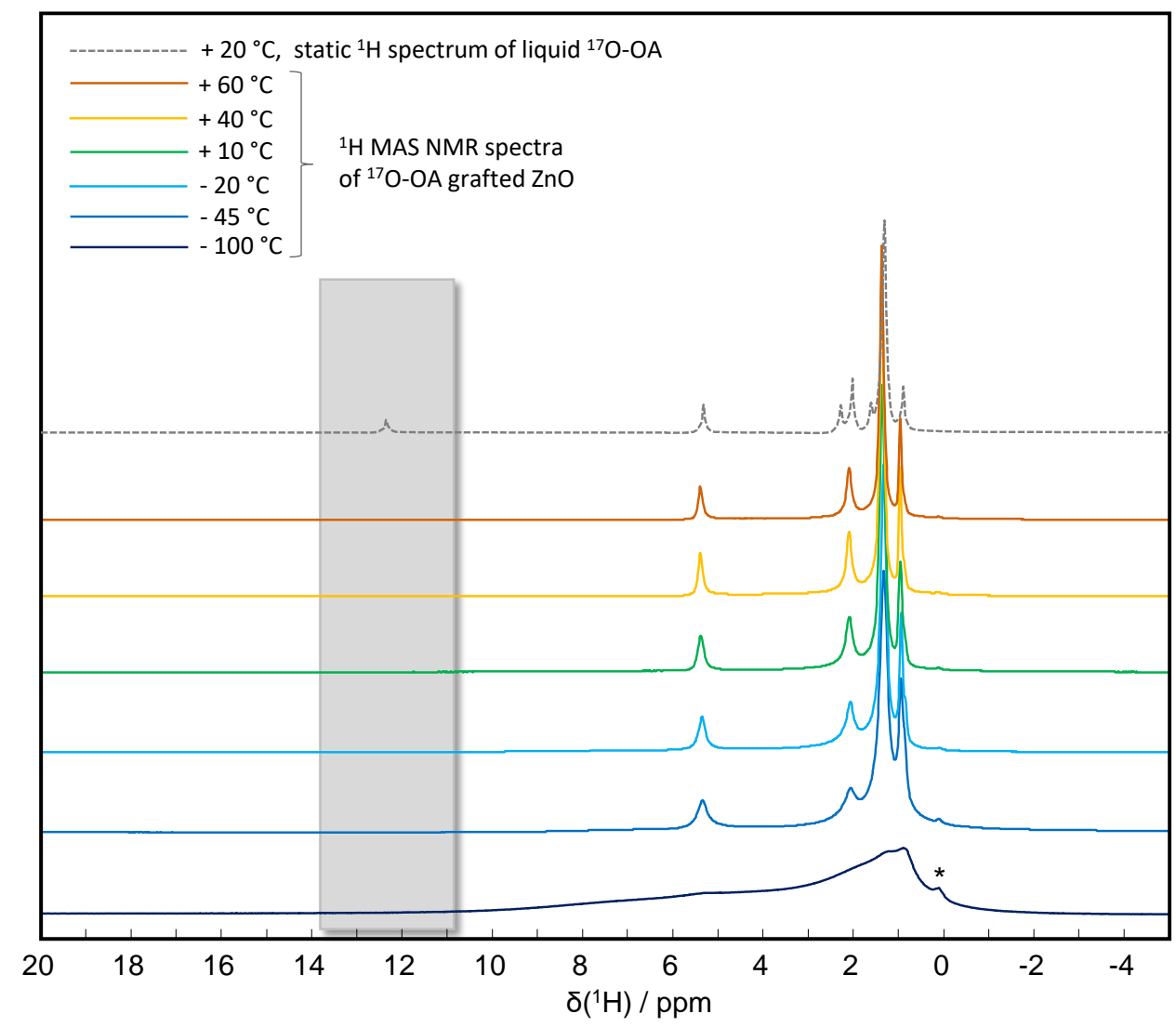


Figure D1S7. Variable-temperature ${ }^{17} \mathrm{O}$ MAS NMR spectra of the ${ }^{17} \mathrm{O}-\mathrm{OA}$ grafted nanorods $\left(\mathrm{B}_{0}=14.1 \mathrm{~T}, 16 \mathrm{kHz}\right.$ spinning speed, DFS-onepulse sequence). (The “*” symbol indicates a spinning sideband of $\mathrm{ZnO}$ ).

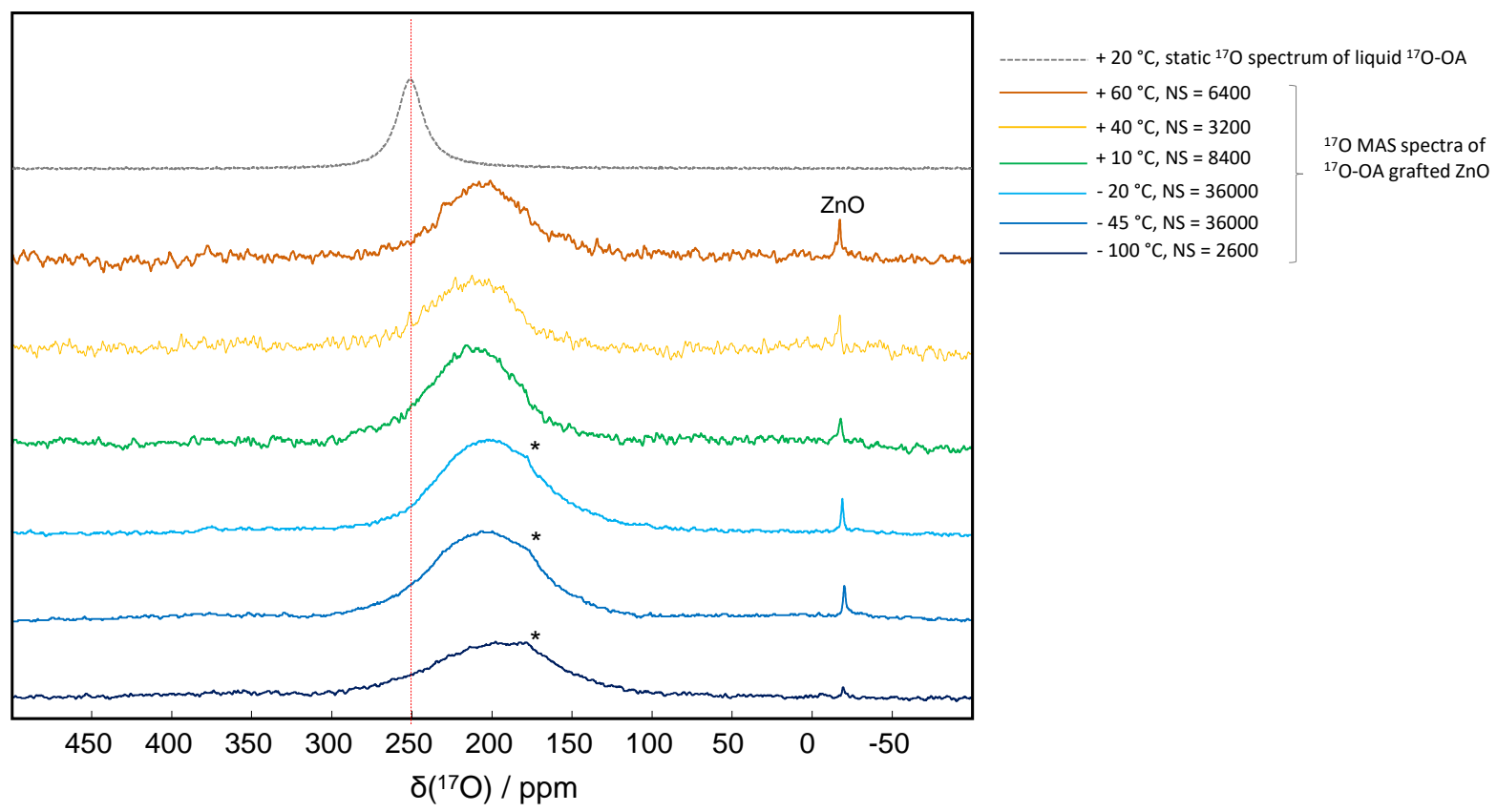

Figure D1S8. ${ }^{13} \mathrm{C}$ NMR spectra of oleic acid $\left({ }^{13} \mathrm{C}\right.$ solution NMR of a concentrated solution, OA/DMSO- $d_{6}$ 96/4 v/v; orange), ${ }^{17} \mathrm{O}$-labeled $\mathrm{Zn}$-oleate $\left({ }^{13} \mathrm{C}\right.$ solid state CPMAS NMR, grey) and grafted nanorods $\left({ }^{13} \mathrm{C}\right.$ solid state CPMAS NMR, black).

The ${ }^{13} \mathrm{C}$ CPMAS NMR spectrum of grafted nanorods shows that the aliphatic chains of the oleic acid molecules are mobile, because $(i)$ the chemical shifts of the methylene resonances are more similar to those of liquid oleic acid than crystalline Zn-oleate, attesting of the presence of more gamma-gauche and trans-gauche conformations at the surface of the grafted nanoparticles, ${ }^{34}$ and (ii) the very weak signal of the methyl end-group in CPMAS.
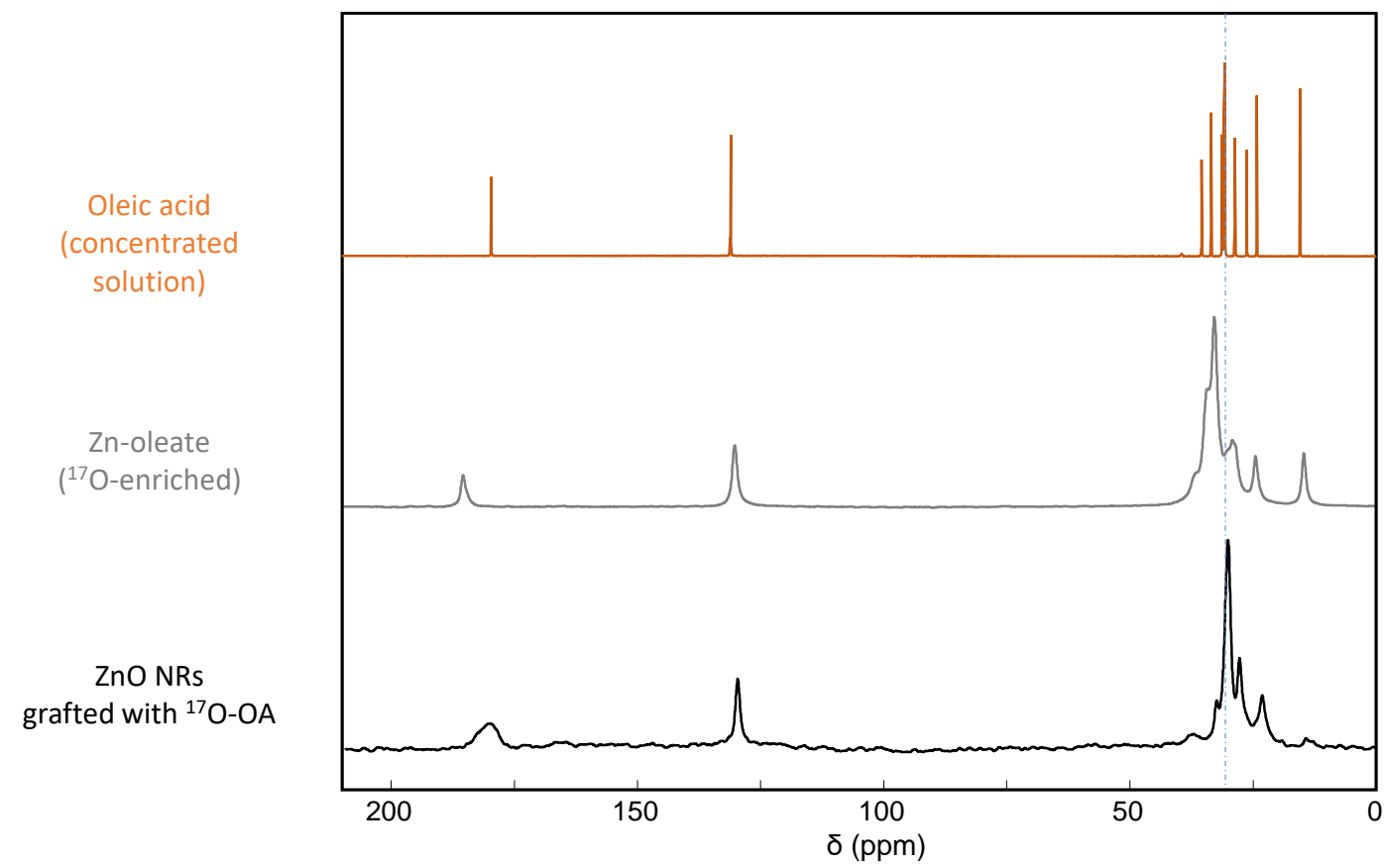
Figure D1S9. ${ }^{13} \mathrm{C}$ CPMAS NMR spectra of ZnO-NRs, before (black) after (green) grafting of ${ }^{17} \mathrm{O}-$ labeled OA. Spectra were purposely super-imposed here with a similar intensity in the carboxylic region (where the signals from grafted acetate and oleate can overlap). The comparison of these spectra shows that after OA-grafting the amount of residual acetates is small, as a much stronger intensity in the $-\mathrm{CH}_{3}$ region would have been observed, if this were not the case.

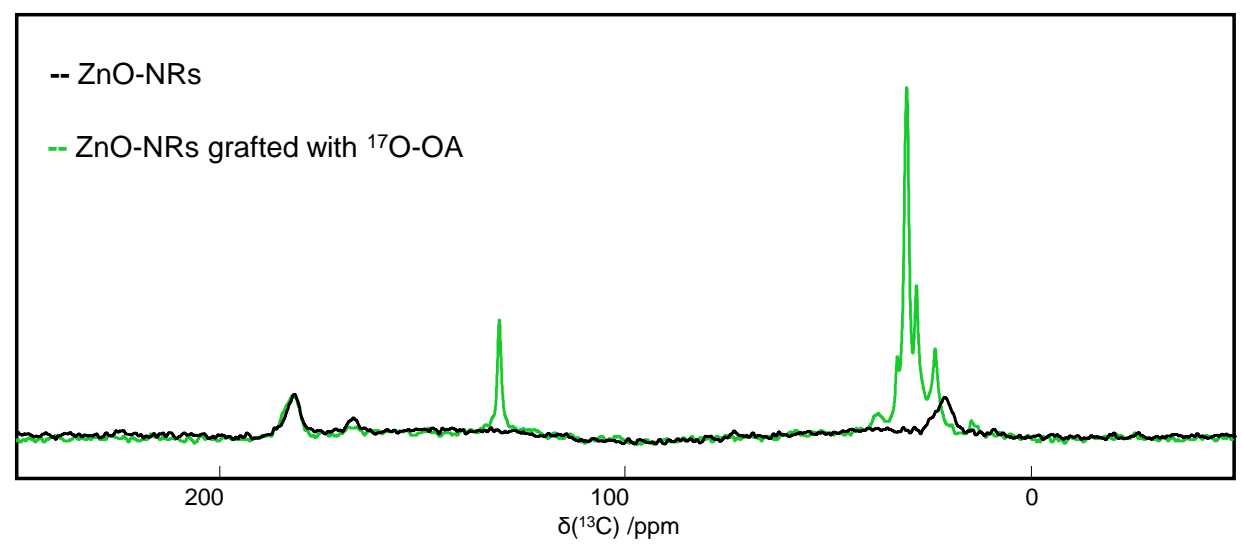


Figure D2S1: Analyses of ZnO-NRs grafted with non-labeled OA, before (black) and after irradiation (blue) and heat-treatment (red). ${ }^{13} \mathrm{C}$ and ${ }^{17} \mathrm{O}$ NMR acquisition parameters can be found in Tables A3S1 and A3S2. For the ${ }^{17} \mathrm{O}$ MAS NMR data, “*” symbols correspond to a $\mathrm{ZnO}$ spinning sideband, and " $\vee$ " symbols to the $\mathrm{ZrO}_{2}$ rotor.

a/ TEM

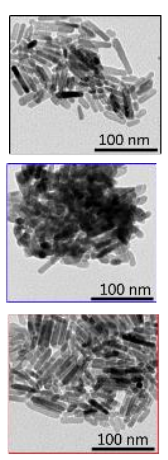

ZnO-NRs grafted

(natural abundance)

After 6h irradiation

After $6 \mathrm{~h}$ heating

\section{b/ X-ray diffraction}

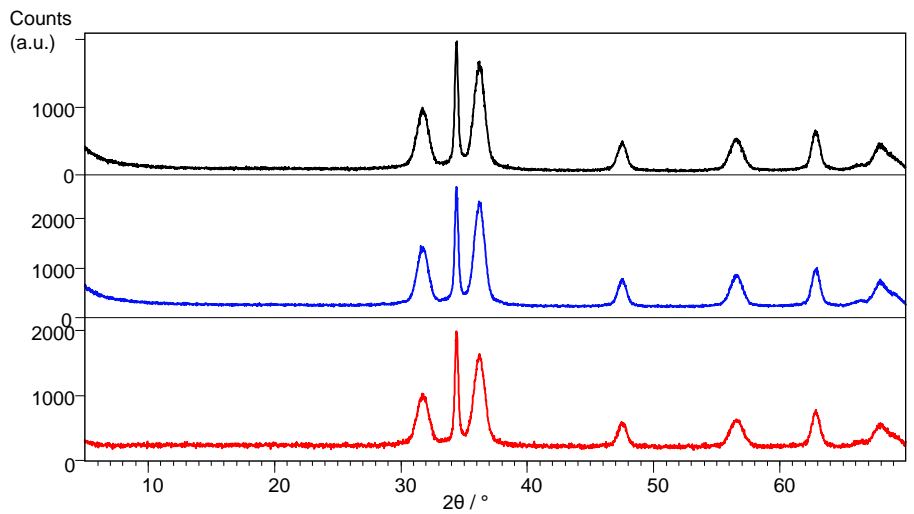

\section{c/ IR spectroscopy}

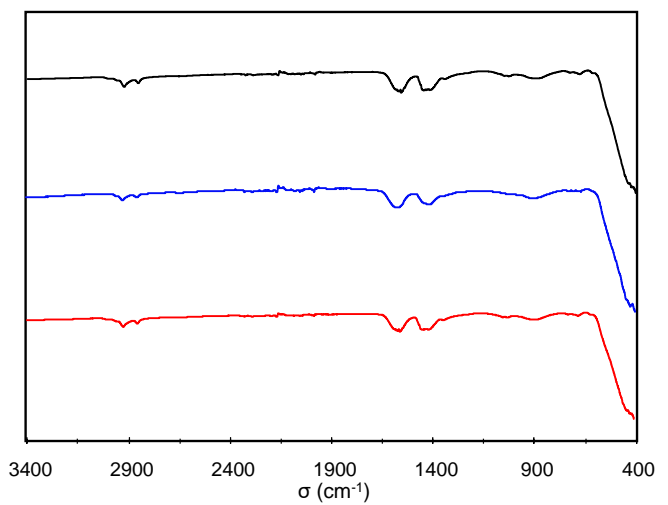

e/ ${ }^{17}$ O MAS NMR

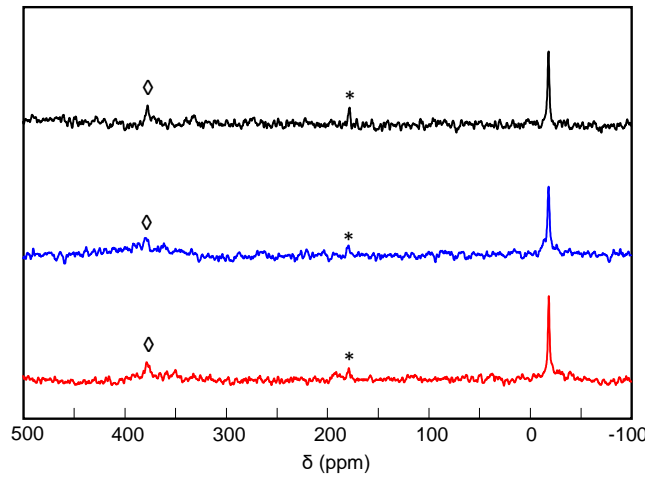

d $/{ }^{13}$ C CPMAS NMR

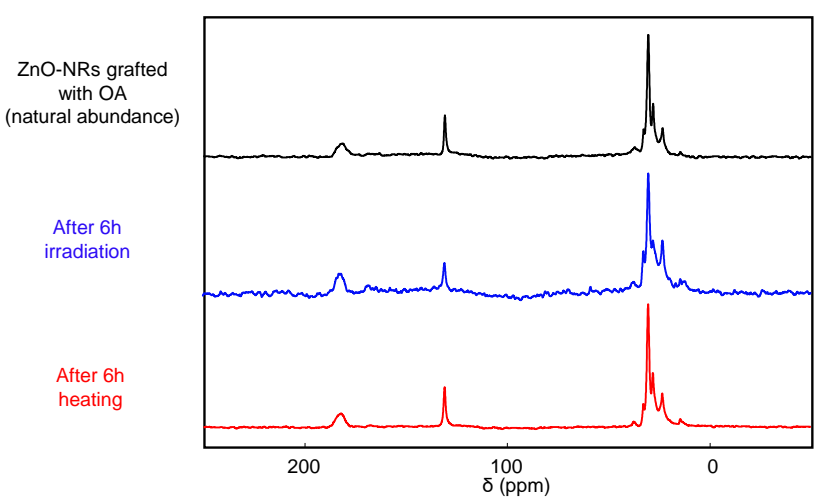

ZnO-NRs grafted

with $O A$

(natural abundance)

After $6 \mathrm{~h}$

irradiation

After $6 \mathrm{~h}$

heating 
Figure D2S2: Analyses of non-grafted $\mathrm{ZnO}-\mathrm{NRs}$, before (black) and after irradiation (blue) and heat-treatment (red). ${ }^{13} \mathrm{C}$ and ${ }^{17} \mathrm{O}$ NMR acquisition parameters can be found in Tables A3S1 and A3S2. It is worth noting that for bare nanorods, the irradiation treatment induces a change in nanorod size and shape (as shown by XRD and TEM) and an increase in the relative amount of carbonates detected by ${ }^{13} \mathrm{C}$ CPMAS NMR (signal at $\sim 166$ ppm, blue spectrum).

a/ TEM
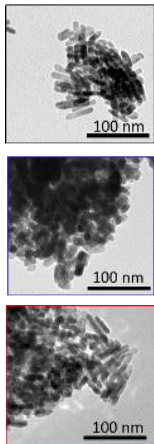

After $6 \mathrm{~h}$

heating

ZnO-NRs (non grafted)

\section{After $6 \mathrm{~h}$}

irradiation

$100 \mathrm{~nm}$ c/ IR spectroscopy

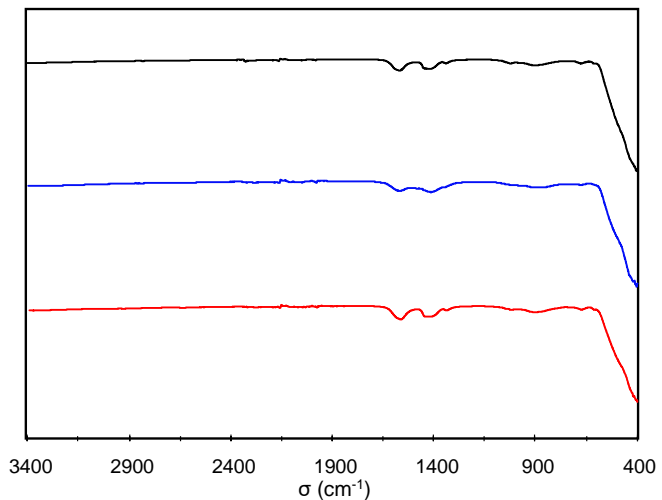

e/ ${ }^{17} \mathrm{O}$ MAS NMR

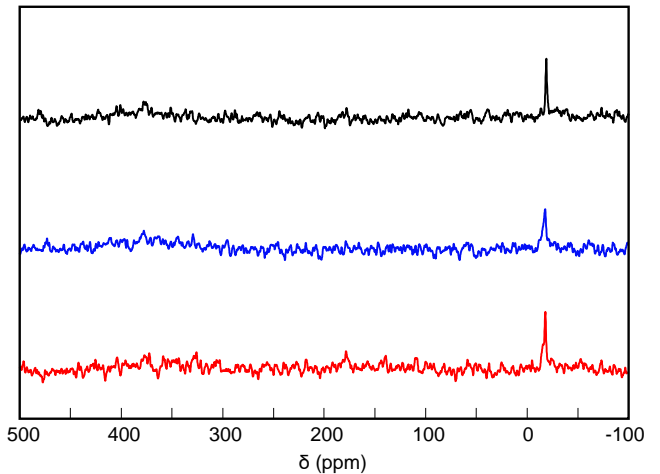

\section{b/ X-ray diffraction}

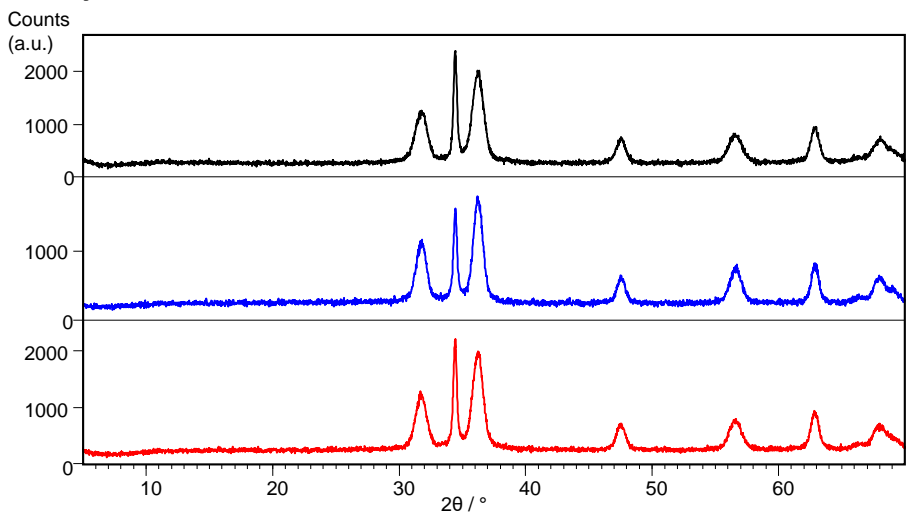

$\mathrm{d} /{ }^{13} \mathrm{C}$ CPMAS NMR

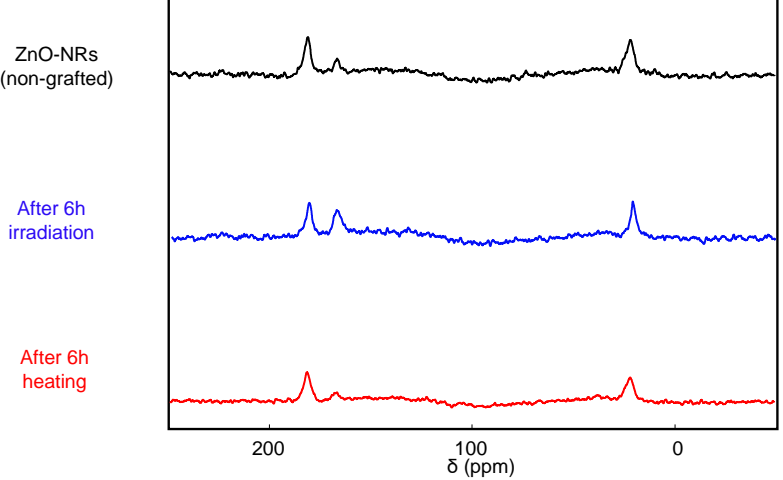

ZnO-NRs

(non-grafted)

After $6 \mathrm{~h}$

irradiation

After $6 \mathrm{~h}$

After $6 \mathrm{~h}$ 
Figure D2S3: Analyses of Zn-oleate, before (black) and after irradiation (blue) and heat-treatment (red). ${ }^{13} \mathrm{C}$ and ${ }^{17} \mathrm{O}$ NMR acquisition parameters can be found in Tables A3S1 and A3S2. (“*” symbols on the X-ray diffraction powder patterns correspond to $\mathrm{NaCl}$, as explained in section $\mathrm{C} 3$ ). It was found that the heating of the $\mathrm{Zn}$-oleate phase globally leads to a significant increase in its crystallinity, as shown by X-ray diffraction (stronger intensity of the diffraction peaks) and ${ }^{17} \mathrm{O}$ MAS NMR (more features on the NMR spectra).

\section{a/ X-ray diffraction}

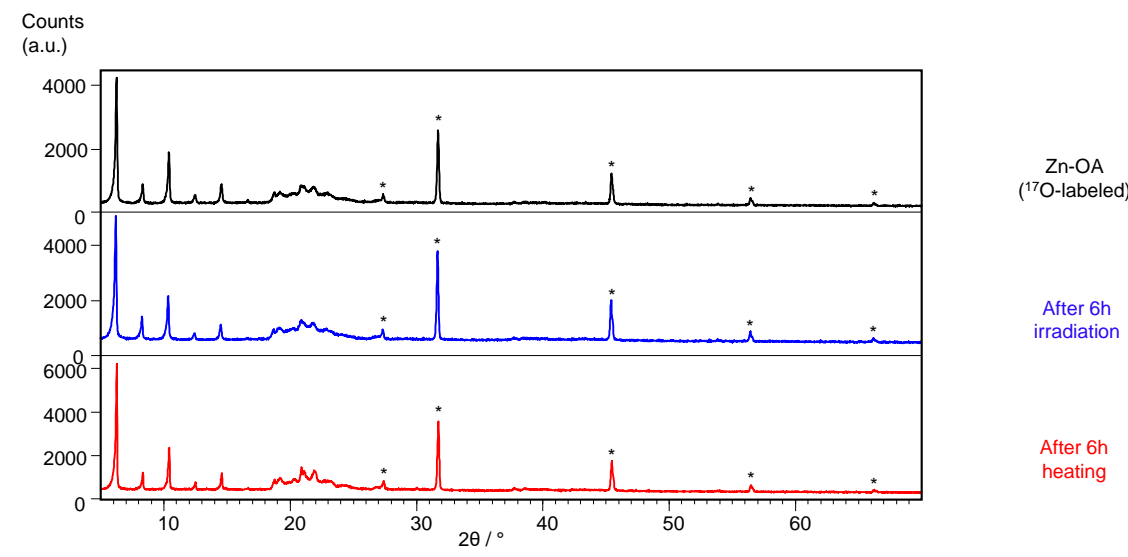

b/ IR spectroscopy

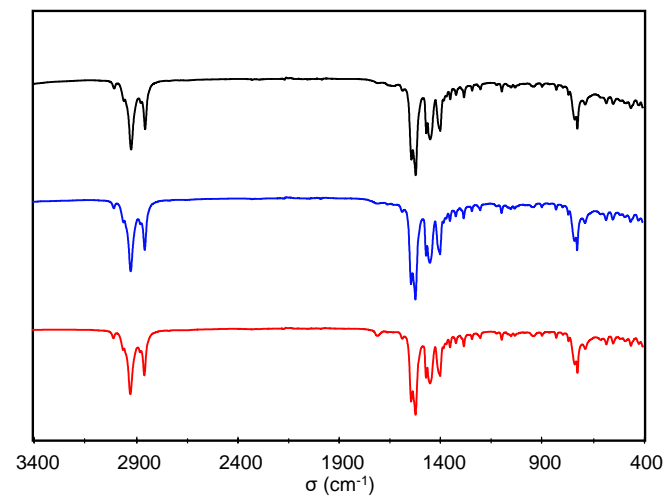

\section{d/17O MAS NMR}

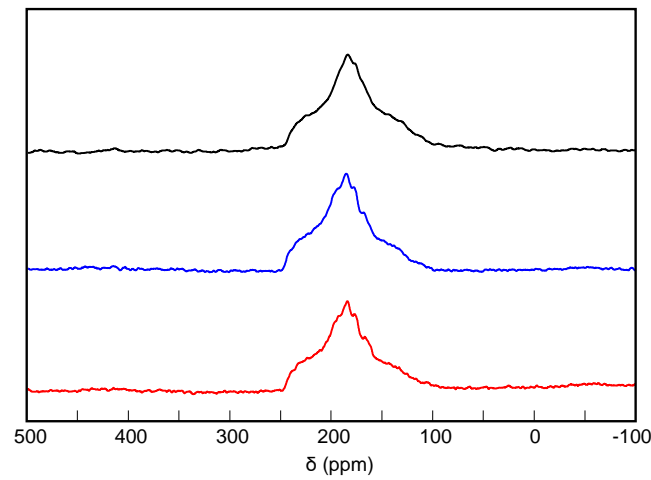

C/ ${ }^{13} \mathrm{C}$ CPMAS NMR

$\mathrm{Zn}-\mathrm{OA}$

Zn-OA
(17O-labeled)

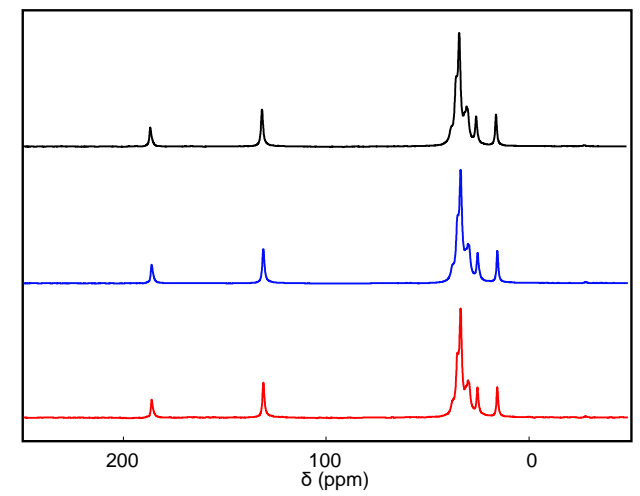

$\mathrm{Zn}-\mathrm{OA}$

( ${ }^{17} \mathrm{O}-$ labeled)

After $6 \mathrm{~h}$

irradiation

After $6 \mathrm{~h}$

heating 
Figure D2S4. TGA of OA-grafted NRs before (black) and after 6h irradiation (blue). Weight loss before irradiation is $10.1 \%$ and corresponds to grafting density of $\sim 2$ molecules per $\mathrm{nm}^{2}$. Weight loss after irradiation is $8.6 \%$.

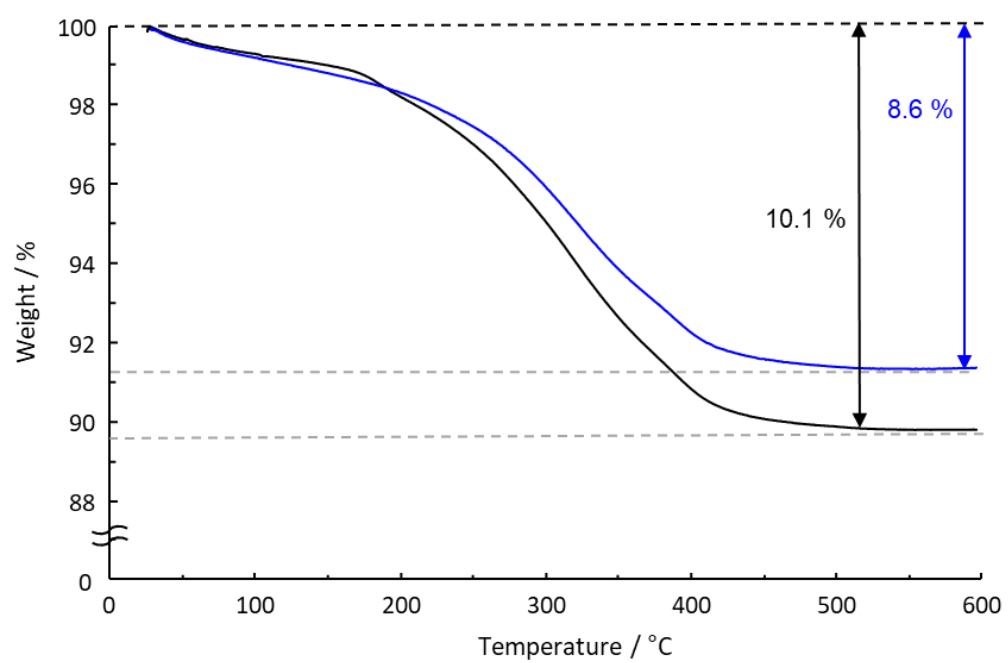




\section{References}

1. Perras, F. A.; Viger-Gravel, J.; Burgess, K. M. N.; Bryce, D. L., Signal enhancement in solidstate NMR of quadrupolar nuclei. Solid St. Nucl. Magn. Reson. 2013, 51-52, 1-15.

2. Gan, Z.; Hung, I.; Wang, X.; Paulino, J.; Wu, G.; Litvak, I. M.; Gor'kov, P. L.; Brey, W. W.; Lendi, P.; Schiano, J. L.; Bird, M. D.; Dixon, I. R.; Toth, J.; Boebinger, G. S.; Cross, T. A., NMR spectroscopy up to 35.2T using a series-connected hybrid magnet. J. Magn. Reson. 2017, 284, 125-136. 3. Gan, Z.; Gor'kov, P. L.; Brey, W. W.; Sideris, P. J.; Grey, C. P., Enhancing MQMAS of low- $\gamma$ nuclei by using a high $\mathrm{B}_{1}$ field balanced probe circuit. J. Magn. Reson. 2009, 200, 2-5.

4. Massiot, D.; Fayon, F.; Capron, M.; King, I.; Le Calvé, S.; Alonso, B.; Durand, J.-O.; Bujoli, B.; Gan, Z.; Hoatson, G., Modelling one- and two-dimensional solid-state NMR spectra. Magn. Reson. Chem. 2002, 40, 70-76.

5. Taylor, R. A.; Ellis, H. A., Anhydrous polymeric zinc(II) pentanoate. Acta Cryst. E 2008, 64, m895.

6. Lacouture, F.; Peultier, J.; Francois, M.; Steinmetz, J., Anhydrous polymeric zinc(II) octanoate. Acta Cryst. C 2000, 56, 556-557.

7. Hafner, J., Ab-initio simulations of materials using VASP: Density-functional theory and beyond. J. Comput. Chem. 2008, 29, 2044-2078.

8. $\quad$ Giannozzi, P.; Baroni, S.; Bonini, N.; Calandra, M.; Car, R.; Cavazzoni, C.; Ceresoli, D.; Chiarotti, G. L.; Cococcioni, M.; Dabo, I.; Dal Corso, A.; de Gironcoli, S.; Fabris, S.; Fratesi, G.; Gebauer, R.; Gerstmann, U.; Gougoussis, C.; Kokalj, A.; Lazzeri, M.; Martin-Samos, L.; Marzari, N.; Mauri, F.; Mazzarello, R.; Paolini, S.; Pasquarello, A.; Paulatto, L.; Sbraccia, C.; Scandolo, S.; Sclauzero, G.; Seitsonen, A. P.; Smogunov, A.; Umari, P.; Wentzcovitch, R. M., QUANTUM ESPRESSO: a modular and open-source software project for quantum simulations of materials. J. Phys.: Cond. Matter 2009, 21, 395502.

9. Perdew, J. P.; Burke, K.; Ernzerhof, M., Generalized Gradient Approximation Made Simple. Phys. Rev. Lett. 1996, 77, 3865-3868.

10. Troullier, N.; Martins, J. L., Efficient pseudopotentials for plane-wave calculations. Phys. Rev. B 1991, 43, 1993-2006.

11. Pickard, C. J.; Mauri, F., All-electron magnetic response with pseudopotentials: NMR chemical shifts. Phys. Rev. B 2001, 63, 245101.

12. Métro, T.-X.; Gervais, C.; Martinez, A.; Bonhomme, C.; Laurencin, D., Unleashing the Potential of ${ }^{17} \mathrm{O}$ NMR Spectroscopy Using Mechanochemistry. Angew. Chem. Int. Ed. 2017, 129, 69076911.

13. Burmeister, C. F.; Kwade, A., Process engineering with planetary ball mills. Chem. Soc. Rev. 2013, 42, 7660-7667.

14. Barman, S.; Vasudevan, S., Mixed Saturated-Unsaturated Alkyl-Chain Assemblies: Solid Solutions of Zinc Stearate and Zinc Oleate. J. Phys. Chem. B 2007, 111, 5212-5217.

15. Barman, S.; Vasudevan, S., Contrasting Melting Behavior of Zinc Stearate and Zinc Oleate. J. Phys. Chem. B 2006, 110, 651-654.

16. Choi, S.-H.; Kim, E.-G.; Park, J.; An, K.; Lee, N.; Kim, S. C.; Hyeon, T., Large-Scale Synthesis of Hexagonal Pyramid-Shaped $\mathrm{ZnO}$ Nanocrystals from Thermolysis of $\mathrm{Zn}-$ Oleate Complex. J. Phys. Chem. B 2005, 109, 14792-14794.

17. Reinoso, D. M.; Damiani, D. E.; Tonetto, G. M., Zinc carboxylic salts used as catalyst in the biodiesel synthesis by esterification and transesterification: Study of the stability in the reaction medium. Appl. Catal. A 2012, 449, 88-95.

18. Xiangrong, K.; Jun, Z.; Xiaowei, Y.; Yanwei, Z., Ethanol-assisted synthesis of $\mathrm{Zn}_{0.5} \mathrm{Fe}_{2.5} \mathrm{O}_{4}$ nanocrystals in thermal solvent of paraffin. J. Alloys Compds 2008, 464, 418-421.

19. Sehmi, S. K.; Noimark, S.; Bear, J. C.; Peveler, W. J.; Bovis, M.; Allan, E.; MacRobert, A. J.; Parkin, I. P., Lethal photosensitisation of Staphylococcus aureus and Escherichia coli using crystal violet and zinc oxide-encapsulated polyurethane. J. Mater. Chem. B 2015, 3, 6490-6500.

20. Corbeil, M.-C.; Robinet, L., X-ray powder diffraction data for selected metal soaps. Powder Diffraction 2002, 17, 52-60. 
21. Kim, T.; Jung, Y. K.; Lee, J.-K., The formation mechanism of CdSe QDs through the thermolysis of $\mathrm{Cd}$ (oleate) $)_{2}$ and TOPSe in the presence of alkylamine. J. Mater. Chem. C 2014, 2, 55935600 .

22. Glassy, B. A.; Cossairt, B. M., Ternary synthesis of colloidal $\mathrm{Zn}_{3} \mathrm{P}_{2}$ quantum dots. Chemical Commun. 2015, 51, 5283-5286.

23. Robinet, L.; Corbeil, M.-C., The Characterization of Metal Soaps. Studies in Conservation 2003, $48,23-40$.

24. Otero, V.; Sanches, D.; Montagner, C.; Vilarigues, M.; Carlyle, L.; Lopes, J. A.; Melo, M. J., Characterisation of metal carboxylates by Raman and infrared spectroscopy in works of art. J. Raman Spectrosc. 2014, 45, 1197-1206.

25. Ishioka, T.; Shibata, Y.; Takahashi, M.; Kanesaka, I., Vibrational spectra and structures of zinc carboxylates II. Anhydrous zinc acetate and zinc stearate. Spectrochim. Acta A: Mol. Biomol. Spectrosc. 1998, 54, 1811-1818.

26. He, P.; Xu, J.; Terskikh, V. V.; Sutrisno, A.; Nie, H.-Y.; Huang, Y., Identification of Nonequivalent Framework Oxygen Species in Metal-Organic Frameworks by ${ }^{17} \mathrm{O}$ Solid-State NMR. $J$. Phys. Chem. C 2013, 117, 16953-16960.

27. Bignami, G. P. M.; Davis, Z. H.; Dawson, D. M.; Morris, S. A.; Russell, S. E.; McKay, D.; Parke, R. E.; Iuga, D.; Morris, R. E.; Ashbrook, S. E., Cost-effective ${ }^{17} \mathrm{O}$ enrichment and NMR spectroscopy of mixed-metal terephthalate metal-organic frameworks. Chem. Sci. 2018, 9, 850-859.

28. Sun, B.; Sirringhaus, H., Solution-Processed Zinc Oxide Field-Effect Transistors Based on SelfAssembly of Colloidal Nanorods. Nano Lett. 2005, 5, 2408-2413.

29. Pacholski, C.; Kornowski, A.; Weller, H., Self-Assembly of ZnO: From Nanodots to Nanorods. Angew. Chem. Int. Ed. 2002, 41, 1188-1191.

30. Awada, H.; Medlej, H.; Blanc, S.; Delville, M.-H.; Hiorns, R. C.; Bousquet, A.; DagronLartigau, C.; Billon, L., Versatile functional poly(3-hexylthiophene) for hybrid particles synthesis by the grafting onto technique: Core@ shell ZnO nanorods. J. Polym. Sci. A: Polym. Chem. 2014, 52, 3038 .

31. Oliva-Puigdomènech, A.; De Roo, J.; Kuhs, J.; Detavernier, C.; Martins, J. C.; Hens, Z., Ligand Binding to Copper Nanocrystals: Amines and Carboxylic Acids and the Role of Surface Oxides. Chem. Mater. 2019, 31, 2058-2067.

32. Kauffman, D. R.; Ohodnicki, P. R.; Kail, B. W.; Matranga, C. Selective Electrocatalytic Activity of Ligand Stabilized Copper Oxide Nanoparticles, J. Phys. Chem. Lett. 2011, 2, 2038-2043.

33. Azaïs, T.; Laurent, G.; Panesar, K.; Nossov, A.; Guenneau, F.; Sanfeliu Cano C.; TournéPéteilh, C.; Devoisselle, J.-M.; Babonneau, F. Implication of water molecules at the silica-ibuprofen interface in silica-based drug delivery systems obtained through incipient wetness impregnation. J. Phys. Chem. C, 2017, 121, 26833-26839.

34. Pawsey, S.; Yach, K.; Halla, J.; Reven, L., Self-Assembled Monolayers of Alkanoic Acids: A Solid-State NMR Study. Langmuir 2000, 16, 3294-3303. 